Florida International University

FIU Digital Commons

3-22-2019

\title{
Auditing Quality: A Critical Exploration of Faculty Members' Experiences with Quality Matters
}

Matthew M. Acevedo

Florida International University, macev028@fiu.edu

Follow this and additional works at: https://digitalcommons.fiu.edu/etd

Part of the Higher Education Commons

\section{Recommended Citation}

Acevedo, Matthew M., "Auditing Quality: A Critical Exploration of Faculty Members' Experiences with Quality Matters" (2019). FIU Electronic Theses and Dissertations. 4015.

https://digitalcommons.fiu.edu/etd/4015

This work is brought to you for free and open access by the University Graduate School at FIU Digital Commons. It has been accepted for inclusion in FIU Electronic Theses and Dissertations by an authorized administrator of FIU Digital Commons. For more information, please contact dcc@fiu.edu. 


\section{FLORIDA INTERNATIONAL UNIVERSITY}

Miami, Florida

\section{AUDITING QUALITY: A CRITICAL EXPLORATION OF FACULTY MEMBERS' EXPERIENCES WITH QUALITY MATTERS}

A dissertation submitted in partial fulfillment of

the requirements for the degree of

DOCTOR OF PHILOSOPHY

in

HIGHER EDUCATION

by

Matthew M. Acevedo 
To: $\quad$ Dean Michael R. Heithaus

College of Arts, Sciences and Education

This dissertation, written by Matthew M. Acevedo, and entitled Auditing Quality: A Critical Exploration of Faculty Members' Experiences with Quality Matters, having been approved in respect to style and intellectual content, is referred to you for judgment.

We have read this dissertation and recommend that it be approved.

Benjamin Baez

James Burns

Eric Dwyer

Daniel Saunders, Major Professor

Date of Defense: March 22, 2019

The dissertation of Matthew M. Acevedo is approved.

Dean Michael R. Heithaus
College of Arts, Sciences and Education

College of Arts, Sciences and Education

Andrés G. Gil

Vice President for Research and Economic Development and Dean of the University Graduate School

Florida International University, 2019 
(C) Copyright 2019 by Matthew M. Acevedo

All rights reserved. 


\section{DEDICATION}

For Rosco. 


\section{ACKNOWLEDGMENTS}

I would not have been able to undertake this project, let alone doctoral study, if it were not for the unfailing support and encouragement of my incredible wife, Veritza, who has always put up with my constant rambling and venting and never once complained about the time and efforts I spent reading, writing, and thinking over these last several years. No words can adequately express how much her love, care, and support have meant to me.

I owe a tremendous debt of gratitude to the members of my dissertation committee, Dr. Eric Dwyer, Dr. James Burns, Dr. Benjamin Baez, and my Chair, Dr. Daniel Saunders. Thank you all for your thoughtfulness, methodological direction, theoretical guidance, moral support, interest in my work, and confidence in me.

This process would have been much more taxing and isolating if it were not for the community provided by my friends and comrades in the doctoral program; many thanks to Almi, Eric, Jessica, Justin, Michael, and all my other Higher Ed colleagues. Thanks also to my good friends and collaborators Gus Roque and Jessica Rodriguez Pavon for their input, feedback, and support.

Lastly, I am beyond grateful to all of the study's research participants for making this dissertation possible by sharing their perspectives, experiences, insight, stories, and confessions. 


\section{ABSTRACT OF THE DISSERTATION \\ AUDITING QUALITY: A CRITICAL EXPLORATION OF FACULTY MEMBERS' \\ EXPERIENCES WITH QUALITY MATTERS}

by

Matthew M. Acevedo

Florida International University, 2019

Miami, Florida

\section{Professor Daniel Saunders, Major Professor}

Online education has become a pervasive and embedded instructional modality in American higher education, with nearly one-third of all students taking at least one course at a distance and another $15 \%$ enrolled exclusively in online courses. Concomitant with the growth in online education has been increased pressure from institutions, administrations, lawmakers, accreditors, and the public to regulate the quality of online courses. Some institutions have responded to this pressure by pursuing quality assurance certification programs. Quality Matters $(\mathrm{QM})$ is a non-profit organization that facilitates a peer-reviewed quality assurance program for online courses and is the predominant mechanism of online course quality assurance used by higher education institutions. Understanding the QM course review as an audit practice, the purpose of this qualitative study was to explore how faculty members negotiated, maneuvered, and resisted the Quality Matters process; the motivational factors, impacts, and significance that led up to and followed their engagement with Quality Matters; and the relations between the standards of the Quality Matters rubric and faculty members' own conceptualizations of quality. Semi-structured interviews were conducted with eight university faculty 
members, representing a variety of faculty ranks and subject areas, who have successfully passed a formal Quality Matters course review for one or more online courses. Interview transcripts and documentary artifacts were analyzed to identify salient themes. The results indicated that participants' conceptualizations of course quality were not fully aligned with the QM rubric, resulting in an expectations gap. Participants engaged in Quality Matters because of factors relating to perceptions of prestige, recognition, and distinction; the possibility of a monetary incentive; or because it was mandated or expected. Participants in this study were able to navigate and maneuver QM in large part through the support of a decoupled organizational structure and resisted through various performative means. The major impacts of Quality Matters included colonization of QMrelated logics into other aspects of their teaching practice and its role as a platform for self-reflection. Ultimately, the findings from this study suggest that the Quality Matters audit represents an encroachment on the professional autonomy of teaching faculty emblematic of the neoliberalization of the university. 


\section{TABLE OF CONTENTS}

CHAPTER

PAGE

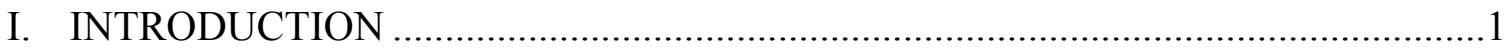

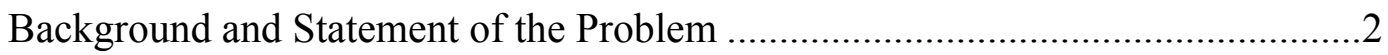

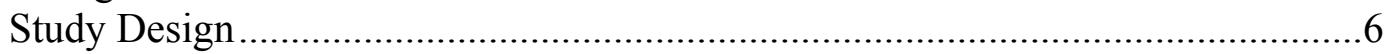

Purpose and Research Questions ..................................................................

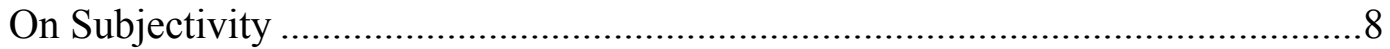

Significance of the Study ...............................................................................11

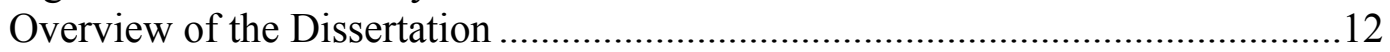

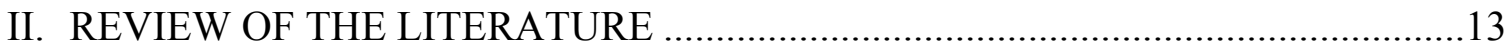

Dominant Understandings of Quality in Higher Education....................................14

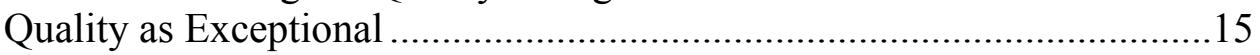

Quality as Perfection or Consistency .......................................................17

Quality as Fitness for Purpose ............................................................17

Quality as Value for Money...............................................................19

Quality as Transformation ...................................................................19

Quality Assurance and Quality Enhancement in Higher Education ......................21

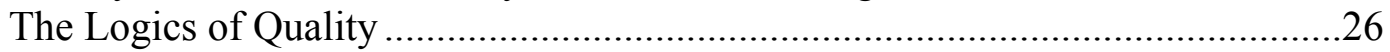

Teaching Quality......................................................................................

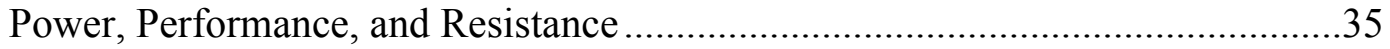

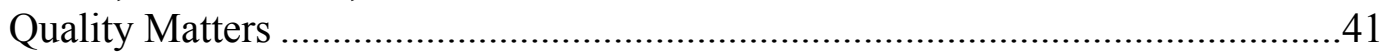

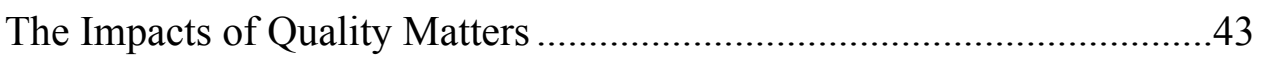

Quality Matters and Perceptions of Quality...............................................50

On Quality Matters Scholarship............................................................52

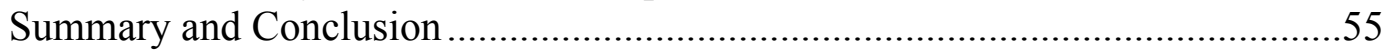

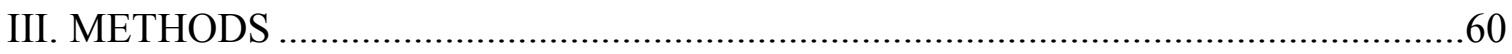

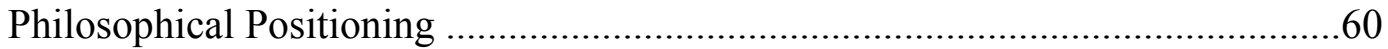

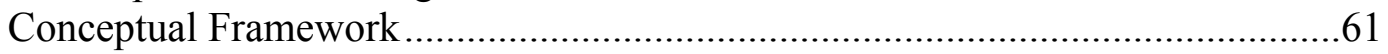

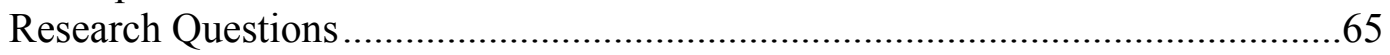

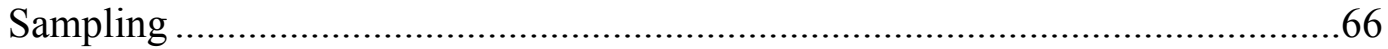

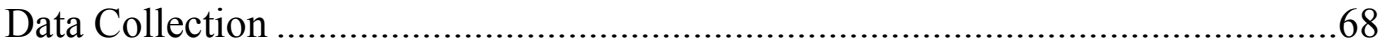

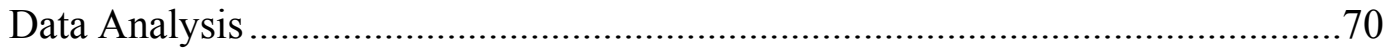

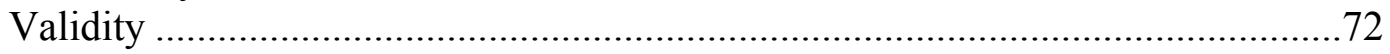

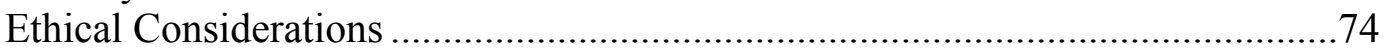

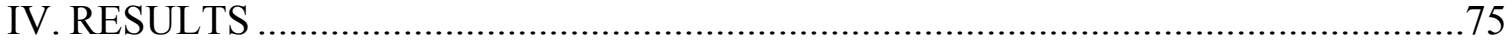

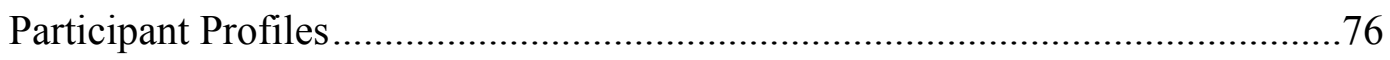

Faculty Members' Understandings of Quality ......................................................78

Programmatic Elements of QM: Helping You Deliver on Your Online

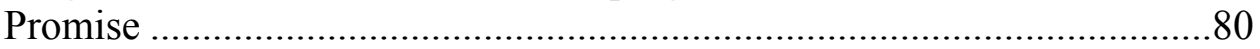

Technological Elements of QM: Design, Not Delivery..............................84 
Conceptualizations of Quality: It's Like the Russian Figure Skaters........86

Motivations for Pursuing QM ......................................................................97

Prestige, Recognition, and Distinction: I Made an Amazing Course, and

Everyone Was Really Amazed by It .....................................................99

Monetary Incentive: \$500 is Certainly a Plus.......................................102

Expectations and Mandates: Because They Told Me To .......................105

Negotiating, Maneuvering, and Resisting QM ..............................................110

Decoupling: The Good Thing About the Way FIU Went Through It .....111

Performing Quality: It Was All About Repackaging..............................120

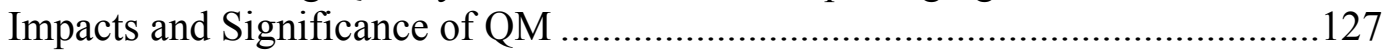

Colonization: I Can't Imagine a World Without QM ...........................129

Reflection: That Modicum of Mindfulness...........................................138

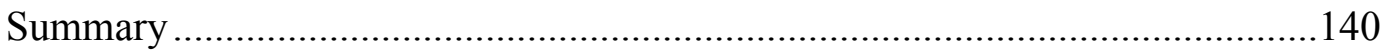

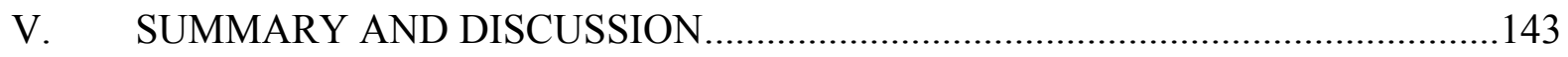

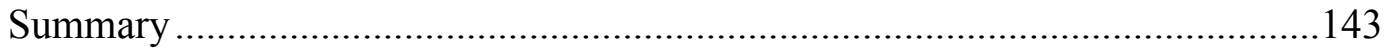

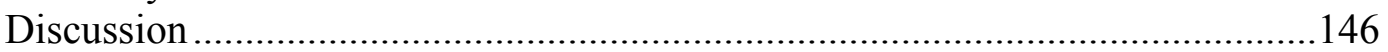

Directions for Practice ............................................................................. 149

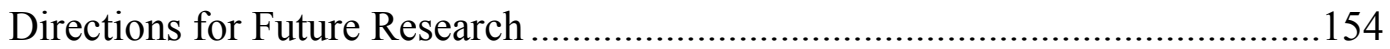

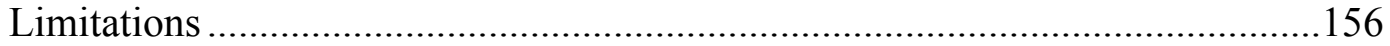

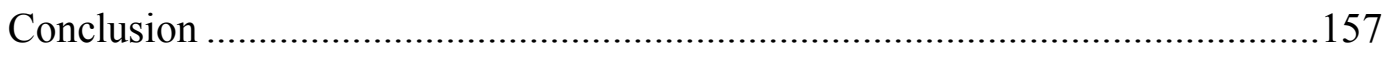

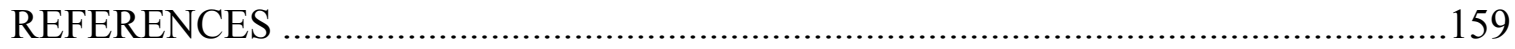

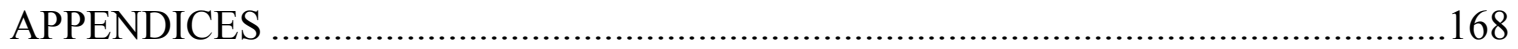

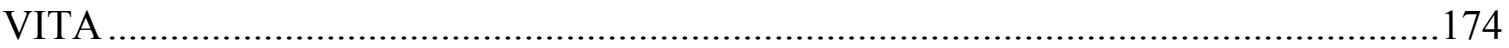




\section{LIST OF ABBREVIATIONS}

\begin{tabular}{|c|c|}
\hline ADA & Americans with Disabilities Act \\
\hline CAQDAS & computer-assisted qualitative data analysis software \\
\hline \multirow[t]{2}{*}{ ESG } & Standards and Guidelines for Quality Assurance in the European \\
\hline & Higher Education Area \\
\hline FIPSE & Fund for the Improvement of Postsecondary Education \\
\hline FIU & Florida International University \\
\hline FSU & Florida State University \\
\hline GWU & George Washington University \\
\hline ID & instructional designer \\
\hline NPM & New Public Management \\
\hline NZQA & New Zealand Qualifications Authority \\
\hline OSCQR & Open SUNY Course Quality Review \\
\hline QAA & Quality Assurance Agency \\
\hline QM & Quality Matters \\
\hline SUNY & State University of New York \\
\hline TEF & Teaching Excellence Framework \\
\hline TQA & Teaching Quality Audit \\
\hline TQM & Total Quality Management \\
\hline UF & University of Florida \\
\hline UK & United Kingdom \\
\hline
\end{tabular}




\section{CHAPTER I}

\section{INTRODUCTION}

Online education has become a pervasive and embedded instructional modality in American higher education, with nearly one-third of all students taking at least one course at a distance and another $15 \%$ enrolled exclusively in online courses. The vast majority of these students attend public institutions, dispelling any suggestion that online education is a largely for-profit phenomenon (Seaman, Allen, \& Seaman, 2018). With continued growth spanning more than a decade and no signs of abating in the public sector, online education is a space in need of increased and continued critical inquiry.

Concomitant with the growth in online education has been increased pressure from institutions, administrations, lawmakers, accreditors, and the public to regulate the quality of online courses. Mandates to ensure and certify online course quality have been initiated at the state, institution, and academic unit levels. For example, in my home state of Florida, the Florida Board of Governors has declared a goal of ensuring that $90 \%$ of online courses at Florida's public universities bear a "high quality" ranking (Florida Board of Governors, 2015). No such goal exists for other instructional modalities.

In response to the increased scrutiny of quality in online higher education, various organizations have developed quality assurance programs, including the Quality Matters (QM) program, the Online Learning Consortium Quality Scorecard, the Blackboard Catalyst Exemplary Course Award, and the Open SUNY Course Quality Review (OSCQR). Quality Matters seems to be the predominant quality assurance program currently used by institutions; it is the only program whose parent organization exists solely for quality assurance and has a series of regional and national conferences, special 
issues dedicated to it in academic journals, and so on (Moore, 2017; Layne, 2014). Quality Matters is owned and controlled by a non-profit organization that facilitates a peer-reviewed quality assurance program for online courses and online aspects of hybrid or blended courses. Returning to my example of Florida, responses to a survey sent to state college and universities by the Taskforce for Online Strategic Planning Quality Subcommittee indicate that several state institutions define course quality as meeting Quality Matters standards (Florida Board of Governors, n.d.). Furthermore, in order to meet the goal of ensuring that $90 \%$ of online courses offered in the state meet a quality standard, the Board of Governors has approved a measure to use Quality Matters as the statewide metric for the determination of whether a given online course is a quality course (Florida Board of Governors, 2017, p. 2).

While efforts to assure, enhance, and regulate the quality of higher education, such as regional and program accreditation, have been met with critical analysis, programs such as Quality Matters that purport to evaluate and certify the quality of online courses have encountered far less criticism, analysis, and resistance. It is within this context that I situate the present study.

\section{Background and Statement of the Problem}

Quality Matters is a non-profit organization that facilitates a peer-reviewed quality assurance program for online courses and online aspects of hybrid or blended

courses. The Quality Matters program was created as a result of a U.S. Department of Education Fund for the Improvement of Postsecondary Education (FIPSE) grant awarded to MarylandOnline, Inc., a consortium of Maryland colleges, to develop a scalable peer review-based quality assurance process for online courses (Quality Matters, 2018g). The 
QM program evaluates courses based on a point system using a rubric of eight General Standards, each containing between four and nine Specific Review Standards, comprising a total of 42 items. Each Specific Review Standard is worth 1, 2, or 3 points. The standards include elements of course navigation, learner support, accessibility, and, most crucially to pass a review, alignment between and among measurable course- and unitlevel learning objectives, instructional materials, and assessment instruments (Quality Matters, 2018a). Quality Matters reviews are conducted by a team of three QM-certified peer reviewers who have taught online at the college level and have completed a Peer Review Course. The reviewers independently evaluate the course and determine whether each standard has been "met" or "not met," and points are awarded for a standard when at least two of the three reviewers agree that it has been met to a degree of $85 \%$ or better. To successfully pass a Quality Matters review and be designated as a certified quality course, all Specific Review Standards valued at 3 points must be met and $85 \%$ of the total point value of all standards (or 84 of 99 points) must be earned (Quality Matters, 2018a). As of November 2018, a fee of $\$ 1,400$ is assessed for a Quality Matters review, or $\$ 1,000$ for QM subscriber institutions (Quality Matters, 2018f).

The Quality Matters rubric is applied universally to online courses regardless of content area, pedagogical priorities, student population, or curricular context - an introductory biology course is expected to meet the same set of standards as a graduate philosophy course. Thus, it follows what Espeland and Stevens (1998) called a logic of commensuration or "the expression or measurement of characteristics normally represented by different units according to a common metric...a way to reduce and simplify disparate information into numbers that can easily be compared" (pp. 315-316). 
Commensuration normalizes objects of inquiry by reducing or erasing differences among them; not only are the biology course and philosophy course evaluated by the same rubric, but abiding by the expected quality performances also reduces the difference between them: Both courses, per the Quality Matters rubric, must have a network of behavioral objectives or competencies, must be organized in easily consumed "modules," must have "instructional materials that represent up-to-date theory and practice," must have "assessment instruments [that are] sequenced, varied, and suited to the level of the course," must ask "learners to introduce themselves to the class," must have multiple provisions that support "ease of use," must provide expectations for etiquette for communications and state "requirements for learner interaction," and so on (Quality Matters, 2018a, p. 51). Through its standards, the Quality Matters rubric creates a norman archetype - by which all online courses can be compared and judged. In this way, not only do the Quality Matters standards limit pedagogical choices, reducing the agency and autonomy of the teacher, but they also, as Espeland and Stevens put it, "create what they purport to describe" (p. 338). This runs contrary to the idea that, as Houston (1997) suggested in his critique of quality assurance in the academy, "the purpose of higher education, rather than conformity, should be to promote diversity: to extend each student toward realising their own individual potential" (p. 11).

For this study, I am considering the Quality Matters review process as an audit practice. Audit practices are characterized by "independence from the matter being audited; technical work in the form of evidence gathering and the examination of documentation; the expression of a view based on this evidence; [and] a clearly defined object of the audit process" (Power, 1997, p. 5, emphasis in original). The QM review is 
intended to responsibilize and accountibilize instructors in what Power (1997) described as a ritual of verification: faculty members should be held answerable for ensuring that their courses meet certain standards of quality in order to provide students with the best possible learning experiences. These standards are external to and imposed on faculty, and the criteria of quality are presumed to be universal. Similar to Readings's (1996) characterization of the discourse of excellence as "incontestable ground" (p. 23), the quality standards that comprise the Quality Matters rubric may seem natural, normal, and unquestionable; "any question of such performance indicators is positioned as a resistance to public accountability, a refusal to be questioned according to the logic of contemporary capitalism" (p. 27).

According to Power (1997), "the idea of audit shapes public conceptions of the problems for which it is the solution; it is constitutive of a certain regulatory or control style which reflects deeply held commitments to checking and trust” (p. 7). Audit necessarily takes place in the context of institutionalized distrust; in online education, faculty members and instructional designers are assumed incapable of self-regulating or verifying the quality of their outputs. Furthermore, since auditing reflects "a system of values and goals which are inscribed in the official programmes which demand it" (p. 7), quality standards are necessarily imbued with a certain normativity that privileges a narrow range of pedagogical choices. For example, a course will not pass a Quality Matters review if an instructor prioritizes outcomes that may not be associated with particular observable and measurable behaviors or opts to forego the use of "tools that promote learning engagement and active learning” (Quality Matters, 2018a, p. 51). 
The logics and practices of audits in higher education can be linked to the rise of neoliberal rationality (Shore \& Wright, 1999, 2000). While neoliberalism is a concept with many understandings (Clarke, 2008), for the purposes of this study, I approach neoliberalism as a rationality that elevates and applies economic logic to all spheres of life and society, emphasizing competition as a "natural" allocator of resources and markets as valid determiners of value or worth. Neoliberal rationality normalizes the application of private-sector concepts and practices of into public domains, including quality and quality assurance. To Shore and Wright $(1999,2000)$, neoliberal regulatory mechanisms such as audits inscribe norms and values that allow the conduct of individuals to be transformed in service of political aims: "The audited subject is recast as a depersonalized unit of economic resource whose productivity and performance must constantly be measured and enhanced" (Shore \& Wright, 2000, p. 62).

Given this background, the problem that undergirds this study is that Quality Matters has the potential to affect materially the teaching practice of faculty members, thus restricting their professional autonomy—a situation that becomes more pressing as the mandate for achieving quality looms. This study is an exploration of how those teachers navigate, maneuver, and resist the Quality Matters process; the motivations, impacts, and significance they ascribe to QM; and how their perceptions and opinions of quality relate to the requirements of the Quality Matters rubric.

\section{Study Design}

For this qualitative interview study, I conducted interviews with eight faculty members who teach online at Florida International University and have had one or more of their courses pass a formal Quality Matters review. I analyzed the interview data I 
collected, as well as relevant textual data, such as the QM Rubric Workbook and QM websites, to identify relevant and salient themes pertaining to their experiences with the Quality Matters program. My study was informed and guided by using Power's (1997) and Shore and Wright's $(1999,2000)$ scholarship on audits and audit practices as an interpretive lens.

From the outset, my intention was to conduct a critical study of how faculty members perceive Quality Matters and how it affects their teaching practices; my use of the term "critical" is informed (and best explained) by a definition put forth by Morris and Stommel (2018) in the context of their work on critical digital pedagogy. To them, the term "functions in several registers": "Critical, as in mission-critical [or] essential"; "Critical, as in literary criticism and critique, providing definitions and interpretation"; "Critical, as in reflective and nuanced thinking about a subject"; "Critical, as in criticizing institutional, corporate, or societal impediments to learning"; and "Critical Pedagogy, as a disciplinary approach, which inflects (and is inflected by) each of these other meanings" (p. 3). Each of these overlapping and interwoven conceptualizations resonated with me in how I approached and conducted this study.

\section{Purpose and Research Questions}

The purpose of this qualitative study was to explore how faculty members negotiate, maneuver, and resist the Quality Matters process as well as the motivational factors, impacts, and significance that preceded and followed their engagement with QM. In addition, this study explored the relations between the standards of the QM rubric and faculty members' own conceptualizations of quality. To that end, the following overarching research questions drove and guided this study: 
- What are the relations between the understandings of course quality among faculty members who have gone through the Quality Matters process and the criteria used by Quality Matters?

- What motivated them to pursue Quality Matters certification?

- How have they negotiated, maneuvered, and/or resisted the QM program and process?

- What impacts and significance do these faculty members ascribe to Quality Matters?

\section{On Subjectivity}

According to Maxwell (2013), the separation that researchers frequently make between their research and the rest of their lives in the interest of objectivity is "harmful to good research" (p. 24). The attempt at this separation can create the illusion that research is guided by rational and impersonal motives and decisions, and it causes researchers to overlook the influence of their actual motives and agendas on their process and conclusions (Maxwell, 2013). In keeping with this theme, I cannot—and do not endeavor to-make any claims of objectivity in relation to the topic of quality assurance in online education. This is an area where I have an extensive professional background and substantial personal experience which have shaped my feelings, perceptions, and opinions on the topic. In a previous professional context, I managed a large instructional design and course development team that was charged with collaborating with faculty members to design, development, and maintain online higher education courses and instructional materials. Essentially, I was a middle manager between the front-line instructional design staff and the distance learning unit's leadership. In this institution and 
department, there was an overriding concern about course quality, manifested and operationalized in Quality Matters and its rubric and course certification process. This concern was often couched in the neoliberal language of quantification and competition.

Operationally, this overriding concern translated to mandates for instructional designers to certify as many courses as possible, and official quotas were implemented. As a result, the relationship between instructional design and faculty member shifted from one of flat power relationships, collaboration, and collegiality (Aleckson \& RalstonBerg, 2011) to one of sales and coercion. Like used car salesmen, instructional designers were expected to "sell" QM to their faculty under the looming threat of punitive action if they failed to meet quotas.

This coincided with the implantation and growth of a colossal internal auditing apparatus in which the instructional designers were enrolled in courses they did not design or develop to conduct a quality audit based on the Quality Matters rubric, a tedious and time-consuming process, the results of which were returned to the original course designer to then adjust. The purpose of this apparatus was to inch courses closer to certification, and it existed without the knowledge or consent of the faculty members teaching those courses. It reflected what Power (1994) described as a shift from the firstorder work of course design and development to second-order verificatory activities. What I witnessed and experienced, in other words, was a shift in the role of designer to that of auditor. While certainly not making empirical claims, I have the sense that this shift, ironically, may have had the effect of reducing overall course "quality"; so much time and effort were spent on these second-order activities that there were fewer overall resources for meaningfully engaging with faculty to improve courses. Importantly, my 
feeling is that the goal through all of this was not course quality but rather signification of course quality through certification. Only the metric mattered. Admittedly, this state of affairs was one contributing factor in my decision to leave that institution.

The increasing pressure surrounding course quality at my previous institution fed into a growing suspicion of the Quality Matters program as a useful mechanism for improving student outcomes or learning experiences. Over the span of my career in instructional design and higher education, there has been a profound shift in my own thinking in and orientation to this area. In my earlier years, I unquestioningly accepted the regime of quality. I have designed and developed six courses that earned Quality Matters certification. I have presented at the Quality Matters conference—-several times—and have published about Quality Matters (Acevedo, 2013, 2014a, 2014b, 2014c). However, several years of close involvement and seeing dubious results in terms of what students actually experienced and learned planted the seed of doubt about the process, the rubric, and the whole enterprise. This uneasiness grew, culminating in a somewhat epiphanic moment involving a conversation with instructional design colleagues in which we discussed the possibility of two scenarios: First, we agreed an online course could meet all Quality Matters standards, pass a formal Quality Matters review, and still be considered a "bad" course by reasonable educational expectations; second, we also agreed that another course could meet few or none of the standards but still be an effective, powerful, meaningful, and transformative learning experience for students. If the possibility exists that these two hypothetical examples could take place, it raises some crucial questions. What does the Quality Matters program actually 
accomplish as opposed to what it says it does? What, exactly, is "quality," if it means anything at all?

Given my abiding interest in matters of pedagogy and power, it is this set of concerns - What is quality? What does QM accomplish and how does it affect educators? - that drove this research study.

\section{Significance of the Study}

As I will discuss in Chapter II, there has been little critical analysis or inquiry of quality in relation to online and distance education. While a rich body of literature exists that critiques the role of quality and quality assurance in higher education and the literature on the effects and uses of Quality Matters is steadily growing, I have been able to find only scant literature that is critical or questioning of QM. My intention with this study was to conduct a critical study of Quality Matters and online course quality assurance - one that explored how faculty members who engage with it navigated, maneuvered, and resisted it. Extending more broadly, I also explored whether faculty members' conceptualizations of quality were reflected by the QM rubric used to evaluate courses.

The significance of this study is that it deals, at its core, with issues of power and hierarchy as they relate to faculty autonomy and pedagogy. I feel that these issues are more pressing than ever given the continued growth in online education described earlier in this chapter. Fundamentally, I believe in the potential of online education to expand access to education to students who want it but are unable to pursue it in historically traditional ways. However, if regimes of "quality" reduce faculty agency and autonomy and exert a normalizing, pedagogically limiting influence on online education, I worry 
that these will contribute to the relegation of online education as a means of neoliberal profit-seeking rather than access and liberation. My hope is this study will be a voice that questions, critiques, and draws awareness to the influence of factors that may pose a threat to the liberatory potential of education that takes place at a spatiotemporal distance.

\section{Overview of the Dissertation}

This dissertation is structured in five chapters. This chapter, Chapter I, was an introduction to the problem and the research study. I discussed some of the salient issues surrounding online course quality and the Quality Matters program and introduced the research questions that guided this study. Chapter II is a review of the literature on quality in higher education and the Quality Matters program and process. Chapter III discusses the methodology and methods of the study, including my epistemological orientation, the justification for employing a qualitative interview study, and the details of how I collected and analyzed my data. Chapter IV of the dissertation includes the results of my research study, centered around the salient themes I identified in the course of analyzing the data collected in relation to the research questions. Chapter V includes a summary of my findings, suggestions for future research and practice, limitations, and ultimate conclusions from the study. 


\section{CHAPTER II}

\section{REVIEW OF THE LITERATURE}

This chapter of the dissertation reviews the scholarly research literature relevant to the study, starting with a broad overview of the concepts of quality and quality assurance with a focus on higher education context, followed by a review of the literature on quality and quality assurance as related to teaching and learning in higher education. Next, this chapter explores the literature on the underlying logics of quality and audits, as well as how higher education faculty understand, maneuver, and resist quality-related practices and mechanisms. The chapter concludes with a review of the salient literature related to Quality Matters and its impacts on online course design and student outcomes. My goal with this chapter is to situate and contextualize this research study on Quality Matters within the broader literature on quality and quality assurance in higher education.

The scholarship on quality in higher education, as noted by Blanco Ramírez (2013), is dominated by a technical-rational perspective. He suggested that this perspective represents the managerial application of a positivist epistemological paradigm that is informed by economic liberalism and a bureaucratic organizational method. Blanco Ramírez noted, "nearly all the scholarship that explores quality in higher education takes for granted that rationality is the justification that motivates qualityrelated practices and decisions" (p. 128). Furthermore, technical-rational approaches to quality "take for granted that quality assurance, as a technical endeavor, is beneficial in all settings" (p. 131). Blanco Ramírez also suggested that, under technical rationality, any questioning of the quality enterprise can be interpreted as irrational, which presents a challenge to anyone who seeks or puts forth alternate perspectives on quality. While this 
study is undergirded by a philosophical stance that differs from technical rationality, which will be detailed further in the next chapter, I have set out in this chapter to explore research on quality from a variety of perspectives.

\section{Dominant Understandings of Quality in Higher Education}

The concepts of quality, quality assurance, and quality enhancement are imports from the world of business and finance (Birmbaum, 2000; Stensaker, 2007; Reeves \& Bednar, 1994), and the definitions of these concepts are notoriously enigmatic. Quality means different things to different people at different times in different contexts, and the same person may shift her conceptualizations of quality (Harvey \& Green, 1993). Quality is a relative concept in that it is relative to whoever is evoking it and, by some definitions, it is relative to the benchmarks and processes that construe it (Harvey \& Green, 1993). Furthermore, the idea of quality, particularly in higher education, is ideologically constructed in a network of fluctuating discourses (Filippakou, 2011). Filippakou suggested that

there are multiple discourses of quality, constructed and perpetuated in different contexts through diverse channels such as national quality agencies, journals, conferences, informational conversations between colleagues, and even between students and tutors. Some discourses of quality are dominant, representing the interests of powerful groups with the wider social framework, or perhaps accepted as "common sense" or "natural" by the majority of the social collectivity. While others may be subservient, even if articulate, alternative perspectives. (p. 18)

Filippakou argued that the meaning of higher education itself can be influenced by the ideological discourses of quality, particularly in relation to teaching and learning. For instance, the Quality Assurance Agency in the United Kingdom emphasizes student employment as a major concern, reflecting a dominant neoliberal ideology and thus positioning higher education in terms of its unquestionable economic utility (p. 19). 
Acknowledging the socially constructed and often conflicting definitions of quality, Harvey and Green (1993), in their seminal work on defining quality in higher education, identified five broad conceptualizations of quality, which are discrete but interrelated: quality as exceptional, quality as perfection or consistency, quality as fitness for purpose, quality as value for money, and quality as transformative.

\section{Quality as Exceptional}

According to Harvey and Green (1993), "the exceptional notion of quality takes as axiomatic that quality is something special" (p. 11). Variations on this notion include the traditional view of quality as distinctive, the view of quality as excellence or meeting very high standards, and the view of quality as passing minimum standards.

The traditional view of quality is that it refers to the state of something being exceptional or special. Something of quality is distinctive and exclusive; it confers a level of status on its users or owners. This idea of quality is not associated with particular standards or benchmarks but is instead assumed by the distinctive and inaccessible nature of the thing in question. A Harvard education, for instance, is assumed to be one of quality simply by its exclusive nature. Harvey and Green also described the German higher education system as demonstrative of this view of quality; at the time of their writing, there was no centralized or external quality assurance agency in Germany, and the assurance of quality in German institutions was "self-evident" (p. 11). Since then, however, political pressures in Germany have led to the development of a national system of quality assurance and accreditation (Schade, 2003).

A related but distinctly different conceptualization of the exceptional view of quality is quality as excellence or exceeding high standards. Harvey and Green (1993) 
noted that the terms "quality" and "excellence" are often used interchangeably. However, while the view of quality as excellence is similar to the traditional view of quality as exceptional, it abandons the taken-for-granted nature of quality and replaces it with standards that are "almost unattainable" (p. 12). Harvey and Green described this conceptualization as "elitist" (p. 12) since it positions quality as only attainable in very limited circumstances and is tightly coupled with an institution's reputation and the extent of its resources. For example, Harvey and Green suggested that in this view, "if you are lectured by Nobel prizewinners, have a well-equipped laboratory with the most up-todate scientific apparatus and a well-stocked library, then you may well produce excellent results" (p. 12). Readings (1996) poignantly problematized the discourse of excellence in higher education, suggesting that the university's traditional role as promoter of national culture has been supplanted by its pursuit of excellence, a term which he described as “entirely meaningless, or to put it more precisely, non-referential" (p. 22).

The final conceptualization of quality that Harvey and Green (1993) categorized as exceptional is that which meets a set of minimum checks or standards. They suggested that this view of quality represents a further diluted definition from quality as distinctive and quality as excellence. According to Harvey and Green, “a 'quality' product in this sense is one that has passed a set of quality checks. Rather than unattainable, the checks are based on attainable criteria that are designed to reject 'defective' items" (p. 12). Furthermore, “'quality' is thus attributed to all those items that fulfil the minimum standards set by the manufacturer or monitoring body" (p. 12, emphasis in original). In this conceptualization, a check for quality may be conducted by an external agency and may be evaluated on a pass/fail basis or on a scale. Harvey and Green noted that "this 
approach to quality implicitly assumes that 'standards' are 'objective' and static" (p. 13), although, importantly, "quality as conformance to (relative) standards tells us nothing about the criteria used to set the standards. We may not agree that something is a quality product or service even if it conforms to the standards that have been set for it" (p. 14). Many common manifestations of quality in higher education, such as regional accreditation, reflect this conceptualization of quality, including the Quality Matters online course review program that is the subject of this research study.

\section{Quality as Perfection or Consistency}

The second approach to quality outlined by Harvey and Green (1993) — quality as perfection or consistency_focuses on conformance to specifications and pursuit of "zero defects." Under this understanding of quality, "a quality product or service is one which conforms exactly to specification and a quality producer or service provider is one whose output is consistently free of defects" (p. 15). Harvey and Green noted that this conceptualization of quality is minimally applicable in higher education since "higher education is not about delivering specifications in as near a perfect way as possible. It is, arguably, about encouraging, inter alia, the analytic and critical development of the student" (p. 16).

\section{Quality as Fitness for Purpose}

The third approach to quality described by Harvey and Green (1993) is quality as fitness for purpose, or the extent to which a given product or service fits its designated purpose. They noted that "this notion is quite remote from the idea of quality as something special, distinctive, elitist, conferring status or difficult to attain. It is a functional definition of quality rather than an exceptional one" (p. 16). The salient issue 
with this conceptualization of quality, however, is determining whose purpose matters and how fitness is assessed. One possible answer is fitness for purpose based on the customer's specification, which identifies quality "in terms of the extent to which a product or service meets the specifications of the customer," (p. 17). This conceptualization, Harvey and Green noted, is problematic for a number of reasons. Customers may not be able to specify their individual requirements, and they may be influenced by the producer's marketing efforts. They also suggested that the notion of "customer" is contentious in higher education, an argument supported by Saunders (2015), who found that students do not necessarily express a customer orientation toward their education.

An alternative view of quality as fitness for purpose shifts the purpose back to that of the institution, thus seeing quality "in terms of the institution fulfilling its own stated objectives, or mission...A high quality institution is one which clearly states its mission (or purpose) and is efficient and effective in meeting the goals which it has set itself"' (Harvey and Green, 1993, p. 19). Harvey and Green suggested that this definition of quality can be seen in the American higher education system, "with each institution being encouraged to carve out its own niche" (p. 19).

Ultimately, conflicting views regarding the purposes of higher education render the fitness-for-purpose definitions problematic (Harvey and Green, 1993). Different institutions and higher education stakeholders may have different objectives and emphases, with different means for evaluating the fitness of these purposes. 


\section{Quality as Value for Money}

The fourth conceptualization of quality outlined by Harvey and Green (1993) is quality as value for money, or meeting a standard or specification while optimizing or reducing costs. This view of quality emphasizes the measurement of inputs and outputs in financial terms or through metrics of efficiency. Central to this perspective is the notion of accountability; services such as higher education are expected to be accountable to those that fund it (governments, taxpayers, parents, students) and those who use it (students). Value-for-money approaches to quality use a variety of control mechanisms, such as performance indicators, teaching observations, and research assessment exercises. However, Harvey and Green argued that these types of instruments may be more effective at measuring efficiency than effectiveness. They also noted that this perspective of quality is favored by the political right and is informed by economic individualism and market competition, although a contemporary interpretation of this logic transcends party lines; accountability and efficiency are hallmarks of predominant neoliberal rationality (Olssen \& Peters, 2005).

\section{Quality as Transformation}

Harvey and Green's (1993) final category of quality is quality as transformation, which emphasizes continuous positive change over time. Embedded in this view of quality is a critique of the product-based notions of quality such as fitness for purpose or value for money. In higher education, this can be viewed as what they call "enhancing the participant" (p. 24), or providing students with new knowledge, skills, and abilities or empowering students or giving them the power to influence their own transformations. Harvey and Green described four ways of "empowering" students: student evaluation, 
minimum standards of provision, student choice through electives and learning contracts, and developing students' critical thinking ability. The authors favor this latter conceptualization, arguing that "empowerment must lie at the heart of a quality culture in education" (p. 27), while ultimately concluding that the elusive and varying understandings of quality do not absolve educators from the responsibility for maintaining and enhancing quality. While quality as transformation might be an improvement over some conceptualizations of quality in its privileging of the student experience, Harvey and Green's ideas around “empowerment” are problematic: student evaluations are notorious for introducing complex and uneven power dynamics among teachers and students (Hou, Lee, \& Gunzenhauser, 2017), critical thinking may itself have conflicting definitions or manifestations (Barnett, 1997), and the idea of holding students to learning contracts seems antithetical to the concept of empowerment.

Despite Harvey and Green (1993) articulating these definitions of quality 25 years ago, these conceptualizations are still used by scholars and policymakers today, and recent decades have seen a shift in emphasis from the perspectives of quality as fitness for purpose or value for money to quality as excellence (Harvey \& Stensaker, 2008; Kristensen, 2010; Cheng, 2011). Regardless of whichever conceptualization is used or implied at a given time or in a given context, organizational practices related to quality in higher education manifest in a variety of forms, such as regional and national accreditation, evaluations, audits, assessments, professional accreditation and licensure, national qualifications frameworks, state-conducted subject assessments, performancebased funding, rankings, and surveys (Birnbaum, 2000; Dill, 2010). These practices may exist at a system, institution, academic department, academic program, or course level. 
Quality Matters, the program that is the subject of this research study, primarily operates at the course level, although a variant examines academic programs (Quality Matters, 2018a). Furthermore, quality practices can be broadly categorized into two distinct categories: quality assurance and quality enhancement. The next section of this chapter provides an overview of these practices.

\section{Quality Assurance and Quality Enhancement in Higher Education}

Writing about the practices of quality assurance and quality enhancement, Williams (2016) suggested that "these two concerns underpin all discussions of quality in higher education" (p. 97). He added that, while the two activities are distinct, there have been "remarkably few studies that have directly explored the relationship between them" (p. 97). Harvey's (2018) Analytic Quality Glossary included what Williams described as "the most comprehensive" definitions of these terms: Quality assurance, broadly, is "the collections of policies, procedures, systems and practices internal or external to the organisation designed to achieve, maintain and enhance quality," and quality enhancement is "a process of augmentation or improvement" (Harvey, 2018). Williams further suggested a spectrum of possible relationships between quality assurance and quality enhancement, ranging from the two activities taking place without reference to each other at all, to both being parts of unified linear process, to each being entirely in opposition to one another. However, Filippakou and Tapper (2008) suggested that quality enhancement may not actually be distinctly different from quality assurance and that quality enhancement could be merely a discursive evolution of the top-down agenda of quality assurance. Ultimately, Williams concluded that "the question of how the two concepts are related has important implications for how staff are treated, respect and trust, 
how institutional data can be used to improve what the institutions, and ultimately, what universities are actually for" (p. 101). Quality Matters (2018a, 2018c, 2018g) materials indicate no claims regarding quality enhancement—only quality assurance.

Quality assurance practices in higher education can be characterized by internal and external quality programs or mechanisms. Internal quality assurance refers to the practices undertaken by the community of a higher education institution; external quality assurance is "activity that validates the reliability and efficiency of internal quality assurance procedures" (Stumbrys, 2004, p. 158). There is a critical interaction between internal and external quality assurance; the goal of external quality assurance is to check and verify the activities involved in internal quality assurance (Kristensen, 2010). For example, Part 1 of the Standards and Guidelines for Quality Assurance in the European Higher Education Area (ESG) sets out standards for institutions' internal quality assurance, and Part 2 puts forth standards for external quality assurance carried out by agencies (Standards and Guidelines for Quality Assurance in the European Higher Education Area (ESG), 2015). According to the ESG, "external quality assurance in Part 2 recognises the standards for internal quality assurance in Part 1 thus ensuring that the internal work undertaken by institutions is directly relevant to any external quality assurance that they undergo" (p. 9). With respect to internal and external quality assurance, Quality Matters breaks from the precedent set by other quality assurance mechanisms in higher education; while it is external to the institution, it employs a direct examination of a course itself rather than serving the purpose of verifying and validating quality assurance mechanisms that take place within an institution. Despite this difference, Quality Matters shares much in common with other forms of teaching quality 
assurance such as teaching quality audits, which are covered in the next section of this chapter.

In the United States, external quality assurance at the institutional and program levels falls under the purview of private, non-profit accrediting bodies. As of 2013, there were 85 institutional and programmatic accrediting organizations serving as regional accreditors, national faith-based accreditors, national career-related accreditors, and programmatic accreditors (Eaton, 2015). According to Eaton, these organizations and their myriad accreditations serve as the primary means by which institutions and programs signal quality to students and other higher education stakeholders. Institutions and programs are required to meet threshold standards to pass accreditation reviews, reflecting Harvey and Green's (1993) conceptualization of quality based on minimum standards and diluted excellence. While these standards vary among bodies, the factors typically under examination include institutional governance arrangements, qualifications of faculty members, adequacy of provision of instruction, and, increasingly, student learning outcomes (Ewell, 2007). The operations involved in institutional accreditation include a written self-study by the institution seeking accreditation, peer review by faculty and administrative peers, a site visit by a visiting inspection team, and judgment by the accrediting organization (Eaton, 2015; Ewell, 2007). Accrediting agencies themselves are recognized by the Council for Higher Educational Accreditation, a national coordinating body, and the U.S. Department of Education (Ewell, 2007).

In contrast to the fractured, decentralized accreditation system in the United States, the quality assurance program in the United Kingdom is centralized and more robust and has undergone a number of significant revisions. Following the 1992 Further 
and Higher Education Act, which abolished the binary line that formally divided universities and polytechnics, the government implemented the Teaching Quality Assessment (TQA), an external quality assurance program that operated from 1993 to 1997 and evacuated teaching quality at the institutional level (Cheng, 2010; Laughton, 2003; Harvey, 2005). In 1998, TQA was superseded by the Quality Assurance Agency (QAA) Subject Review, which evaluated teaching quality at the subject level (Cheng, 2010, Harvey, 2005). Quality Assurance Audit Subject Review, in place from 1997 to 2001, was highly criticized; Laughton (2003) conducted a text analysis of academics' contributions to the Times Higher Education Supplement regarding the QAA Subject Review and found concerns related to administrative and financial burdens, grade inflation and gamesmanship, elitist bias, unintended outcomes, and philosophical objections. Laughton suggested that these concerns were grave enough to prompt the head of the QAA to resign and the government to commission a new methodology. In 2001, QAA Subject Review was replaced with QAA Institutional Audit. This system, developed in response to the criticisms of Subject Review, was considered to be "lighter touch" in that it focused on assessing the efficacy of institutions' own internal quality assurance mechanisms (Laughton, 2003; Harvey, 2005). However, in a drastic shift away from this approach, a new teaching quality system was implemented in the United Kingdom in 2017: the Teaching Excellence Framework (TEF). The Teaching Excellence Framework focuses on institutional outputs, including student satisfaction survey results, retention rates, and the number of graduates who gain skilled employment or move onto further study (Gillard, 2018). Based on their results, UK institutions are awarded Gold, Silver, or Bronze, or provisional standing (Gillard, 2018), and public 
institutions that perform well on TEF are permitted to increase tuition fees (Canning, 2017). While at the time of this writing, TEF is too new for much scholarly literature to have been published about it, initial responses have been not particularly favorable. Canning (2017), for example, condemned TEF as a Baudrillardian hyperreal simulacrum in that it "is detached from both reality and representation, namely the practice of teaching in higher education and the evaluation/assessment of that teaching" (p. 4). Tomlinson, Enders, and Naidoo (2018) called TEF a form of symbolic violence and one of the more recent manifestations of the UK's onslaught of neoliberal reforms. Despite its many forms and incarnations, the UK quality assurance systems have consistently been critiqued as elitist, favoring pre-1992 universities (the institutions that were classified as universities prior to the abolishment of the binary divide in 1992), which typically had access to greater resources, thus promoting existing hierarchies (Laughton, 2003; Drennan \& Beck, 2001).

Systems of quality assurance and accreditation in the United States and United Kingdom serve as salient models for the discussion of quality in higher education writ large. However, these types of systems are by no means limited to the Anglosphere; new programs continue to proliferate in higher education systems around the globe in the growing context of market competition for education and increased state oversight. Academics' reactions to these programs have been decidedly mixed. (De Vincenzi, Garau, \& Guaglianone, 2018, Tavares, Sin, Videira, \& Amaral, 2017; Pham, 2018). While most quality assurance systems and programs in higher education adopt a broad, institutional approach to quality, Quality Matters operates at a much more granular level in its inspection of the individual course. As the design of a course is inextricably 
interwoven with its implementation, QM is, fundamentally, an audit of teaching quality.

The next section of this chapter more deeply explores the underlying logics behind quality assurance and audit practices.

\section{The Logics of Quality}

The previous sections of this chapter explored different conceptualizations of the idea of quality in higher education as well as different manifestations of state and institutional mechanisms related to quality assurance. This section of the literature review considers scholarship that examines underlying logics that undergird the ideas of quality and quality assurance. The discourse of quality is inextricably linked to those of managerialism, accountability, efficiency, and control. Jarvis (2014) noted the peculiar position of the university in relation to the tension inherent in quality assurance:

In the contemporary era, the university thus sits oddly amid two narratives; one that prizes academic freedom, independence of thought and expression, heterodoxy and exploration to create new knowledge frontiers, on the other hand an increasingly intrusive series of regulatory regimes that seek to manager, steer and control the sector in ways that serve the interests of the state and the economy by applying specific ideational motifs about efficiency, value, performance, and thus the economic worth of the university to the economy. (p. 156)

To Jarvis, the proliferation of quality assurance regimes in higher education systems is the result of shifting public understandings about the purpose of the university toward the training of graduates for the workforce, coupled with government pressures intended to promote academic capitalism and income generation. He concluded that "QA regimes are not benign managerial instruments - they must also be understood as part of a broader series of agendas associated with neo-liberal policy prescriptions that valorize market rationality" (p. 164). This outlook is shared by Tomlinson, Enders, and Naidoo (2018), who described the UK's new Teaching Excellence Framework as "an instrument for the 
entrenchment and amplification of neoliberal market competition in [higher education]"

(p. 1). The rise of quality assurance has also been linked to changes in student

populations, technology, and funding. D'Andrea (2007) noted that:

The rationale most often cited for importing the ready-made quality assessment review processes from the world of business and industry is the need for governments and others who fund higher education to seek assurance that the rapidly changing higher education environment, including increasing massification and the concomitant shift in student demographics, technological change, and globalization among others, is not adversely affecting higher education outcomes. (p. 212)

Quality assurance is closely associated with the discourses of New Public Management (NPM) and New Managerialism. According to Olssen and Peters (2005), "the core dimensions of new public management are: flexibility (in relation to organizations through the use of contracts); clearly defined objectives (both organizational and personal), and a results orientation (measurement of and managerial responsibility for achievement of)" (p. 324). To Olssen and Peters, NPM is a manifestation of the ascendancy of neoliberal rationality in higher education. A related idea is New Managerialism, which is characterized by "emphasising the primacy of management above all other activities; monitoring employee performance (and encouraging self-monitoring too); the attainment of financial and other targets, devising means of publicly auditing quality of service delivery and the development of quasimarkets for services" (Deem \& Brehony, 2005, p. 220). New Managerialism also emphasizes importing practices and ideas from business and industry into the world of public service (p. 220). The applicability of New Managerialism and NPM to higher education, while popular with some managers and policymakers, is hotly contested (Deem \& Brehony, 2005; Olssen and Peters (2005). 
The approach to quality assurance favored in discourses of NPM and New Managerialism is Total Quality Management (TQM) (Deem and Brehony, 2005; Olssen \& Peters, 2005; Vinni, 2007). While "there are no generally agreed upon definitions what TQM is or what it does" (Houston, 2007, p. 6), TQM is generally understood as an approach to quality management that emphasizes the needs of customers, continuous improvement, and the reduction of variation in inputs and outputs (Bensimon, 1995; Houston, 2007; Venkatraman, 2007). Total Quality Management has been imported into higher education from the world of manufacturing, where the "customer" is more clearly defined and reduction of variation is highly desirable. Often this adoption has occurred as a result of pressure from the industry, which has desired work-ready graduates as the university's "product" (Houston, 2007). However, the applicability of industry thinking to higher education is dubious; according to Houston, "simply assuming the advantages and accepting the purposes of externally developed frameworks should not be acceptable in universities with the fundamental roles of critical evaluation in higher learning" ( $p$. $11)$.

Some have argued that TQM is appropriate for higher education contexts, such as Venkatraman (2007), who suggested that the fundamental principles of TQM "fall well in line with the value set of many modern universities and their faculties" (p. 95), adding that "academic institutions that are slow to embrace TQM, at best, miss the opportunity to lead change and, at worst, run the risk of becoming less relevant to the business world" (p. 96). Others view TQM as incompatible with higher education, including Bensimon (1995), who employed a post-structuralist, feminist analysis to critique the basic postulates of TQM. She questioned who is meant to be the customer in higher education 
since within the academy, "TQM is conspicuously evasive about who has the status to be regarded as the customer with the ultimate power, authority, or influence to determine what constitutes quality and what constitutes variation" (p. 598). She suggested that the ultimate customers of the TQM enterprise are actually the large, multinational corporations that expect well-trained, competent, and productive workers. She also critiqued TQM's emphasis on reducing variation as possibly perpetuating the oppression of marginalized groups because differences are considered inferior and unwanted. She added that "faculty whose scholarship and pedagogy defy normative standards may be regarded as undesirable because their unorthodox work, while it may be popular, will not contribute substantively to...quality 'ratings"' (p. 604). Ultimately, she concluded that TQM is unfit for the academy as it "is a natural ally of those who believe it is more important to defend traditional values than to reconstruct the academy to make it more responsive for diversity" (p. 608). Houston (2007) reached a similar conclusion:

The focus of $[\mathrm{TQM}]$ is the reduction in variation in core productive processes and products towards compliance with predetermined specifications... [TQM's] use assumes that product characteristics can be precisely specified in measurable terms and that reducing variation around the target values for product characteristics... [These assumptions] do not match the nature of learning and teaching processes and outcomes: they are far more complicated. Each student entering the process is unique... The purpose of higher education, rather than conformity, should be to promote diversity: to extend each student toward realising their own individual potential. (p. 11)

While Quality Matters does not claim any kinship to TQM, the underlying assumptions are closely related, particularly the emphases on measurement and specifications.

As demonstrated in this section, quality-related practices are manifestations of a particular set of logics - particularly those associated with managerialism, accountability, efficiency, control, and reduction of variation. There is inherent tension between these 
notions and the nature of higher education, which, at its core, deals with human

experiences. Perhaps these tensions could be overlooked, ignored, or forgiven if quality-

related practices resulted in meaningful, positive changes in institutions. However,

Harvey and Williams (2010), reviewing 15 years of papers published in the journal

Quality in Higher Education, concluded that studies on the impact of quality assurance

reinforce the view that quality assurance is about compliance and accountability and has contributed little to any effective transformation of the student learning experience. Where changes to the student experience have taken place, this has arguably been the result of factors other than external quality monitoring. (p. 104)

Even more harshly, Harvey and Newton (2007) levied a devastating blow to the logics of quality and accountability:

At the core, the contention is that asking an amorphous group of academics to identify their strengths and weaknesses and for an agency of ministerial department to send out a raiding party to pass summary judgment on the quality of provision may ensure compliance to policy or regulation or contribute to some form of control over the sector, and it may satisfy the illusion of accountability, but has nothing do with the essential nature of quality. It is a bureaucratic process quite removed from either the student learning or creative research processes, which, it is argued, lies at the heart of quality in higher education. (p. 226)

Given this tension, an exploration of how these logics manifest in relation to the teaching mission of higher education is necessary for this study, which explores faculty members' experiences with the teaching audit of Quality Matters.

\section{Teaching Quality}

As discussed previously in the chapter, quality is a nebulous and socially constructed concept with different definitions, priorities, and related practices. Efforts to define, measure, and assure the quality of teaching practices, in particular, are similarly fraught with ambiguities and conflicts. For example, using semi-structured interviews, Cheng (2011) explored the varying understandings of quality among institutional 
teaching award winners and their students. Faculty participants in her study had won teaching awards supported by the UK's Higher Education Funding Council for England (HEFCE). Those teachers largely described teaching quality as being related to students' positive experiences, the use of learner-centered teaching strategies as opposed to content-centered, and the development of the student as a whole person, all of which reflect Harvey and Green's (1993) description of quality as transformation. Students' views on quality were more instrumental and pragmatic, indicating that quality teaching had more to do with "academics' knowledge of the subject area, the way academics organised their lectures and the amount of hand-outs academics provided" (p. 12). Using focus groups and a grounded theory approach, Hill, Lomas, and MacGregor (2003) also explored students' perceptions of quality. They found that students' most important aspect of quality was "the quality of the lecturer" (p. 16); they appreciated teachers who were well prepared, interesting, knew their subjects, provided feedback, and had positive relationships with students. Students also valued engaging with a relevant and challenging curriculum. Further demonstrating the fractured understandings of teaching quality, Blackmore (2009) contended that the emerging discourses of quality and managerialism, bolstered by the implantation of generic teaching evaluation instruments, privilege a conceptualization of teaching quality that is informed by market discourse and private sector management principles that emphasize skills transferable to the labor market.

In addition to outcomes measures and student surveys, some teaching quality assurance and enhancement programs use a form of peer review. According to Lomas and Nicholls (2005), peer review of teaching, or "the intentional process of observation in 
which a university lecturer attends a colleague's teaching session with the intention of offering feedback as a "critical friend"” (p. 138), is seen by some as a means through which teaching quality can be enhanced. However, peer review of teaching is also associated with a number of detriments, such as possible challenges to academic freedom and professional autonomy, concerns about objectivity, and the possibility that peer review could be used as part of an accountability or appraisal system (Lomas \& Nicholls, 2005). Despite these potential drawbacks, Lomas and Nicholls suggested that "formative peer review can be a positive means of enhancing teaching and learning within the academic community" (p. 139).

Douglas and Douglas (2006) also advocated the use of peer reviews as part of a broader teaching quality assurance and evaluation system, although, in contrast to Lomas and Nicholls (2005), they considered peer review as a form of inspection that "entails one individual monitoring the behavior of another by watching and listening to how he/she performs, i.e., performance appraisal by inspection. Peer review in higher education falls within this category" (p. 7). In addition to peer review, Douglas and Douglas, who unabashedly espoused a consumerist view of students as customers (p. 5), also promoted the use of "mystery students" (p. 11), an idea based on mystery shoppers in retail. These mystery students would use a checklist to

measure such things as the lighting, the temperature, seating comfort, decoration, layout of chairs and tables, cleanliness (based on amount of litter) of the accommodation and the ability of the lecturer to be heard from the back of the room, the clarity of the overhead slides (if used), the length of the lecture and the lecturer's voice modulations. All of these are associated with the delivery process. (p. 6) 
The notion of simultaneously associating teaching quality with both clarity of teaching materials and seating comfort is troubling. However, Douglas and Douglas did admit that, in the course of conducting semi-structured interviews with faculty members regarding different measures of teaching quality, their interview questions relating to mystery students "were the most emotive and thought provoking for some interviewees, with one person expressing shock and disgust that it could even be considered, with another saying that it would be an attack on academic freedom" (p. 11). I echo these concerns.

Given the breadth of understandings of teaching quality and the mechanisms used to assure teaching quality, a relatively limited number of studies have investigated the impacts of quality assurance on teaching and learning. Following a qualitative study that included in-depth interviews with administrators, focus groups with faculty, and structured questionnaires with students, De Vincenzi, Garau, and Guaglianone (2018) suggested that that state-sponsored quality assurance mechanisms led to "higher quality of curricula, improved learning conditions with enhanced physical and technological resources in classrooms, and the revision of students assessment and follow-up mechanisms" (p. 63). They concluded that these processes have resulted in increased attention toward matters of pedagogy and learning, including faculty training and "the promotion of good practices leading to students' autonomous learning” (p. 64). In contrast, Pham (2018) found in a single-institution case study at a Vietnamese university that new quality assurance mechanisms in that country were "unable to help the university improve quality of teaching and learning" (p. 177). Instead, this system proved costly and time-consuming and led to ritualistic compliance among university managers. Similarly, Tavares, Sin, Videira, and Amaral (2017), using a survey sent to all teaching 
faculty in Portugal, found that respondents indicated that state-mandated internal quality assurance systems did more to increase bureaucracy than to meaningfully improve teaching and learning. Jones (2003) suggested that institution-level metrics of teaching quality are inadequate and incapable of taking into account the richness of feedback that can be collected from students at the course level. She suggested, based on a case study of a quality improvement in an MBA program in the United Kingdom, that course-level feedback and teaching awards can be communicated upward through a school's academic administration. While Jones raised valid points about the disparity in richness between institution and course-level quality feedback, her bubble-up method of communicating feedback through the academic administration is unlikely to be applicable to many other settings as other institutions' administrators may not be as amenable to that sort of communication.

Ultimately, mechanisms for assuring, measuring, or enhancing teaching quality rarely take into account learning theory or pedagogy (D'Andrea, 2007). D'Andrea suggested that quality reviews in higher education should be better grounded in learning theories such as behaviorist, cognitivist, humanist, and social theories. While this seems superficially axiomatic, D'Andrea's concern is well founded.

The literature reviewed in this section holds relevance to this study on Quality Matters because QM represents an audit of teaching. Quality Matters claims to assure the quality of only course design:

The Quality Matters Rubric specifically focuses on course design, rather than on course delivery or academic content. For the purposes of a review, consider the design aspect to include the instructor's role in the forethought and planning of the course, as well as in the creation, assembly, and layout of instructions and course components. Not under review is the instructor's implementation of the design as 
he or she delivers the course and interacts with learners. (Quality Matters, 2018a, p. 5)

However, issues of forethought, planning, and creation cannot be so simply disaggregated from the teaching process. All of these elements are pedagogical. Coercive attempts to shape or modify teaching in the name of quality or as the result of audit reflect the exercise of power. The next section of this chapter examines how faculty members understand, perform, and resist quality.

\section{Power, Performance, and Resistance}

As previously discussed in this chapter, quality assurance practices, including those related to university teaching, are undergirded by the logics of accountability, efficiency, and control. The role that quality audits play as an instrument of power in manifestation of these logics has been a subject of inquiry for some scholars (Barrow, 1999; Brennan \& Shah, 2000; Cheng, 2010; Filippakou, 2011; Morley, 2003; Shore \& Wright, 1999, 2000; Worthington \& Hodgson, 2005). For example, Shore and Wright $(1999,2000)$ derided audit practices as a new technology of neoliberal governmentality. To them, "an audit is essentially a relationship of power between scrutinizer and observed" (Shore \& Wright, 2000, p. 558, emphasis in original). As a result of audits and the prevailing neoliberal rationality,

The learning experience itself is becoming increasingly bureaucratized, standardizes and quantified, the new philosophy being that what cannot be measured is of little value. In many respects the meaning of quality has been usurped by management teams who are in offices away from the main campus and remote from classroom practice. (p. 567) 
Ultimately, in higher education, audit "encourages the displacement of a system based on autonomy and trust by one based on visibility and coercive accountability" (p. 566). Worthington and Hodgson (2005) also used this language in relation to quality:

Quality is, then, a form a coercive accountability. Quality assurance processes have created a situation in which university teachers today are compelled to fashion their teaching in accordance with pre-given quantifiable teaching objectives and learning outcomes that correspond with managerial notions of "best practice" to meet individual student needs and expectations and those of industry. (p. 106).

This is echoed by Morley (2003), who conducted semi-structured interviews with 36 faculty and staff members across 35 institutions in the United Kingdom, providing thick descriptions of participants' experiences and perspectives that illuminated the micropolitics of power resulting from that the UK's quality assurance mechanisms. She concluded:

For some, quality assurance has provided new paradigms for thinking about academic work and new career opportunities. For others, it is about suspicion, mistrust and the management of processes, rather than standards, with considerable wastage and frustration involved. As a new disciplinary technology it has exacerbated old or introduced new power relations. The imposition of interpretation and scoring on multiple academic realities has created potential for major misrecognition and inequalities. As such it has been a form of symbolic violence. (p. 170)

Similarly, Filippakou (2011) conducted semi-structured interviews with 12 institutional quality managers at four universities and two "key players" (p. 16) in quality policymaking bodies in the United Kingdom to provide empirical support for her conceptual framework of quality as a network of ideological discourses as discussed earlier in this chapter. Among the key themes she identified through her interviews was the idea that quality mechanisms had become a natural part of university life that was simply accepted and lived with, partially as a result of the inculcation of younger academics. She also 
found that participants expressed feeling voiceless as the dominant discourses of quality became increasingly powerful and unquestionable. Quality mechanisms were also said to be wielded as an instrument of power; as one of her respondents put it, "it's always open to abuse the Quality Assurance Agency, because it can be about, you'd better do this because otherwise we'll fail the inspections on you" (p. 23). According to Filippakou, "quality processes share the dimensions of power; but those power dimensions are liable to be both external (imposed from without) and internal (imposed from within)" (p. 24).

Shifts in power resulting from quality assurance mechanisms occur as at several different levels, as suggested by Cheng (2010), who interviewed 64 faculty members at a pre-1992 university in England about the QAA Institutional Audit. She noted that some of her participants described a power dynamic between the QAA and the institution itself; she described "a sense among them that a bureaucratic power relationship existed between the QAA and their university. However, most interviewees interpreted this power relationship as more symbolic than actual because some quality assurance mechanisms were implemented inconsistently between departments/schools" (p. 268). Her respondents also noted a shift in power dynamics between teachers and students that had resulted from the audits' use of student evaluations; there were concerns that this caused students "to be more demanding in terms with their relationship with academics through lectures, course unit content, lecture style, and pastoral care" (p. 266), although some participants noted that they felt that this might also serve to "weed out bad teaching practices" (p. 266).

In addition to literature on the relationship between quality and power, some literature has more specifically explored forms of resistance to these techniques of power, 
which range from dramaturgical compliance to outright refusal. Worthington and Hodgson (2005), who conducted more than 50 qualitative interviews with faculty members at 14 UK institutions, found that "how academics perform when under the normative 'gaze' of the quality auditing inspectors, during assessment trials, and what they actually do in practice once they are beyond their gaze, are often two entirely different things" (p. 107). Among their research participants, resistance to quality audits was reported to be quite common but came at the expense of what they called peer exploitation, or "how distancing strategies of resistance are used by certain academics to enable them to avoid responsibility for, or significant involvement in, quality auditing, at the expense of those who, as one academic called it, "do the quality stuff"' (p. 97). For example, they described scenarios in which some faculty would purposely botch documentation, feign ignorance or incompetence regarding the reporting requirements for subject reviews, or outright refuse to be involved, in all cases leaving the burden to other colleagues - frequently those who were junior or female.

Employing a Foucauldian framework, Barrow (1999) discussed a case study on the implementation of the New Zealand Qualifications Authority (NZQA), a quality assurance body resulting from 1989 legislation in that country. He noted a "considerable adverse reaction" (p. 29) to the NZQA's systems approach to quality, describing this quality management system as an instrument of Foucauldian governmentality. According to Barrow, the NZQA

is an array of the 'technologies of government'; the strategies, techniques and procedures used to seek to realise programmes and to regulate the actions of individuals and groups within the organization in a way that will achieve a level of self-discipline and control the will eventually be accepted as normal. (p. 31) 
Barrow theorized that, while New Zealand institutions had been able to provide evidence of compliance with the NZQA, this compliance was merely dramaturgical, that is, "the sum of this compliance is not the achievement of the outcomes defined by the institutions as being quality in higher education, nor ongoing quality improvement” (pp. 32-33), further suggesting that "a culture of dramaturgical compliance is perhaps an almost inevitable consequence of the systems approach and the manner of its development" ( $p$. $33)$.

In the most comprehensive investigation of academics' responses to quality assurance, Newton's $(1999,2000,2002)$ long-term ethnographic study of faculty members and faculty administrators at a university in the United Kingdom explored their perceptions of what he called the quality policy "implementation gap," or the "gap between what is designed into a policy, and situational factors which prevent this from being achieved" (Newton, 2000, p. 154). His research was situated "in an increasingly challenging external quality monitoring environment and a turbulent organisational and work context" (p. 154). Newton's interviews focused on how faculty members and administrators viewed efforts regarding quality monitoring and the extent to which such efforts actually promoted quality enhancement. He found that participants in his study noted that abiding by quality assurance, with its ritualist characteristics, was associated with resistance in the forms of a "sterile and ritual" theater-like performativity and gameplaying (Newton, 2002, p. 40), prompting him to question "whether external assessment serves 'quality' purposes for an institution and its academic staff, or if 'impression management' takes over" (Newton, 2000, p. 156). Furthermore, he noted that quality monitoring was more associated with notions of accountability and managerialism than it 
was with the actual improvement of teaching activities, finding that participants “associated the quality system with 'discipline' and 'technology' for validation, monitoring, and external scrutiny" (p. 158). Ultimately, he concluded that:

The findings provide evidence that staff, especially front-line academic do not mutely accept change or the particular demands of quality assurance policy or systems. Policy implementation is complex and uneven. Through their own interpretive work actors attach meaning to the various aspects of the quality system as they interact with it. They are not passive recipients of management objectives... They respond, adapt to or even resist and, while this may be patterned, it is not uniformed. Accordingly, there is a need to focus on what academics think and do, and what meanings they attach to different facets of policy, and how they work, change or even "work around" policy. (Newton, 2002, p. 59)

Building upon Newton's (1999, 2000, 2002) study, Anderson (2006) interviewed 30 academics across 10 institutions in Australia, leading to similar findings. Regarding Australia's quality assurance mechanisms, which included student evaluations of teaching and managerial performance reviews, she reported that "as for Newton's respondents, they were 'games' to be played, which bore little relationship to their notions of quality and the meanings they associated with the term" (p. 171). She concluded that "until there is some alignment between academics' and university management's ideas about the nature of this thing they both call quality there seems little likelihood that this game playing will be transformed into anything more productive" (p. 171).

As demonstrated in this chapter, quality assurance is associated with techniques of power manifested on and among faculty members and others in higher education. These techniques of power are also subject to forms of resistance, including game-playing, dramaturgical compliance, and outright refusal. In the next section of the chapter, I 
examine the salient literature on the Quality Matters program and its impacts on teaching and learning.

\section{Quality Matters}

Several programs exist to ensure, regulate, accredit, verify, recognize, or assure quality in online higher education, including the Quality Matters program, the Online Learning Consortium Quality Scorecard, the Blackboard Catalyst Exemplary Course Award, and the Open SUNY Course Quality Review (OSCQR). With the exception of OSCQR, each of the popular programs is operated by third-party organizations that are unaffiliated with higher education institutions, and both the complete Quality Matters rubric and Online Learning Consortium scorecard are only available to paid subscribers of their respective programs. Despite the existence of these myriad quality assurance regimes in online higher education, I focused my analysis in this study on the Quality Matters program, as it seems to be the predominant form used by institutions today and is the only program that has a series of regional and national conferences, special issues dedicated to it in academic journals (Moore, 2017; Layne, 2014), statewide initiatives (as discussed in Chapter I), and so on. Quality Matters is also the only program whose parent organization exists solely for quality assurance; the other programs are offshoots of organizations with broader aims.

Quality Matters is a non-profit organization that facilitates a peer-reviewed quality assurance program for online courses and online aspects of hybrid or blended courses. The Quality Matters program evaluates courses based on a point system using a rubric of eight General Standards, each containing between four and nine Specific Review Standards, comprising a total of 42 items. Each Specific Review Standard is 
worth 1,2, or 3 points. The standards include elements of course navigation, learner support, accessibility, and, most crucially to pass a review, alignment between and among measurable course- and unit-level learning objectives, instructional materials, and assessment instruments (Quality Matters, 2018a). Quality Matters reviews are conducted by a team of three QM-certified peer reviewers; according to QM,

Peer Reviewers must have online teaching experience in a college credit-bearing course and complete the Peer Reviewer Course to be eligible to serve on an official QM Course Review. The peer review team consists of at least one member from an institution other than the course's home institution and one member from a discipline that matches that of the course (the subject matter expert); and is led by a team chair who is a QM-Certified Master Reviewer. This combination of Reviewers ensures a diverse set of perspectives. (Quality Matters, 2018a, p. 50)

These reviewers are granted access to a version of a completed, previously taught, "mature" online course that has been stripped of all student activity and artifacts. The remaining course shell may contain the syllabus, instructional materials, assignments and tests, discussion prompts, meta-instructional items (such as instructions, lists of learning objectives, rubrics, and policies), and records of one-way instructional communications from instructors to students (Quality Matters, 2018b). Independently, the reviewers evaluate the course and determine whether each standard has been "met" or "not met," and points are awarded for a standard when at least two of the three reviewers agree that it has been met to a degree of $85 \%$ (Quality Matters, 2018a). To successfully pass a Quality Matters review and be designated as a certified quality course, all Specific Review Standards valued at 3 points must be met, and $85 \%$ of the total point value of all standards (or 84 of 99 points) must be earned. Quality Matters certifications are valid for a period of five years, after which the course may be re-reviewed (Quality Matters, 
2018a). As of November 2018, a fee of $\$ 1,400$ is assessed for a Quality Matters review, or \$1,000 for QM subscriber institutions (Quality Matters, 2018f).

Quality Matters purports to be research-based and to support QM-related research; while Quality Matters maintains a curated list of this literature, much of their supporting research is QM-funded and unpublished, limiting the amount of literature that can be examined (Quality Matters, 2018e). In the remainder of this section, I review the available and salient literature on the impacts and perceptions of the Quality Matters review program, process, and rubric, focusing on studies that explored the possible impacts on student outcomes and the studies that investigated perceptions of Quality Matters standards.

\section{The Impacts of Quality Matters}

Before exploring the research on the impact of Quality Matters, I will address a concern raised by Legon (2015): whether empirical research on the impact of QM is worthwhile or even possible. Legon, now Executive Director Emeritus of Quality Matters, suggested that it is "impossible to answer" the question of whether applying the Quality Matters rubric increases outcomes such as retention, grades, and student satisfaction (p. 168). To Legon, such attempts are fraught with methodological problems: comparing outcomes before and after a QM review is problematic because many teachers have been exposed to QM and QM-related materials prior to pursuing a course review; there are a variety of approaches to meeting each of the QM standards; and "real-world" courses are too different from each other to make meaningful comparisons (p. 168). He concluded that "the net effect of all these factors is to make experiments to isolate the impact of the Rubric across a wide range of courses and institutions a practical 
impossibility" (p. 168). Instead, he suggested that studies should isolate the effects of specific clusters of the rubric, although he failed to note that such studies would be subject to the same methodological limitations. In his abstract—with no mention of these points in the body of the article - Legon added:

There are other impacts that the adoption of the QM Rubric, principles, and emphasis on continuous improvement can have, such as fostering a dialogue within an institution or academic unit on what constitutes quality in online education, encouraging consistency of online course design, and so on, at the institutional level, and others. (p. 27)

Legon's assertion that institutions should adopt QM absent any demonstration of its effectiveness is an inversion of the burden of proof akin to Bertrand Russell's teapot:

If I were to suggest that between the Earth and Mars there is a china teapot revolving about the sun in an elliptical orbit, nobody would be able to disprove my assertion provided I were careful to add that the teapot is too small to be revealed even by our most powerful telescopes. But if I were to go on to say that, since my assertion cannot be disproved, it is intolerable presumption on the part of human reason to doubt it, I should rightly be thought to be talking nonsense. (Russell, 1952, pp. 547-548)

Legon essentially suggested that educators should engage with QM on faith without any proof of its efficacy, placing the value of QM in the same orbit as the celestial teapot. $\mathrm{He}$ was fundamentally wrong to suggest that research into the efficacy and impact of applying the QM rubric is impossible and, presumably, not worthwhile. He discounted the possibility of a multitude of other research designs such as cross-institution studies, qualitative studies, or quasi-experimental multi-course studies, including those reviewed below (Aman, 2009; Miner, 2014). His narrow understanding of "impact" further excluded the possibility of studies on the perceptions and impact on faculty, such as the present study. Furthermore, the implication that something is impossible to researchparticularly something he is clearly personally and professionally vested in—reeks of 
intellectual chicanery. For the remainder of this literature review, I will proceed as though studies that explore the impact of Quality Matters are not only possible but imperative.

Despite Legon's (2015) suggestion and prior to its publication, a number of studies have explored the effects of course revisions resulting from a Quality Matters review. Aman (2009) examined the influence of a QM review on students' reported levels of satisfaction and on retention. Using 455 survey responses from students in 41 courses across nine community colleges, he found that differences in overall student satisfaction were not statistically significant between students in 14 courses that had undergone a QM review and 27 of those that had not, suggesting that students' overall satisfaction was unchanged as the result of the review or any rubric-based changes to the design of the reviewed courses. However, he noted a significant increase in a calculation he termed "mean of factor means," which was derived from the overall mean "of a small set of questions related to each of the five quality factor means," which included questions related to outcomes, assessment, resources, interaction, and technology (p. 103). In other words, he found a significant increase in the overall aggregate average score of 17 specifically selected survey items from the 30-question survey. Furthermore, Aman found no significant difference in the levels of retention as measured by the difference between course enrollment in the first and last weeks of the academic semester between courses that had undergone a Quality Matters review and those that had not.

Similarly, Miner (2014) studied students' reported levels of satisfaction, final grades, and rates of retention in courses before and after Quality Matters certification. To determine student satisfaction levels, she incorporated a survey instrument informed by Garrison, Anderson, and Archer's (2000) Community of Inquiry conceptual framework, 
which examines online interactions on the dimensions of social presence, teaching presence, and cognitive presence; she found no statistically significant differences in students' levels of satisfaction between the pre-QM and post-QM course sections. She also found no significant differences in levels of retention between the pre-QM and postQM course sections as defined by the proportion of students who remained enrolled in the course after the drop deadline. Lastly, she found no significant differences in the grades between pre-QM and post-QM course sections. Miner conducted her research using courses at Florida International University, the site of this study.

In a single-course study, Swan, Matthews, Boles, Bogle, and Day (2012) examined the effects of a QM-based course redesign effort in a graduate-level online course in educational research methods. The course was submitted for formal Quality Matters review and failed, "mostly due to a lack of stated course objectives" (p. 84). The course was redesigned to meet Quality Matters standards and passed a review the following semester. The revisions "centered on developing detailed objectives at the unit level and linking the objectives to assessments. This process also resulted in revisions to course lectures, study guides, and quizzes to make sure they were tightly focused on particular concepts" (p. 86). From the pre-QM and post-QM course sections, the researchers collected overall course grades, grades on two major assignments, and survey responses based on the Community of Inquiry framework that measured students' perceptions of teaching presence, social presence, and cognitive presence. They found that student grades increased after the redesign, although not statistically significantly so. Measures of cognitive presence, social presence, and teaching presence each remained relatively the same or dropped following the course redesign, although the researchers 
did not receive enough survey responses to conduct statistical analysis due to the small class sizes.

In another single-course study, Hollowell, Brooks, and Anderson (2017) investigated the impact of QM-based revisions on an introductory biology course. The course's instructor made revisions following Quality Matters training, leading to a higher score on an informal Quality Matters review by a single reviewer. Comparing one preQM academic term with three post-QM-revision terms, final exam scores in the course were lower in two of the three post-QM terms than in the pre-QM version of the course. The average course grade increased by 10 points in the two semesters immediately following QM-based revisions but then dropped to a level lower than the pre-QM term. Despite these mixed results, the authors' statistical analysis suggested correlations between the informal QM review score and the final exam and course averages. Using linear regressions, they suggested that every one-point increase in an informal QM review score would lead to an expected 0.124 increase in average final exam (out of 100) scores and a 0.175 increase in the course average. There were a number of issues with this study. First, the course in question was only informally reviewed by a single reviewer rather than the formal review with three reviewers. As such, the results of the review and any apparent effects were highly dependent upon this one individual's subjectivities during the review. Furthermore, a linear regression was likely inappropriate for this analysis since the predictor variable was a score reflecting a composite of QM standards, which are not equally weighted in the rubric. Ultimately, the conclusions of single-course studies such as this one and the study described by Swan et al. (2012) should be 
interpreted cautiously since generalizability to a broader range of courses and contexts may be extremely limited.

In a study that explored student outcomes in relation to QM-related faculty development, Harkness (2015) described a five-year case study in which the University of the District of Columbia launched its institutionally supported online course offerings, including a comprehensive professional development program with training from Blackboard and QM. According to Harkness, "QM Rubric and course design standards were integrated as a best-practices approach toward faculty professional development within a four-tier progressive approach and were part of the vocabulary at each tier" ( $\mathrm{p}$. 203). At the end of the case study period, informal QM reviews (reviews conducted by institution staff, not by external reviewers) indicated a 73\% increase in the mean QM rubric score to 74.0, which was still not a passing score but a "noteworthy accomplishment" nonetheless (p. 206). Quantifying course quality by using the numeric scores from a QM review is highly problematic because it assumes that the underlying constructs and rubric standard weights are valid and measurable. Between 2007 and 2012, during which time the institution deployed its partnership with Blackboard and QM and created a dedicated center for online teaching, Harkness noted a $19.74 \%$ increase in pass rates in online courses, a $66.66 \%$ decrease in failure rates, and a $23.53 \%$ decrease in withdrawal rates (statistical analysis was not conducted). The extent to which QM-based faculty development and course review efforts played a role in these changes is not clear.

In what might be my favorite article on the impact of Quality Matters because of its sheer bizarreness, Simunich, Robins, and Kelly (2015) explored the relationship between what they call "findability" and perceptions of online course quality. Starting 
with courses that passed Quality Matters reviews as controls, they purposely altered versions of the courses to make them illogically organized and unintuitive. "For example," they wrote, "the Course Schedule was in an item labeled "Assignments"” (p. 176). Their intention was to intentionally violate Fourth Edition QM Standard 6.3, which states "navigation throughout the online components of the course is logical, consistent, and efficient" (p. 176). In a laboratory environment, students were randomly assigned to view either the control courses or the experimental, altered courses as though it was their first day of the course. One group of students participated in a focus group discussion at the end of the session and another group wore special eye-tracking hardware that tracked their eye movements on the screen as they viewed the course; each group had students viewing either the control or experimental courses. All students completed a survey that asked them if items were easy to find, if they enjoyed the experience, if they would recommend the course, if the instructor would be good, and if they thought the course would be frustrating to take. Obviously, students who experienced a course that was purposefully disorganized reported statistically significantly higher levels of frustration and lower levels of enjoyment, perceived ease of finding items, and likeliness to recommend to friends. Furthermore, gaze plots from students who wore the eye-tracking devices indicated that they had more trouble distinguishing among choices when searching for particular items, such as a syllabus. The researchers concluded that their study validated the navigation standards of the QM rubric, ultimately arguing that "findability" should assume a more prominent role in the rubric, since other important standards may be hindered by navigation issues. This study is the educational equivalent of Ford Motor Company pulling all of the hoses out of a car's engine and using test 
drivers' frustrations as evidence of the quality of their engine designs. Furthermore, this study suffered from a low level of construct validity; the researchers' conceptualization of “findability," measured on a binary scale of either QM-certified or purposefully jumbled with the intention of making the course unintuitive, was extraordinarily problematic.

\section{Quality Matters and Perceptions of Quality}

Some studies on the impact of Quality Matters have explored students' perceptions of online course quality. Ralston-Berg (2014) studied student priorities of quality standards by surveying 3,160 students who had taken or were enrolled in online courses. These students were asked to rank each of the Quality Matters standards, rewritten in language that reflected the student perspective, on a three-point scale of 1,2 or

3, thus mirroring the three-point maximum of the QM rubric Specific Review Standards. She then compared the means of each survey item with the corresponding standard and its QM rubric point value in order to identify areas that potentially reflected similar or different levels of priority between students and the rubric. For example, the mean response for the survey item, "Learning activities encourage me to interact with other students" (p. 126) was 1.24 out of 3, while the corresponding QM rubric Specific Review Standard is a required three-point item, indicating that learner-to-learner interaction was less of a priority for students than it was for those who had input on the construction of the rubric. Curiously, Ralston-Berg drew no conclusions for any possible discrepancy in her unusually short article, opting instead to provide just the results without analysis. However, in a similar, earlier study, Ralston-Berg and Nath (2008) found statistically significant differences in the priorities of students and those of the QM rubric, although 
this study suffered from several issues that limited its generalizability, including the omission of a sample size.

Building on this line of research, Barczyk, Hixon, Buckenmeyer, and RalstonBerg (2017) found significant differences in perceptions of the importance of the Quality Matters standards in age groups and working statuses; older students placed more emphasis on technology support, while younger students preferred clarity in assignments and grading. Students who worked full-time or were unemployed valued most standards significantly higher than students who worked part-time, leading the authors to conclude that "it could be that students who do not work are ones who focus on their studies and as such have higher expectations for course quality" (p. 182), whereas "those who work full-time have higher quality expectations because they are likely supporting themselves and have significant financial obligations" (p. 182). In another study that explored students' perspectives on Quality Matters, You, Hochberg, Ballard, Xiao, and Walters (2014) found statistically significant differences in the degree to which students and QM reviewers perceived several essential Quality Matters standards to have been met in two different courses. For example, in one course that was used for the study, students reported that the grading policy was clearly articulated, while QM reviewers reported that it was not.

The studies that explored students' perspectives of quality (Ralston-Berg, 2014; Barczyk, Hixon, Buckenmeyer, and Ralston-Berg, 2017; Ralston-Berg and Nath, 2008; You et al., 2014) all started with the assumption that QM is a valid arbiter of quality and presumed that QM, its underlying constructs, and rubric standard weights were valid and measurable. The validity of QM standards as an appropriate measure of quality was never 
questioned and was accepted uncritically. This is consistent with observations by Blanco Ramírez (2013), who noted that scholarship on quality is dominated by an unquestioned technical rationality. Furthermore, these studies limited student input to items directly related to the QM rubric. Perhaps a different approach would have allowed students to articulate priorities of online course quality that had no relation to QM, particularly since students may prioritize elements of an online course that are not addressed by the QM rubric, such as the instructor's expertise, support, and facilitation during the course or collaborative learning opportunities (Paechter, Maier, \& Macher, 2010). A possible model for this type of study is by Cheng (2011), who explored students' perceptions of good teaching practice though open-ended interviews.

\section{On Quality Matters Scholarship}

All of the studies reviewed in this section on Quality Matters thus far took for granted that QM is a valid construct of online course quality. Quality Matters was equated, unquestioningly, with quality itself. This passage by Simunich, Robins, and Kelly (2015) is typical of how QM is situated in these studies:

For purposes of the study, two courses were selected for the control group. Both courses were English writing courses to minimize the possible confounding variable of course discipline. Both courses underwent Quality Matters ${ }^{\mathrm{TM}}$ review by four independent Certified Peer Reviewers and met Quality Matters Rubric ${ }^{\mathrm{TM}}$ standards. Quality Matters (QM) is a faculty-centered, peer-review process that focuses on the design of online and hybrid courses and is intended to certify their quality. The process utilizes an extensive rubric, organized under eight general standards and forty-three specific standards; the review is conducted by three Certified Peer Reviewers. The researchers used QM as a baseline indication of course quality, as it is a nationally recognized evaluative measure for online courses. (Simunich, Robins, and Kelly, 2015, pp. 175-176)

I was only able locate one study that appeared to take a somewhat tentative stance toward QM in that it suggested limitations or deficiencies with the program. Youger and Ahern 
(2015) suggested that the measurable, standardized approach of the QM was insufficient to determine a holistic effectiveness of online course, arguing that two other factorsvalue and worth—are also important in evaluating a course. They suggested that "the quality of a course matters only if the course has value and is worthwhile to students," adding that "the QM process does not measure 'worth'... simply adhering to QM standards dot not ensure an instructional module is worthwhile — student engagement is vital to the worth of a course" (p. 3). To demonstrate this, the authors engaged in a cognitive walkthrough process using a think-aloud protocol for a course that met QM standards. Despite meeting QM standards, the results of the walkthrough indicated that "some level of dissatisfaction with the actual experience of the course" (p. 4). They found that "customization and instructor/peer interaction was needed to add value the course and enhance the worth of the individual learning experience" (pp. 4-5). Ultimately, the researchers determined QM to be an insufficient tool for course design and evaluation and recommended that instructors and course developers seek other ways to enhance the value and worth of the course.

Despite mixed findings in student outcomes as a result of Quality Matters, several researchers continue to support the use of QM in course design and faculty development (Aman, 2009; Hollowell, Brooks, and Anderson, 2017; Miner, 2014; Swan et al., 2012). For instance, having found no significant differences in student satisfaction, grades, and retention, Miner (2014) wrote:

Quality Matters certification allows college and university administrators a relatively easy way to address quality assurance without ruffling too many faculty feathers. Faculty unions and governing bodies are very protective of their academic freedom. The Quality Matters program and process is collegial and collaborative and was designed for faculty by faculty. Faculty peer-reviewers 
make the ultimate decision about online course quality. However, college completion rates are abysmal. Federal and state governments are increasingly tying student outcomes, retention, and college completion with aid. There is evidence that Quality Matters certification improves the quality of course design and contributes to faculty professional development. (pp. 108-109)

This passage is particularly notable because, on one hand, Miner acknowledged the possible tension between academic freedom and quality assurance, while on the other hand, she continued to advocate the use of Quality Matters despite the findings of her own study. Similarly, Swan et al. (2012) continued to promote the use of Quality Matters in course redesign efforts, despite the absence of any statistically significant changes in student grades. Researchers' continued promotion and adoption of Quality Matters, despite the lack of convincing evidence of meaningful impact, is curious. Perhaps this is related to some sort of ideological element in which the regime of quality cannot be questioned (Filippakou, 2011; Morley, 2003). As noted, despite mixed findings in the research on Quality Matters, almost none of the literature in this section suggested any critical or questioning perspective on the program, the process, or the rubric.

Furthermore, I found no indication that any of the research on QM engaged at all with the literature on quality assurance in other higher education contexts as reviewed in earlier sections of this chapter; certainly, no QM-related literature engaged with the idea of quality as power (Barrow, 1999; Brennan \& Shah, 2000; Cheng, 2010; Filippakou, 2011; Morley, 2003; Shore \& Wright, 1999, 2000; Worthington \& Hodgson, 2005). Ultimately, the literature on Quality Matters is representative of Blanco Ramírez's (2013) observation that scholarship on quality is dominated by an unquestioning technical rationality. 


\section{Summary and Conclusion}

The intention of this chapter was to contextualize this research study by providing a general overview of issues related to quality in higher education and situating the literature on Quality Matters within this scholarship. Quality in higher education is a concept with many socially and ideologically constructed understandings (Harvey \& Green, 1993; Filippakou, 2011). In their seminal article on quality in higher education, Harvey and Green (1993) identified five dominant conceptualizations of quality: quality as exceptional, quality as perfection or consistency, quality as fitness for purpose, quality as value for money, and quality as transformation. While they favored the last of these, predominant uses of the term in recent decades have included quality as fitness for purpose and quality as excellence (Harvey \& Stensaker, 2008; Kristensen, 2010; Cheng, 2011).

Quality-related practices in higher education can broadly fall under one of two umbrellas: quality assurance and quality enhancement; "these two concerns underpin all discussions of quality in higher education" (Williams, 2016, p. 97). Quality assurance practices in higher education can be characterized by internal and external quality programs or mechanisms. Internal quality assurance refers to the practices undertaken by the community of a higher education institution, while external quality assurance is "activity that validates the reliability and efficiency of internal quality assurance procedures" (Stumbrys, 2004, p. 158). In this chapter, I discussed the context and arrangements of the external quality assurance mechanisms in the United States and the United Kingdom, the former because of its geographic relevance and the latter because of its rich history and influence on other countries' systems. 
The logics that undergird quality and quality practices in higher education are influenced by the discourses of managerialism, accountability, efficiency, and control, and the proliferation of quality assurance regimes has been associated with a wide range of interrelated factors, including academic capitalism, the need for workforce training, shifting student demographics and massification, new technologies, reduced public funding, market rationality, globalization, and neoliberalism (D'Andrea; 2007; Jarvis, 2014; Tomlinson, Enders, \& Naidoo, 2018; Olssen \& Peters, 2005). Quality in higher education is further linked to the discourses of New Public Management, New Managerialism, and Total Quality Management, which are all similarly concerned with quantification, measurement, efficiency, clearly defined objectives, and reduction in variation (Deem \& Brehony, 2005; Houston, 2007; Olssen \& Peters, 2005; Venkatraman, 2007). The application of these ideas in higher education is hotly contested, with some scholars suggesting that they are incompatible with the purposes of higher education (Bensimon, 1995; Houston, 2007).

Efforts to define, measure, and assure the quality of teaching practices more specifically are similarly fraught with ambiguities and conflicts. Teaching quality often means different things for faculty members, students, and quality assurance mechanisms (Blackmore, 2009; Cheng, 2011; Hill, Lomas, and MacGregor, 2003). Peer review of teaching practices may be a useful means of enhancing teaching quality, but it may also introduce issues related to academic freedom, professional autonomy, and accountability (Douglas \& Douglas, 2006; Lomas \& Nicholls, 2005). In general, findings about the impacts of teaching quality assurance are mixed (D'Andrea, 2007; De Vincenzi, Garau, \& Guaglianone, 2018; Jones, 2003; Pham, 2018; Tavares, Sin, Videira, and Amaral, 2017). 
Some scholarly articles have explored the role that quality audits play as an instrument of power in manifestation of the logics of accountability, efficiency, measurement, and control (Barrow, 1999; Brennan \& Shah, 2000; Cheng, 2010; Filippakou, 2011; Morley, 2003; Shore \& Wright, 1999, 2000; Worthington \& Hodgson, 2005). Several scholars have referred to quality assurance as a form of coercive accountability (Shore \& Wright, 1999, 2000; Worthington and Hodgson, 2005); others have called it symbolic violence (Morley, 2003; Tomlinson, Enders, \& Naidoo, 2018). Others have explored how faculty members who were subjected to quality assurance engaged in resistance to it; this resistance manifested in game-playing, dramaturgical compliance, and outright refusal (Anderson, 2006; Barrow, 1999; Newton, 1999, 2000, 2002; Worthington \& Hodgson, 2005). However, Worthington and Hodgson (2005) noted that sometimes this resistance came at the expense of other faculty colleagues, often those who were junior or female.

The penultimate section of this chapter explored the research relating to Quality Matters, the predominant quality assurance program for online courses in higher education. Despite the former Executive Director of Quality Matters making a dubious assertion that research on the impact of QM is "a practical impossibility" (Legon, 2015, p. 168), several studies have explored the impact of Quality Matters on student outcomes such as satisfaction, retention, and grades, resulting in largely non-significant findings in multi-course studies (Aman, 2009; Miner, 2014). Single-course studies have also resulted in mixed findings (Hollowell, Brooks, \& Anderson, 2017; Swan et al., 2017). Despite these mixed findings, many of these researchers continue to advocate QM's use in course design and faculty development (Aman, 2009; Hollowell, Brooks, and Anderson, 2017; 
Miner, 2014; Swan et al., 2012). Other Quality Matters-related studies have explored students' perceptions and priorities of online course quality (Ralston-Berg, 2014; Barczyk, Hixon, Buckenmeyer, and Ralston-Berg, 2017; Ralston-Berg and Nath, 2008; You et al., 2014); these studies, by unquestioningly using QM as a starting point in investigating students' understandings of quality, have failed to acknowledge that quality is multifaceted and ideologically constructed (Harvey \& Green, 1993; Filippakou, 2011).

The literature is this chapter, taken as a whole, situates and justifies the present study that explored faculty members conceptualizations of course quality and sought a greater understanding of how faculty navigated and maneuvered the program QM program. Practically no literature on Quality Matters has taken an approach similar to those scholars who adopted a critical stance toward exploring how quality assurance manifests as an instrument of power (Barrow, 1999; Brennan \& Shah, 2000; Cheng, 2010; Filippakou, 2011; Morley, 2003; Shore \& Wright, 1999, 2000; Worthington \& Hodgson, 2005).

The scholarship on quality, as noted by Blanco Ramírez (2013), is dominated by a technical-rational perspective. Seen particularly in the literature on Quality Matters, these studies "take for granted that quality assurance, as a technical endeavor, is beneficial in all settings” (p. 131). Blanco Ramírez also expressed the need for further research on quality using methodologies that apply perspectives other than technical rationality: “Are there ways of conducting research that acknowledge the limits of technical rationality? Perhaps in the future we will see more phenomenological or ethnographic accounts of the implementation of quality practices" (p. 138). The qualitative interview research study described in this dissertation answers Blanco Ramírez's call for research that transcends 
the technical-rational perspective. To that end, the next chapter of the dissertation discusses the methodology and methods of the present study, including my epistemological orientation, justification for employing a qualitative interview study, and the details of how I collected and analyzed my data. 


\section{CHAPTER III}

\section{METHODS}

\section{Philosophical Positioning}

Chapter I of the dissertation presented the problem addressed by this study, provided an overview and purpose of the study, and introduced the research questions. In Chapter II, I reviewed the salient literature on quality in education higher and Quality Matters. This chapter outlines the methods of this research study, including the conceptual framework, methodology, data collection and analysis strategies as well as issues related to validity. First, however, I will outline the postmodern philosophical orientation to the study. According to Creswell and Poth (2018), researchers always bring their beliefs and philosophical assumptions to their research and face the challenge of recognizing them and deciding whether to actively incorporate them into qualitative studies. I approached this project from the perspective that my philosophical positioning is important, not only to recognize but to actively guide and inform the study.

According to Bloland (1995), postmodernism is an imprecise and highly contested term with no fixed position, but it generally refers to a philosophical orientation that developed as a critique of the assumptions and institutions of modernism, which

requires faith that there are universals that can be discovered through reason, that science and the scientific method are superior means for arriving at truth and reality, and that language describes and can be used as a credible and reliable means of access to that reality. (p. 523)

Postmodernism critiques these assumptions, rendering modernist institutions and assertions questionable and problematic, including the modern institution of higher education. As discussed in the last chapter, quality assurance in higher education, with its 
emphasis on continuous improvement, quantification and calculability, and standardization of performance, has been critiqued as a modernist enterprise (Bensimon, 1995), and the scholarship on quality is dominated by technical rationality (Blanco Ramírez, 2013). Postmodernism, then

focuses on the indeterminacy of language, the primacy of discourse, the decentering and fragmentation of the concept of self, the significance of the "other," a recognition of the tight, unbreakable power/knowledge nexus, the attenuation of a belief in metanarratives, and the decline of dependence upon rationalism. (Bloland, 1995, p. 526)

By adopting and embracing a postmodern philosophical positioning with this study, I embarked on what is essentially a critique of the modernist assumptions that undergird quality assurance in general and Quality Matters specifically. My intention was to interrogate the metanarrative of quality by exploring the localized experiences of faculty members who have gone through Quality Matters.

\section{Conceptual Framework}

Conceptually, I approached this study of faculty members' perceptions of and experiences with Quality Matters by considering QM as an audit practice, incorporating scholarship by Power (1997) and Shore and Wright (1999, 2000). According to Power (1997), the audit requires a relation of accountability in which one party (the agent) must provide an account to another party (the principal), who is distant from the actions of the agent and unable to directly observe or verify them. While Power is generally reluctant to define "audit," as the term's ambiguity is one of its essential characteristics, he suggests several broad elements that constitute audit practices: "independence from the matter being audited; technical work in the form of evidence gathering and the examination of documentation; the expression of a view based on this evidence; [and] a clearly defined 
object of the audit process" (p. 5, emphasis in original). Shore and Wright (2000) note that the term connotes "scrutiny, examination, and the passing of judgement" (p. 59). Audit practices are further characterized by programmatic and technological elements. Programmatic elements "relate to the ideas and concepts which shape the mission of the [audit] practice and which, crucially, attach the practice to the broader policy objectives which exist in the political sphere" (Power, 1997, p. 6). At the programmatic level, "broad goals are formulated and it is more or less assumed that the practice is capable of serving these goals" (p. 6). Technological elements include the practices and routines enacted by audit practitioners, including analytic methods, checklists, rubrics, and samples. Expectations gaps develop when there is a loose coupling between the programmatic demands of an audit and the operational capabilities of the technologies and practices, making audits merely "rituals of inspection" (Power, 1997, p. 89).

While audit practices include an array of tests, checks, and evidence gathering, Power (1997) notes that the audit "is also a system of values and goals which are inscribed in the official programmes which demand it" (p. 7). The conceptual history of auditing stems from accounting practices in the finance sector, but transformations in organization and governance (such as New Public Management) have led to the implementation of audit practices in other areas, such as education and medicine. In these cases, implementation requires that things be made auditable in a socially constructed process: "Auditability is a function not of things themselves but of agreement within a specialist community which learns to observe and verify in a certain way ... Auditability cannot be defined; it is negotiated" (pp. 80-81). Accordingly, auditing is not a neutral, objective process; it has impacts and consequences on the audited domain. Power notes 
that, in some contexts, an audit functions "less as a practice of verification and more as an explicit vehicle for change in the name of ideas such as 'cost-effectiveness,' 'efficiency,' 'quality,' and so on" (p. 91). Shore and Wright (2000) note that "audit procedures present themselves as rational, objective, and neutral, based on sound principles of effective management. ... However, these procedures revolve around normative statements and measurements" (p. 61).

Power (1997) suggests that "audits work because organizations have literally been made auditable; audit demands the environment, in the form of systems, and performance measures, which makes a certain style of verification possible" (p. 91). Two ways by which audits transform organizations are decoupling and colonization. In decoupling, organizations create distinct and purposeful sub-units for dealing with and managing external audits. The audit process becomes remote from the operational practices for which it is intended to account, leading to a managed ritualistic or dramaturgical performance. According to Power, "through the creation of compartmentalized organizational units for dealing with external assessment, audit and evaluation can be rendered ceremonial" (1997, p. 96). Decoupling buffers the audit process from the object of the audit; it occurs because "individuals are infinitely more complex and adaptable than normalizing attempts to measure and control them" (p. 120).

In colonization, "the values and practices which make auditing possible penetrate deep into the core of organizational operations" (Power, 1997, p. 97), leading to "new mentalities, new incentives and perceptions of significance" (p. 97). In the logic of New Public Management, for example, colonization is an explicit goal: "The intention is not only to remedy weakness in financial control practices but also to challenge the 
organizational power and discretion of relatively autonomous groups, such as doctors and teachers, by making these groups more publicly accountable for their performance" (p. 97). Through colonization, "new forms of organizational language become institutionalized [and] percolate into domains even where active decoupling is pursued" (p. 120). Similarly, Shore and Wright (1999) suggested that audits "rely on techniques of the self that render political subjects governable by requiring they behave as responsible, self-activating, free agents who have internalized the new normative framework" (p. 566). Power (1997) concluded that decoupling and colonization resulting from the imposition of audit and the creation of auditable performances may lead to dysfunction for the audited service, the opposite of what audits intend.

Ultimately, the proliferation of audit practices reflects a shift in formations of trust from auditee or agent to the audit process itself. According to Power (1997), "many of the audit-related changes which have taken place in the public sector in recent years reflect institutionalized distrust in the capacity of teachers, social works, and university lecturers to self-regulate the quality of their services" (p. 135). For Shore and Wright (2000), audit practices "heralded a significant break with the principle of academic autonomy" (p. 68). They further note that, as a part of the audit practices pervading teaching quality assessments in the UK, "the learning experience must now be quantified and standardized so that it can be measured. The curriculum's merits are today measured in terms of finite, tangible, transferable and, above all, marketable skills" (p. 73).

Using Power's (1997) and Shore and Wright's (1999, 2000) overlapping and mutually supporting conceptualization of the audit as a framework for this study and a lens through which to view QM informed my research questions and, in turn, my 
approach to interviews with faculty members who have gone through the Quality Matters process. Where this conceptualization of the audit falls short in relation to Quality Matters is in the fact that audits are generally considered mandatory conditions for the auditee, whereas Quality Matters, at least in the site of this research study, is an optional (although highly encouraged and often incentivized) process. This may be changing, considering the Florida Board of Governors' goal of ensuring that $90 \%$ of online courses at Florida's public universities bear a "high quality" ranking (Florida Board of Governors, 2015). Despite the limitation, the logic of auditing was a useful frame for this research study. The remainder of this chapter describes the research methods I employed in this study.

\section{Research Questions}

As discussed in Chapter I, the following research questions informed and guided the study:

- What are the relations between the understandings of course quality among faculty members who have gone through the Quality Matters process and the criteria used by Quality Matters?

- What motivated them to pursue Quality Matters certification?

- How have they negotiated, maneuvered, and/or resisted the QM program and process?

- What impacts and significance do these faculty members ascribe to Quality Matters? 


\section{Sampling}

According to Seidman (2013), "at the very heart of what it means to be human is the ability of people to symbolize their experience through language ... Interviewing, then, is a basic mode of inquiry" (p. 8). For Seidman, "the root of in-depth interviewing is an interest in understanding the lived experience of other people and the meaning they make of that experience" (p. 9). Given this study's research questions, which essentially sought to explore and unpack faculty members' experiences with the Quality Matters program and process, a qualitative interview study was appropriate.

In order to conduct a qualitative interview study, it was necessary to identify participants who have experience with the subject under investigation and represent an array of backgrounds, such as faculty ranks, disciplines, and genders. This process is a type of purposeful sampling called "criterion sampling," in which participants are selected based upon their meeting of a particular set of criteria (Creswell \& Poth, 2018). Unlike in quantitative research, sampling in qualitative research is not carried out with the aim of determining a representative sample whose experiences are generalizable to a population; rather, sampling (also described as "selection" in this context) is performed to support the goal of "developing an adequate description, interpretation, and explanation" of the subject of inquiry (p. 79).

I recruited research participants from Florida International University, a large, public university in the Southeast United States that is classified as a Hispanic-serving institution and a Carnegie Highest Research Activity institution (Florida International University, 2018). I selected this university because it has a high level of participation in 
Quality Matters, having certified the second-greatest number of courses of any institution in the United States (FIU Online, 2018), and because of its geographic proximity to me.

The Quality Matters website lists, organized by year, instructors who have completed a Quality Matters review, along with their certified courses and their institutions (Quality Matters, 2018d). Since faculty members who have passed a Quality Matters review and have taught their courses since the review are best positioned to relate their experience with the program and their teaching activities since, I used this website as a starting point to determine participants. To begin my recruitment process, I catalogued all faculty members who had had one or more courses Quality Matters certified in 2018 (at the time), 2017, and 2016; this totaled 79 faculty members. Using Florida International University's public directory, I determined their faculty ranks and academic departments. Employing purposeful sampling to select a range of ranks, disciplines, genders, and number of QM-certified courses, I selected 21 potential participants from the pool to whom I sent requests for participation via email. Refer to Appendix A for the sample participation request email. As part of this initial contact, I indicated that the research is part of a doctoral dissertation study, that their participation was optional, and that their identities as participants would remain confidential. I requested a single 60 -minute interview to take place at their office on campus or another location of their choosing. Out of the 21 requests for participation I sent, I received eight indications of agreement, three messages declining the request, and 10 potential participants never responded or stopped responding in the course of our correspondence. After interviewing eight participants, I decided that that number of participants was suitable, as I had reached data saturation and felt as though I had captured a breadth and 
depth of experiences and perspectives. The participants I interviewed included four men and four women and comprised two associate professors, two assistant professors, two instructors, and two adjunct faculty members. Refer to Appendix D for brief profiles of the participants.

\section{Data Collection}

According to Rubin and Rubin (2012), interviewing as a data collection method enables researchers to "explore in detail the experiences, motives, and opinions of others and learn to see the world from perspectives other than their own" (p. 3). I conducted indepth, semi-structured interviews with each of the eight faculty participants selected during sampling who agreed to interviews. In semi-structured interviews, "the researcher has a specific topic to learn about, prepares a limited number of questions in advance, and plans to ask follow-up questions" (Rubin and Rubin, 2012, p. 31). While some qualitative methodologists suggest a prolonged engagement with participants using a three-interview approach (Seidman, 2013), I opted to initially request a single 60-minute interview, since I felt I might alienate potential participants by initially requesting too much of their time. It is no secret that faculty members are notoriously busy individuals, and I could foresee some potential participants declining on the basis of the time commitment. While I was open to the possibility of follow-up interviews if there was a reasonable possibility to further and meaningfully explore participants' experiences or perspectives, I decided, based on the transcript reviews, that one interview with each participant was suitable. Each interview took place in the participating faculty members' offices or other private locations on the Florida International University campus (for example, I met with one 
adjunct faculty member in a group study room in the library because he did not have an office).

Prior to each interview, I reviewed the informed consent document with the participant, obtained her or his signature, and offered a copy for her or his own records. Refer to Appendix B for the informed consent document.

I conducted each interview using the interview guide I had prepared, which included a range of possible open-ended questions. Refer to Appendix $\mathrm{C}$ for the interview guide. I recorded my interviews with a Tascam TR-22WL portable linear digital audio recorder, as I did not need to worry about storage limitations with a dedicated memory card, and I found its sound quality and reliability to be superior to a mobile phone (when it comes to audio, quality matters). Interview recordings were machine transcribed by an independent transcription service, and I manually cleaned and verified the transcripts for accuracy. To ensure the security and integrity of the collected data, the interview recordings and transcripts of the recordings were stored and secured in Dropbox, a password-protected cloud-storage hosting service. Dropbox files are encrypted at rest using 256-bit Advanced Encryption Standard encryption and in transit using Secure Socket Layer/Transport Layer Security with 128-bit encryption (Dropbox, 2018). I conducted my interviews throughout the month of October of 2018. The beginning of the semester is a notoriously busy time for faculty (and the researcher); starting in October allowed sufficient time after the fall semester had begun to allow faculty participants to have "settled in" with their fall commitments.

In addition to participant interviews, documents and textual artifacts related to Quality Matters and the QM process were critical data for this study. These included the 
various Quality Matters websites, FIU websites, and the QM Rubric Workbook. The Quality Matters Higher Education Rubric Workbook (Quality Matters, 2018a) is the document that most clearly and comprehensively expresses QM's proprietary conceptualization of quality and its quality assurance process. It only available in printed form for a fee to Quality Matters subscriber institutions. Per the first page of the workbook, "Use of this Quality Matters Rubric Workbook is restricted to institutions that subscribe to Quality Matters. This document may not be copied or duplicated without written permission of Quality Matters" (p. 2). However, I was able to procure a Workbook courtesy of an insider at the institution who was sympathetic to my work. The Workbook contains over 40 pages of detailed annotations for the 42 QM Specific Review Standards regarding how each Standard can be successfully met in a QM review, a template of a Course Improvement Plan Worksheet, a hard copy of the 44-question Course Worksheet that is filled out at the outset of a QM review, and an overview of the QM course review process. This document proved to be crucial in understanding participants' understandings of quality in relation to the official accounts of Quality Matters.

\section{Data Analysis}

Data analysis in a qualitative interview study is the process by which answers to the research questions are developed from raw interview data (Rubin and Rubin, 2012). Using transcripts of the interviews I had conducted and other Quality Matters-related textual artifacts, I began the process of data analysis concurrently during the interview period as each interview session concluded. To assist in this process, I used NVivo for Mac 11, a software platform for conducting qualitative analysis. According to Maxwell 
(2013), computer-assisted qualitative data analysis software (CAQDAS) is used both to assist in organizing and coding qualitative data and to link memos to codes or segments of text. While software programs like NVivo do have auto-coding features, I did not use them, instead coding all data manually.

To conduct the analysis, I engaged in a two-cycle coding process. According to Saldaña (2016), a code is "a researcher-generated word or short phrase that symbolically assigns a summative, salient, essence-capturing, and/or evocative attribute for a portion of language-based or visual data" (p. 292). Coding is the process of generating these codes to enable "pattern detection, categorization, or other analytic processes" (p. 292). While reflectively reading the interview transcripts and other relevant textual data within the NVivo software, I used the program's coding function to conduct what Saldaña refers to as concept coding (pp. 119-124) as a first cycle coding process. Concept coding, also known as analytic coding, is a coding process that assigns levels of meaning to data dealing with concepts; Saldaña describes a concept as "a word or short phrase that symbolically represents a suggested meaning broader than a single item or action-a 'bigger picture' beyond the tangible and apparent” (p. 119). Saldaña suggests that concept coding is highly interpretive, which is congruent with my qualitative interview approach to data collection. Following a stage of first cycle coding, I conducted a second cycle of axial coding. Axial coding is a process of determining dominant and less important codes and reassembling them into conceptual categories and sub-categories (Saldaña, 2016).

From the codes and conceptual categories, I identified themes that addressed the study's research questions and were closely related to the conceptual framework. According to Saldaña (2016), a theme is "an extended phrase or sentence that identifies 
what a unit of data is about and/or what it means.... Themes can consist of such ideas as descriptions of behavior within a culture; explanations for why something happens; iconic statements; and morals from participant stories" (p. 297). For this study, I relied heavily on my conceptual framework to generate some themes (such as decoupling, colonization, and performance). Importantly, I adopted an approach of actively identifying and generating themes, embracing my own subjective understanding of the texts in the process; themes do not "emerge," because they do not have agency or autonomy and they do not exist independently of my understanding of them.

\section{Validity}

Validity is a contentious concept in the context of qualitative research. Creswell and Poth (2018, p. 255), for example, outline 11 different perspectives on validity in qualitative research. Some qualitative researchers have argued that the positivist language imported from quantitative paradigms (e.g., internal validity, external validity, or objectivity) is inappropriate in qualitative research (Creswell \& Poth, 2018; Maxwell, 2013). Maxwell (2013) suggests that, while validity is a key issue in qualitative research design that needs to be specifically addressed, validity depends on the relationship of the researcher's conclusions to reality, and no methods can assure this (p. 121). Maxwell describes validity as "the correctness or credibility of a description, conclusion, explanation, interpretation, or other sort of account" (p. 122), adding that this definition of validity "does not imply the existence of any 'objective truth' to which an account can be compared" (p. 122).

Maxwell (2013) outlined two primary threats to validity in qualitative research: researcher bias and reactivity. Researcher bias includes the selection of data that fit the 
researcher's theories or goals or that otherwise stand out. He notes that, since it is impossible to eliminate the researcher's theoretical orientation and beliefs, the appropriate way to address research bias is to explain these biases. In Chapter I, I outlined my pre-existing experience with and bias toward the subject of inquiry in this study; I also explained my intention to embrace my own subjectivities in relation to the study rather than attempting to bracket them off. "Reactivity" refers to the effect that the researcher's involvement has on the participants. However, Maxwell suggests that "while there are some things you can do to prevent the more undesirable consequences of [reactivity] (such as avoiding leading questions), trying to minimize your influence is not a meaningful goal for qualitative research" (p. 125).

Maxwell (2013) suggests a number of validity checks the researcher may perform, including intensive, long-term involvement; collection of rich data; respondent validation; intervention; searching for discrepant evidence and negative cases; triangulation; incorporating quantitative data; and comparison between cases. During my data collection and analysis phases, I incorporated several validity checks in the interest of trustworthiness: First, I collected (and report) rich data; second, I conducted respondent validation during each interview, frequently restating, paraphrasing, and confirming participants' comments; third, I made transcripts available to participants upon request, reminding them of this prior to and following the interview (no one requested a transcript); last, during analysis, I compared results between cases, identifying and noting disconfirming cases. 


\section{Ethical Considerations}

Because this study presented the possibility of participants voicing opinions, perspectives, and practices that could run counter to official positions or that might influence their supervisors' perceptions of their performance, the safety and security of my participants was paramount. Accordingly, in the interest of maintaining the confidentiality of their identities, the research participants have been anonymized, and any details that might make it possible to identify them (e.g., course titles or academic departments) have been redacted or edited in this document. I have also edited participant quotes that mention names of other individuals in order to obscure these individuals' identities. 


\section{CHAPTER IV}

RESULTS

Throughout the month of October 2018, I conducted semi-structured, open-ended interviews with eight Florida International University faculty members who teach online and have successfully passed a Quality Matters review for one or more of their courses. These participants reflected a range of faculty ranks, disciplines, and number of courses that have been Quality Matters certified. This chapter, following brief profiles of each of the study's participants, details the data and salient themes that resulted from my interviews, including relations to and intersections with documentary materials, such as the QM Rubric Workbook (Quality Matters, 2018a). As discussed in the previous chapter, I approached data analysis through the lens of audit practices, principally informed by the scholarship of Power (1997) and Shore and Wright (1999, 2000). To report my findings, I am including frequent extended quotes and interview excerpts. I feel that participants'

own words and voices are the best representation of the salient themes of this study, and using longer quotes when appropriate allows their words to retain their context and authenticity. Direct quotes have been lightly edited for clarity by removing filler words and other speech disfluencies.

As discussed in Chapter I, the following research questions informed and guided the study:

- What are the relations between the understandings of course quality among faculty members who have gone through the Quality Matters process and the criteria used by Quality Matters?

- What motivated them to pursue Quality Matters certification? 
- How have they negotiated, maneuvered, and/or resisted the QM program and process?

- What impacts and significance do these faculty members ascribe to Quality Matters?

\section{Participant Profiles}

For this study, I refer to research participants by the number indicating the order in which I interviewed them (e.g., "Participant 3") rather than by assigning pseudonyms, because I did not want to project my own perceptions of sociocultural nominal associations onto them.

Participant 1 is an adjunct faculty member in a social sciences field as well as a full-time staff administrator at Florida International University. He has earned Quality Matters certification for several fully online courses that he teaches. Teaching online courses offers him the flexibility to accommodate the responsibilities of his primary job at the university, but he occasionally teaches face-to-face courses. He spoke enthusiastically about his involvement with Quality Matters but expressed hesitancies about some aspects of his experience.

Participant 2 is an adjunct faculty member who teaches courses that are multidisciplinary in nature. He has earned Quality Matters for multiple online courses. He also works full time as an administrator at Florida International University, where his role includes working with other faculty members in his academic unit. He teaches online and face-to-face courses. Perhaps more than any other participant, he was incredibly enthusiastic about Quality Matters, attributing positive impacts on his teaching to it. 
Participant 3 is an associate professor in a social sciences field. He teaches primarily face-to-face courses, but also teaches one graduate-level course online, which successfully completed a Quality Matters review. During our interview, he expressed hesitation and skepticism in relation to his experiences with QM and the idea of quality more broadly.

Participant 4 is an assistant professor in an applied science field. She has earned Quality Matters certification for two online courses. She teaches primarily online courses. She spoke positively about her experiences with Quality Matters and with an instructional designer.

Participant 5 is an associate professor in a social science field. She has earned Quality Matters certification for several online courses and has won several teaching awards. She teaches primarily online courses. During our interview, she described a change in her perspectives about QM over time; she found her early experiences with Quality Matters were positive and beneficial, but more recent experiences have prompted some skepticism about the program and the process.

Participant 6 is an instructor in a social science field as well as a faculty administrator in her department. She teaches online and face-to-face courses and has won several teaching awards. She has earned Quality Matters certification for multiple online courses. During our interview, she expressed notable antipathy to Quality Matters and the process, describing it as largely incompatible with her teaching philosophy. She withdrew from the Quality Matters process for two courses because of disagreements with the reviewers and their feedback. 
Participant 7 is an assistant professor in an applied professional field. He has earned Quality Matters certification for multiple courses. He teaches online and face-toface courses. He spoke mostly positively about his experiences with Quality Matters, but also expressed that some aspects of the program and process were neither helpful nor detrimental.

Participant 8 is an instructor in an applied professional field. She has earned Quality Matters certification for one course. She teaches online and face-to-face courses. She expressed mostly positive sentiments about Quality Matters, but conveyed some dismay at the lack of follow-through regarding impacts on learning outcomes.

For reference, Appendix D contains abbreviated profiles of each of the research participants.

\section{Faculty Members' Understandings of Quality}

The first research question of this study asked what are the relations between the understandings of course quality among faculty members who have gone through the Quality Matters process and the criteria used by Quality Matters? As discussed in earlier chapters, I approached this study using the lens of audit to examine Quality Matters (Power, 1997; Shore and Wright, 1999, 2000). According to Power (1997), audit practices are characterized by programmatic and technological elements. Programmatic elements "relate to the ideas and concepts which shape the mission of the [audit] practice and which, crucially, attach the practice to the broader policy objectives which exist in the political sphere" (p. 6); technological elements include the practices and routines enacted by audit practitioners, including analytic methods, checklists, rubrics, and samples. Expectations gaps develop when there is a loose coupling between the programmatic 
demands of an audit and the operational capabilities of the technologies and practices, making audits merely "rituals of inspection" (p. 89). For example, in the financial auditing sector, "if official meta-accounts of auditing overemphasize the goal of detecting fraud, then programmatic expectations may be created in excess of those that it can really satisfy," leading to an expectations gap (p. 9). This gap can be highlighted by the "the more 'local' stories which are told of the [audit's] underlying operational capability" (p. 7).

As with any audit practice, Quality Matters can also be characterized by programmatic elements and technological elements. My first research question can be answered by exploring whether and how participants' programmatic expectations of quality were aligned with Quality Matters's technological capacities. According to Power (1997):

All practices give accounts of themselves which are aspirational rather than descriptive. These accounts exist at the collective, or what can be called the "official," level and for many years sociologists and others have been interested in digging into these accounts, showing what they leave out and demonstrating how a certain ideal and institutionally acceptable "front stage" account of a practiced is produced after much "back stage" work, which is rendered invisible... What has been left out must be brought back in, even at the expense of the official account itself. (pp. 7-8)

This section of the chapter examines if participants" "local" stories of "back stage work" with Quality Matters illustrate an expectations gap. This section of the chapter details the programmatic and technological elements of $\mathrm{QM}$, followed by an exploration of research participants' own conceptualizations of online course quality. 


\section{Programmatic Elements of QM: Helping You Deliver on Your Online Promise}

The programmatic claims of Quality Matters can be traced to its inception as an initiative started by a consortium of Maryland higher education institutions that offer online courses. According to the QM website (Quality Matters, 2018g):

Quality Matters began with a small group of colleagues in the MarylandOnline, Inc. (MOL) consortium who were trying to solve a common problem among institutions: how do we measure and guarantee the quality of a course? This question was especially important as institutions began to create a system where they could share available seats in their online courses with other institutions. They needed a way to ensure course quality - that courses would be equivalentfor their students, regardless of where the course originated. (para. 1)

By describing a need to "measure and guarantee quality" as a "problem," Quality Matters conveys a sense of urgency and necessity. Its stated goal of ensuring that courses are "equivalent" is reminiscent of Total Quality Management's tenet of reduction in variation (Houston, 2007; Bensimon, 1995), although, as Houston (2007) put it, "the purpose of higher education, rather than conformity, should be to promote diversity" (p. 11). The QM website further states that "today Quality Matters is a nonprofit organization comprised of a dedicated staff that works together virtually—-from cities all over the United States - to support everyone's quality assurance goals (Quality Matters, 2018g, para. 5). Quality Matters, by suggesting that it is capable of meeting "everyone's quality assurance goals," implies a universal, objective, and measurable quality standard that transcends subject matter and local context.

The first page of the Quality Matters Higher Education Rubric Workbook, the document that most clearly and comprehensively expresses QM's proprietary conceptualization of quality and its quality assurance process, starts with a large heading: "Why Quality Matters?" (Quality Matters, 2018a, p. 2). The Workbook continues: 
Quality Matters ${ }^{\mathrm{TM}}(\mathrm{QM})$ is an international, U.S.-based, non-profit organization specializing in standards, processes and professional development for quality assurance in online and blended learning. QM tools and resources are regularly revised to reflect current research and best practices. When you see QM Certification Marks on courses or programs, it means they have met QM Course Design Standards or QM Program Review Criteria in a rigorous review process. (p. 2)

At the bottom of the first page is QM's vague, but inspiring, slogan: "Helping you deliver on your online promise.” (p. 2). The Quality Matters website also discusses the program in relation to this elusive "promise":

Continuous. Centered. Collegial. Collaborative. The QM Quality Assurance System relies on these core principles to create a culture of continuous improvement so you deliver on your promise day after day, semester after semester. Keeping learners engaged is different in online courses. Getting them past the "packaging" - the mechanics of the course - so they can focus on content and learning objectives can be a challenge. That's where our researchbased Rubrics and Standards really shine: they provide objective, evidence-based ways to evaluate the components of online learning. The commitment? It's significant. The impact? Substantial! (Quality Matters, 2018c, para. 1)

The Rubric Workbook further explains that the "Quality Matters Toolset and Process" are "based on national standards of best practice, research findings, and instructional design principles"; "designed to promote student learning"; "integral to continuous quality improvement"; and "part of an inter-institutional, faculty-driven, peer review process" (p. 2). These materials imply a linkage between the Quality Matters program and student outcomes such as student learning and engagement, but the mechanism by which the QM process is designed to promote these outcomes is unclear. Notably, Legon (2015), former Executive Director of Quality Matters, suggested that demonstrating this connection between application of the QM rubric and student outcomes is "a practical impossibility" (p. 168), a view not supported by the literature reviewed in Chapter III. 
The local programmatic elements of Quality Matters_ideas that characterize the mission of the audit practice that relate to broader policy objectives at the institutional level - are evident in materials published by the Florida International University, the site of this research study. The website of FIU Online, the university's distance learning unit, positions Quality Matters prominently as part of a section on its "Quality Commitment":

FIU Online is dedicated to remaining a leader in distance education by ensuring the highest quality experiences and services in online learning...FIU Online adopted Quality Matters (QM) as their quality assessment program in Fall 2011 by running a small pilot with only seven courses. Since then, upwards of 300 courses have been certified across all disciplines, recognizing Florida International University as the second highest institution with QM certifications nationwide. (FIU Online, 2018, para. 1)

Here, the programmatic claim implied by FIU is the need for "quality assessment," and the reported growth in the number of certified courses emphasizes the growing need for this mechanism. Furthermore, using the language of "leader in distance education" and "second highest institution," Quality Matters is couched in the language of competition, further reinforcing the neoliberal underpinnings of quality logics. In a report published on the FIU Online website, Quality Matters-certified and non-certified online courses from spring 2016 were compared on the basis of data obtained from the learning management system (FIU Online, 2016). The report's findings suggested that, compared to noncertified courses, QM-certified courses were more interactive because students in those courses clicked on links more often; had more items, assignments, tests, and activated tools; and that students logged into QM-certified courses more times and stayed logged in longer. The report concluded that "the evidence suggests that online courses that have the QM certification are more effective and engaging" (p. 12). The findings of this report are highly problematic; clicks hardly equate to interactivity, and the amount of content and 
number of assignments do not indicate effectiveness. However, this report demonstrates how the institution has also positioned Quality Matters to support supplemental programmatic claims of quality in relation to course effectiveness and engagement.

Ultimately, the programmatic demand that is deemed served by Quality Matters is the determination of whether a given online course meets a socially accepted quality standard. Although the QM Rubric uses a 100-point scale for reviews, the final determination and public reporting is binary: a course is either quality certified or it is not. Most of the scholarly literature on the impact of Quality Matters reviewed in the previous chapter assumed that QM meets this policy goal, and published materials by FIU suggest that the site of this research study does as well.

Critically, policymakers and administrators may also consider Quality Matters as meeting the programmatic demands of determining the quality of online courses. For example, responses to a survey sent to Florida colleges and universities by the Taskforce for Online Strategic Planning Quality Subcommittee indicated that several state institutions defined course quality itself as meeting Quality Matters standards (Florida Board of Governors, n.d.), and the Florida Board of Governors has approved a measure to use Quality Matters as the statewide metric for the determination of whether a given online course is a quality course (Florida Board of Governors, 2017, p. 2). The issue to be explored in the rest of this section is whether the understandings of course quality among participants in this research study reflected and were suitably met by the technological and operational capabilities of Quality Matters. 


\section{Technological Elements of QM: Design, Not Delivery}

The technological elements of a Quality Matters review include the QM Rubric that is used as the basis for determining if an online course meets the requirements for certification as a quality course as well as the review process itself. The QM Rubric comprises eight General Standards, with each having between four and nine Specific Review Standards. The General Standards include Course Overview and Introduction, Learning Objectives, Assessment and Measurement, Instructional Materials, Learning Activities and Learner Interaction, Course Technology, Learner Support, and Accessibility and Usability. Each Specific Review Standard is worth one, two, or three points and all three-point standards must be met for a successful review (Quality Matters, 2018a). The QM Rubric emphasizes alignment between stated, measurable learning objectives and all other instructional aspects of the course; of the 23 required Specific Review Standards, nine deal with learning objectives. I discuss the role of learning objectives in Quality Matters in depth later in this chapter.

Quality Matters reviews are conducted by a team of QM-certified peer reviewers, comprising one reviewer who is a subject matter expert in the content area of the course being certified, at least one reviewer who is external to the institution submitting the course, and a QM-certified “Master Reviewer.” In order to serve on a QM review panel, peer reviewers are required to have had online teaching experience in a credit-bearing course and have completed a QM Peer Reviewer Course; Master Reviewers must have completed an additional QM-provided training course (Quality Matters, 2018a). The review panel members are selected by an institutional representative who has access to a database of approved reviewers. 
Each Specific Review Standard is evaluated by the reviewers; points are awarded if at least two of the three reviewers determine that the course meets the standard "at an 85\% or better level" (Quality Matters, 2018a, p. 8). The QM Rubric Workbook does not explain how standards such as "Learners are asked to introduce themselves to the class" or "The relationship between learning objectives or competencies and learning activities is clearly stated" can be evaluated on a percentage scale (p. 51). After all Specific Rubric Standards have been evaluated by the reviews, the course is deemed to have passed if 85 of 100 total points were awarded and all three-point standards were met. In addition to the rubric scores, the review team issues feedback that includes, according to QM:

a rich set of recommendations from the Reviewers indicating the strengths of the course, areas for improvement, and specific recommendations and suggestions for improving the course. Reviewers write recommendations for any Specific Review Standards that were not yet met. They may also write recommendations for improvement even when they mark a Specific Review Standard as "Met," because there can still be room for improvement. (Quality Matters, 2018a, p. 50)

If a course does not pass, the submitting instructor is invited to incorporate the review team's feedback and resubmit within a window of 14 weeks until the course passes (Quality Matters, 2018a). As the Rubric Workbook states, "QM expects that all courses submitted for QM review will eventually achieve certification" (p. 50).

Student performance, student learning, the nature and content of student-tostudent interaction and student-to-instructor interaction, instructional strategy, instructor responsiveness, instructor feedback, and other aspects of the implementation of the course are not considered by the Quality Matters process. Quality Matters concedes that their rubric and process are only capable of evaluating the design of an online course. The Rubric Workbook states, under the heading "Design, Not Delivery," that: 
The Quality Matters Rubric specifically focuses on course design, rather than on course delivery or academic content. For the purposes of a review, consider the design aspect to include the instructor's role in the forethought and planning of the course, as well as in the creation, assembly, and layout of instructions and course components. Not under review is the instructor's implementation of the design as he or she delivers the course and interacts with learners. (Quality Matters, 2018a, p. 5)

Do forethought, assembly, and layout — the elements of a course that Quality Matters evaluates — equate to a quality learning experience, an “online promise?” Or are there other factors that contribute to course quality? The following subsection of this chapter explores faculty members' perceptions of quality in the context of online courses and the relations between those ideas and the QM rubric.

\section{Conceptualizations of Quality: It's Like the Russian Figure Skaters}

I opened the conversations with my research participants by asking what, in their view, was quality in the context of online education. Salient themes I identified in the course of analyzing the interview transcripts that related to participants' understandings of quality included navigation, clarity of instructions, course content, engagement and interaction, and student learning. Based on cross-analysis of participants' responses regarding their understandings of quality with documentary artifacts of the programmatic and technical elements of Quality Matters, I further explored whether a disconnect between these data suggested possibility of an expectations gap (Power, 1997).

The extent to which participants' own conceptualization of quality aligned with or differed from the Quality Matters rubric varied. For some participants, quality was nebulous. For others, it was complex and multifaceted. This thorough response from Participant 3, an associate professor in a social science field, is illustrative of the ambiguities of quality: 
Interviewer: What, in the context of online courses, constitutes quality, in your view?

Participant 3: Alright. I don't know, and I'll tell you why. I don't know. I'm not sure I know what quality teaching in any format is. How would you-how could you — judge it? You could judge it by outcomes and that's certainly something the State of Florida is encouraging us to do. You know, do your students get jobs? Did their salaries go up? What are their life chances? On the other hand, what relationship is there between what they learn in school and that? Perhaps nothing. In fact, there's a school of thought that says it's all just credentialing - that anything you actually use that makes you a better employee, that has your salary go up, is learned on the job or you already had it, right?

We could also judge it by content. And to some extent that that's what the university does. You now have to submit documentation to whoever credentials you in these classes in order to be allowed to teach a class. And so, what they're usually looking for is not how many years you've been teaching it, but have you published in the area? Okay. But I'm pretty sure that there is zero relationship between your knowledge of a subject and your ability to teach it. In fact, my long experience in school as a student was that some of the greatest of the great scholars were horrifyingly bad in the classroom and that the good teachers were the ones who had an enthusiasm for teaching and picked up some subject knowledge along the way.

A third way to do it would be to look at structure - that all quality courses meet the checklist and the checklist chunks things in the modules and has at least one component where students interact online, etc., etc., etc. I'm not sure any or all of those things get added. I think there's still probably a sort of a mystery to it. You know a good teacher when you see one, I'm not sure you can bottle that and spray it on everybody else and have them become good teachers.

Participant 3 started with an admission that quality has a number of possible understandings and seemed to infer that it was difficult or problematic to measure. His first example — outcomes, jobs, salaries, life chances—evokes Harvey and Green's (1993) understanding of quality as transformation, and the second example of assuring quality of content by credentialing and the third example of structure both suggest a minimum standards approach. His proposition that "there is zero relationship between your knowledge of a subject and your ability to teach it" was, itself, emblematic of the logic of Quality Matters, which does not evaluate the subject content of a course. Ultimately, by 
describing teaching quality as a "mystery" and that "you know a good one when you see one," he seemed to suggest that teaching quality cannot be evaluated.

Some aspects of other participants' conceptualizations of quality closely aligned with specific Quality Matters rubric standards. Two participants mentioned course navigation as part of quality:

You have to have a good quality course that students are able to navigate and that engages them. (Participant 5)

[Quality includes] the part that the instructional designer does where it comes to navigating a course. So, I think it would not be a good course if it would be complicated to navigate it or students would get lost in it. So, content navigability I would say. (Participant 1)

These comments are consistent with QM Specific Review Standard 1.1, which states, "Instructions make clear how to get started and where to find various course components," and 8.1, which states "Course navigation facilitates ease of use." (Quality Matters, 2018a, p. 51). Both of these are required, three-point Standards.

Some participants noted clarity of instructions as important aspects of quality:

I think good quality is also making clear what are the requirements. So, I mean that starts with a syllabus, of course, but also each of the modules [need] to have, you know, a list of things to do in...that week. (Participant 1)

I also think in that quality has to be where it's something that is clear towards the students in what they are going to get from it...It's everything that's clear and concise. There should be no hindrances or, like, if I should say this, no reason in that a student can say, "I didn't understand the assignment," unless there was something in the rubrics that may have been unclear. (Participant 2)

[Quality is] a program that provides the students with the instructions they need, but at the same time ensures that they understand what you're giving them. (Participant 8)

These statements align with several Quality Matters Specific Review Standards, including 2.3 ("Learning objectives are stated clearly, are written from the learner's 
perspective, and are prominently located in the course."), 2.4 ("The relationship between learning objectives or competencies and learning activities are clearly stated."), and 3.3 ("Specific and descriptive criteria are provided for the evaluation of learners' work, and their connection to the course grading policy is clearly stated.") (Quality Matters, 2018a, p. 51).

However, other aspects of participants' conceptualizations of quality differed meaningfully from the Quality Matters rubric criteria. Course content—specifically excluded by the Quality Matters rubric's “Design, Not Delivery” tenet—was mentioned by five of eight participants. Representative comments include:

Quality, in terms of an online class, would probably be manifold, right? The content of course, I think [is] not related to QM, but that's why a subject matter expert is always necessary, right? So good content is key for labeling of course quality, I think. (Participant 1)

We could also judge it by content. (Participant 3)

You have to have really good content. (Participant 6)

In my opinion, quality for an online course is that it's providing students with a content that is engaging towards them. (Participant 2)

Having a certain rigor in the content that is covered in the class. (Participant 7)

Similarly, engagement and interaction, also excluded by the operational capacities of the

QM rubric, were mentioned by four participants.

You have to have a good quality course that students are able to navigate and that engages them. And then, me as the instructor, I have to be able to engage my students so that they're invested in the material, they want to learn, they're excited about learning. (Participant 5)

In my opinion, quality for an online course is that it's providing students with a content that is engaging towards them, but also in that it allows students the freedom to express and also participate in the class. (Participant 2)

You know, having a certain level of engagement. (Participant 7) 
Participant 6, an instructor in a social science field, spoke in depth about her views regarding engagement and interaction in relation to quality and QM. She emphasized how important it was to her to engage with her students, interact with them, provide them feedback, and give them a sense that she cares about them. She noted that all of these factors, to her, were important elements of course quality that go unnoticed by Quality Matters.

Participant 6: Continual engagement is a big part of high quality for me, both in terms of your interaction with the students, both in terms of quality and quantity. You have to interact with each of your students, which can be challenging for those of us that have large online sections of 70 to 100 students. Lots of interaction, lots of feedback to students, and the students perceiving that you care about them and want them to do well no matter what kind of class you're teaching. So that's how I see quality education.... So Quality Matters doesn't look at any of that. They don't look at your feedback to students. They'll look at your automatic graded quizzes to students and say, oh no, that's, you know, that's low quality, that's a low quality assignment, but they don't see the emails that I'm sending to students who are not scoring highly saying, "Hey, do you want to meet with me during office hours? Let's talk about your study techniques." Or, "Here's an article I found."... So they're missing the interaction piece and they're just seeing the skeleton of the class.

Interviewer: And those missing pieces - the interaction piece — that's something that would be important to you in relation to quality?

Participant 6: Definitely. Definitely. It's what you bring to teaching. I mean, anybody can create a [course] shell.... They're evaluating the contents of your course, not necessarily your presence in the online. And online presence is a big component of the quality of the course. So, they're missing a big piece.

A few participants discussed aspects of student learning in relation to quality,

including higher order thinking, rigor, and application. Participant 5 emphasized the need

for students to be able to apply course material as an important aspect of quality:

And then I think to really truly be a quality course, it has to be structured so that it's not just rote memorization-type. Perhaps it's just the topics I teach, but I see so many students where they're able to memorize facts, but they can't really apply what they've learned outside of the classroom. So, I feel that that's a huge 
component in a quality course - is students being able to learn such that they're able to apply the material. (Participant 5)

Participant 8, an instructor in an applied professional field, noted a similar viewpoint: "So whatever you're teaching them, they understand it and then they can apply it." Participant 7, an assistant professor in an applied professional field, discussed the rigor of a course's instructional content and student achievement of learning goals:

So, it's multi-dimensional. I think quality has to do with achieving certain learning outcomes for the students. You know, having a certain level of engagement. You know, having a certain rigor in the content that is covered in the class. So, it's kind of hard to answer, but I think, kind of, I would say maybe three things. Content, engagement, and achieving learning goals. I think that's, you know, if you can hit on those three, one could say this is a high-quality course. I guess. (Participant 7)

These comments by Participant 5, Participant 7, and Participant 8 suggest that promoting higher order thinking and application of course content for students were important elements of course quality to them. These factors are not examined by the QM review.

Among the major themes I identified in relation to participants' understandings of quality - navigation, clarity of instructions, course content, engagement and interaction, and student learning — only navigation and clarity bear any meaningful alignment with the Quality Matters rubric and are capable of being addressed by the technological elements of a QM audit. This gap between the faculty members' programmatic expectations of Quality Matters and the operational capabilities of QM suggests the possibility of an expectations gap (Power, 1997). To further explore the possibility of an expectations gap, I asked the participants in this study to discuss whether they felt that the criteria used by Quality Matters reflected their own understandings of quality. Participants' perceptions were mixed. Participant 5, who felt that Quality Matters 
improved aspects of her online courses, expressed a disconnect between the Quality Matters criteria and her own priorities:

I feel like the QM rubric is very much geared toward just the course piece. Like, you know, oh, you have your disability resources highlighted, you have your technical support highlighted. You know, very much geared toward the course piece. But I think the course alone does not equate... a good course does not equate to a quality learning experience for students. So, I feel like it's just a piece of it. You know what I mean? (Participant 5)

Here, Participant 5, an associate professor in a social science field, alluded to QM Specific Review Standards 7.4 ("Course instructions articulate or link to the institution's student services and resources that can help learners succeed"), which includes disability resources, and 7.1 ("The course instructions articulate or link to a clear description of the technical support offered and how to obtain it") (Quality Matters, 2018a, p. 51). Both of these Specific Review Standards are required 3-point items. With these two examples, she alluded to a conceptual divide between the course and the learning experience, presenting the possibility of a disconnect between the two. Later in our conversation, she circled back to this disconnect, questioning if there was any relationship at all between QM and the student experience:

Like I said, I really see a disconnect between QM and the student piece. Like I feel like, okay, QM has some standards that perhaps enhance a course, but it doesn't make sure that students are learning. So, is there a connection QM and students? I don't know. (Participant 5)

Participant 8, who was generally very positive about QM, felt that it was lacking in terms of follow-through and student learning:

Quality Matters, I know for sure, is only concerned with the experience for the student when they're online. They're hoping if they meet those requirements, it will increase learning, so they won't have to check to see if the students are learning. That's too much work for them. It's bad enough that they have to do that, but then to follow up each class, it would be too much and too much resources 
would have to be spent, because they'd have to hire people to follow up to see....If they're going to have a stamp that shows that you're doing it, they need to follow up to make sure it's relevant. So, I think that's where QM falls short, which would be a lot of work, not just for them, for us, but they need to reevaluate it. (Participant 8)

Participant 8's suggestion that the connection between the QM standards and student learning is a "hope" and that the program needs to be reevaluated is further indication of an expectations gap.

Participant 2, an adjunct instructor who teaching multi-disciplinary courses who was perhaps the biggest champion for QM among my participants, expressed dissatisfaction with aspects of his experience relating to the operational aspects of his Quality Matters review. He felt that his reviewers did not look at his course at all and instead relied on just the syllabus for the review:

Participant 2: And at one point it looks as though it was reviewing the syllabus, but in my opinion, it didn't seem as if they were reviewing the course itself. So yes, I can give a syllabus that explains everything, matching these objectives...There should, in my opinion, have been maybe a secondary review of the shells themselves, just to make sure that it was mentioned with the syllabus requirements as well because it looks as if at that time they were just looking at the syllabus and nothing else. And again, what if they noticed that there were these inconsistencies? That's just my opinion.... just think the review board should have looked at the shells as well, aside from the syllabus. The syllabus is relevant, but the shells are too.

Interviewer: Yeah. My understanding is that they are supposed to look at your course shell in addition to the syllabus.

Participant 2: In my opinion it didn't seem as if they did that. They just looked at the syllabus, and that was it. That's all they did.

Participant 2's concern that the course reviewers did not look at his course suggests a major issue with the technological elements in his particular experience. QM is abundantly clear about how it conducts a review of a copy of an online course that has been stripped of student artifacts (Quality Matters, 2018a), and this participant's 
impression that this process was not carried out was notable. Participant 2 also felt that QM's review practice of examining a course that was stripped of all course communications and student contributions was detrimental to a holistic understanding of a course's quality:

[A QM-certified course] can still be a bad course where, what the professor is not giving them their feedback? What if they're not giving them their grades on a timely basis? What if they have actually issued a failing grade and have not given enough of reasoning as to why there was a failing grade?....If all they're looking at is just the syllabus and the shell itself, but not at the student data, how do they know, then, if the students are really engaging with material? How do they know if the students are producing work that is alignment with the rubric? (Participant 2)

By raising the concern that a QM-certified course could be a "bad" course resulting from a faculty member's lack of engagement with students, Participant 2 alluded to what he felt was a serious shortcoming with QM's "Design, Not Delivery" tenet. Furthermore, he noted that the technological elements of QM are incapable of taking into consideration whether the course environment facilitates student engagement with course material or if student submissions align with expectations, further lending support to the possibility of an expectation gap.

Participant 6 expressed that she thought that Quality Matters did not honor the local context of the institution's student population. To her, quality should be contextdependent:

I think that they want to find a way to say that online education is high quality and they want to be able to say yes, students are learning. But how do you do that? You'd have to have a mechanism for assessing that. And I think that QM is a solution they're looking at for that. They're outsourcing it rather than having some kind of quality control here in-house that is familiar with our FIU students and their demographic. Because FIU students are weird, you know? They work fulltime. They live with their parents. They're minority. More than half of them are low income to very low income. And we're not like these other schools that QM 
looks at. We're not UF. We're not FSU. You know, they're not a bunch of middleclass white Americans living on campus and partying a lot. You know, most of our FIU studies find that we're strange. You know, even alcohol studies. We have lower instances of drinking. You know, our students drink less. They do drugs less than other colleges. They party less. You know, we have to make adjustments for the way we teach. (Participant 6)

Participant 6's comments were similar to those of other participants who noted that QM's technological elements are incapable of determining if students are learning.

Furthermore, her indication that any meaningful measure of education quality should take into consideration the local context and student population also precludes a one-size-fitsall quality assurance mechanism like Quality Matters.

Ultimately, the degree to which participants' own conceptualizations of quality are reflected by the Quality Matters rubric and process varied. Some felt that Quality Matters was a suitable representation and indicator of quality. Others noted meaningful deficiencies in QM, reflecting a wide expectations gap. These results demonstrate that there are widely varying, overlapping, and even conflicting conceptualizations of online course quality. Quality Matters represents one conceptualization of quality that uses a narrow range of criteria - "forethought and planning of the course, as well as in the creation, assembly, and layout of instructions and course components"- and the relations between faculty members' conceptualization of quality and these criteria only partially align (Quality Matters, 2018a, p. 5). As Filippakou (2011) noted, quality is constructed in a network of fluctuating discourses:

There are multiple discourses of quality, constructed and perpetuated in different contexts through diverse channels such as national quality agencies, journals, conferences, informational conversations between colleagues, and even between students and tutors. Some discourses of quality are dominant, representing the interests of powerful groups with the wider social framework, or perhaps accepted 
as "common sense" or "natural" by the majority of the social collectivity. While others may be subservient, even if articulate, alternative perspectives. (p. 18)

This social construction of quality was colorfully articulated by Participant 3 , who presented a fascinating analogy:

It's like the Russian figure skaters. How do you know that they are always high quality? Well, they have Russian names. Are they from Russia? Was their coach Russian? Therefore, it's great skating. All right. If you [laughs] define it like that, then sure. [acerbic] Sure, you have quality. But if you're, if you think quality is something else, measured by content, measured by learning - however that is assessed - or career outcomes - however that is assessed. I'm not sure it's going to be so direct, but maybe that's the whole ballgame. That's why we have an ed school. Right? (Participant 3)

This intriguing comparison highlights his perspective that "quality" is achieved when the socially agreed upon standards of quality are met, regardless of how meaningful they are.

The findings of this study in relation to the first research question-what are the relations between the understandings of course quality among faculty members who have gone through the Quality Matters process and the criteria used by Quality Matters?suggest that there is some overlap between the QM rubric items and faculty members' conceptualizations of quality, particularly in terms of course navigation and clarity of instructions. However, participants in this study placed more emphasis on other understandings of quality - those relating to course content, engagement and interaction, and student learning — which are not addressed by Quality Matters. Furthermore, since there is a disparity between these ideas of quality; the programmatic goals of QM of assuring quality; and the technological, operational elements of QM, an expectations gap exists in relation to participants' understandings of quality and their expectations of the QM audit (Power, 1997). 


\section{Motivations for Pursuing QM}

The second research question of this study asked what motivated participating faculty members to pursue Quality Matters certification? Quality Matters, absent a state, institution, or academic unit mandate, is an optional process for most instructors at Florida International University, the research site for this study. In this regard, QM differs from most quality assurance mechanisms in higher education such as state and national accreditation. Nonetheless, the Quality Matters review reflects an audit process in that it is characterized by "independence from the matter being audited; technical work in the form of evidence gathering and the examination of documentation; the expression of a view based on this evidence; [and] a clearly defined object of the audit process" (Power, 1997, p. 5, emphasis in original). Under QM, the audit's independence from the object of the process - the reviewed course - is realized in the peer review arrangement. Evidence gathering takes place as the reviewers examine a "mature" version of the course that has been stripped of student activity, gathering evidence of the extent to which the course meets the criteria of the QM Rubric in order to express a view of whether the course meets or does not meet the requirements for certification. Finally, despite the fact that

Quality Matters is usually optional, as was the case with the site of this study, Shore and Wright (1999) suggested that audits render auditees as "as responsible, self-activating, free agents who have internalized the new normative framework" (p. 566).

Thus, understanding Quality Matters as an audit practice, this research question sought to explore why faculty members would opt to undergo the process. In exploring this question with my participants, it became apparent that there was an array of 
motivations for engaging with Quality Matters. For example, three participants noted that care for students was an important factor for them. Participant 4 mentioned:

So, knowing that I could use this checklist to help my online students, I really wanted it to follow it. And it was logical, it was reasonable, and I thought that it would help the students in the long run. It killed me, but it helped them.

(Participant 4).

Participant 2 also suggested that Quality Matters certification was an indication that the instructor cares for students:

I mean, to me it looked [like] a prestigious acknowledgement to where it also says to me that this is a course that really cares for the students. That they really took the time to make it clear for students who-each student learns differently. You've got students that are visual learners, those who are auditory, those who want clear, concise descriptions.... just think that it really shows that the course itself and the professors themselves care about the students and took the time to review the course and give them content and everything that is engaging for students and really works well with students and also one that's everything that's provided to them. (Participant 2)

Participant 7 also explained that his care for students was a factor for him:

I wanted to make my courses as good they can be so I can continue building upon them and using them, or, you know, making them more sustainable. You know, I want to do a good job as a teacher. I want the students to have a good experience. I want them to learn and, you know, I felt like going through QM, together with my instructional designer, will help us, despite some of the parts of it that I'm not sure are helpful, will help us improve. (Participant 7)

In addition to care for students, I identified three major themes relating to participants' motivations for pursuing Quality Matters that were discussed in the course of my conversations with participants_-prestige, recognition, and distinction; a monetary incentive; and an expectation or mandate. The remainder of this section will explore these themes in depth. One final, minor theme-engaging in Quality Matters for the benefit of an instructional designer — will be discussed in relation to decoupling in a later section of this chapter. 


\section{Prestige, Recognition, and Distinction: I Made an Amazing Course, and Everyone}

\section{Was Really Amazed by It}

A major motivational element mentioned by several participants was in relation to recognition, prestige, and distinction, and the extent to which this element was prioritized by participants differed by faculty rank. Participant 1 , an adjunct faculty member who is also a full-time administrative staff member, noted about Quality Matters certification that

It's also about your CV, of course. Your credentials. It's something you put on your teaching portfolio. It's something you put on your CV. It shows, especially since my day job is in the administration and I still want to continue having a chance at an academic job or teaching job, and it shows that I'm still engaged in that, right, if I do QM. (Participant 1).

Participant 2, also an adjunct faculty member and full-time staff administrator, expressed similar thoughts about earning Quality Matters certification in relation to his perceptions of prestige. I was incredibly surprised by his enthusiasm, earnestness, and passion on this topic, and I am opting to include some extended quotes of his to demonstrate this:

To me, it seemed as if, like, it's one of those nationally recognized awards. And, I mean, I love the fact alone that I was able to teach my own online course was amazing. And, to get that QM certification, it would be as if like, this is going to be my first ever certification in my life. And I just really wanted to have that prestige as well. (Participant 2)

He indicated that Quality Matters certification provided a sense of legitimacy in the context of working as adjunct: "To have prestige and recognition, it made me feel as if I was part of faculty. Like, I can tell myself that I am a [faculty member], that I did an amazing job. That acknowledgement." He continued:

So that title and prestige does show... and it's not that it was to make myself, like, giving me, like, value or worth, or anything like that. It's nothing like where I thought I was worthless or anything like that, but it was just so, like, I can tell 
myself that I made an amazing course, and everyone was really amazed by it. And it showed. I got the QM certification. I was...I think I'm the first male [academic department] professor to have received the QM certification for [a course in my department]. And I actually saw the course posted on the QM [website] and I said, wow, I see faculty from Harvard and all these different universities. And like, there I am. That's me. I got posted on Facebook and I said, see, that's my online course. And I remember seeing all the likes and comments, and I just thought, wow. And I never thought in my life that would ever happen. (Participant 2) ${ }^{1}$

To the two adjunct faculty members I interviewed, Quality Matters certification served as a signal of prestige and was coupled with aspirations of legitimacy. Participant 1 related Quality Matters certification to his hopes of obtaining a full-time faculty position. Participant 2 felt as though QM not only made him feel like an actual member of the faculty but that he was also nationally recognized by being listed on the QM website's database of certified courses. These sentiments can be contrasted to those of Participant 3 , an associate professor; when I asked him if recognition or prestige factored into his experiences with QM, he stated:

No, because what I'm judged by is entirely different. Right. If I want to get another job, the only thing that... unless my teaching situation is people hate my classes and I show up drunk... Unless it's that bad that that I become a management problem for my boss because students hate my class so much. As long as I'm off the radar, I don't have to be good. As long as I'm off the radar in terms of being a problem. The thing that people with tenure and tenure-track are judged by... if I am to get a job anywhere else, the only thing they will look at, really, will be my scholarship, and that's just the facts of the matter. (Participant 3)

Whereas the two adjuncts related Quality Matters to professional distinction and legitimacy, the tenured professor dismissed the idea that QM certification had any bearing on his perceptions of this sort of recognition. Participant 6 echoed this; she had an illuminating perspective on this issue because she taught as an adjunct before being

\footnotetext{
${ }^{1}$ As of the time of this writing, no Harvard University courses have earned Quality Matters certification.
} 
hired as a full-time instructor. She noted how her perspective shifted with the change in her position:

It looked really good as an adjunct to say, you know, the whole department got an email that I got QM'd on there and you went on a....went on a website because it was like a rare thing years ago. (Participant 6)

When I asked if that was still the case now that she was no longer an adjunct, she replied:

It's really not. I mean, I've kind of won a whole bunch of teaching awards. I got a big-time award last year: [name of teaching award redacted]. It was a big thing....I'm well on my way to advancement and promotion, so I'm a lot less stressed out about QM, and I pretty much have the freedom to do whatever, but do whatever I want within reason in my classes. (Participant 6)

Despite holding a non-tenure-track position, Participant 6's perspective on QM's relation to prestige and distinction as full-time instructor are consistent with that of Participant 3. Quality Matters certification as an indicator of prestige and distinction also came up with Participant 5, an associate professor, in the context of the possibility that certification could become mandated at the state or institution level.

I think if it was a requirement, it would be less of a distinction, you know? Like, it would be harder for instructors to...I don't want to use the word "shine," but you know, to establish themselves as, you know, invested online. (Participant 5).

When I asked her to unpack the idea of distinction in relation to Quality Matters,

Participant 5 questioned the truth-value of the distinction provided by QM:

I don't know that it's true distinction, but in the eyes of people that don't have it, it's distinction. You know what I mean? Like, especially when they were pushing for everyone to get QM, and then others are like, "I tried. It's just too hard. I can't." You know? Then it looks like, well what's wrong with your courses? Is your course not good enough? Their course may be fine, but, you know, in the middle of a meeting when it's being discussed, and then, you know, my chair says, "Oh, well talk to [Participant 5]. She has QM." It sort of at least gives the appearance that my courses have some sort of distinction. Now is it, is it true distinction? I don't know. Like is my course really any better than someone who tries to get QM and can't? I don't know. Again, I don't think QM is the end all. You could have a horrible structure but you could put so much into your teaching that it makes up for not meeting some of the QM objectives. (Participant 5) 
To varying degrees, recognition, prestige, and distinction played a part in some participants' decisions to pursue Quality Matters certification for their courses or in their perceptions of QM's impact. The participants who were adjunct faculty members ascribed more value to Quality Matters in terms of recognition than tenured and tenuretrack faculty or full-time instructors.

\section{Monetary Incentive: $\$ 500$ is Certainly a Plus}

At Florida International University, the institution where this study's research participants teach, some colleges and schools offer a monetary incentive to faculty members who successfully earn Quality Matters certification for an online course. Based my participants' responses, a financial stipend proved to be a meaningful motivator for some, but not all, of them. Not unlike perceptions of QM certification in relation to prestige and distinction as discussed in the previous section, the degree of importance for the financial incentive was clearly segmented between adjunct faculty (or those who were previously adjunct faculty) and full-time faculty. For example, the stipend was the first thing was the first thing noted by Participant 1 , an adjunct faculty member, among his reasons for pursuing $\mathrm{QM}$ :

Interviewer: Why did you decide to pursue Quality Matters for your courses?

Participant 1: Initially? Because there were $\$ 500$ offers. So, for a QM course... I started teaching as a graduate student during my $\mathrm{PhD}$ program, and you're on a budget. And if you [can choose between getting] \$500 and not getting \$500, I would choose $\$ 500$. Right? Honestly. Now I have my PhD, [so] I earn a little bit more money. So, $\$ 500$ is certainly a plus.

He also mentioned the stipend-I believe half-jokingly, half-seriously—when I asked about the impacts of Quality Matters on students:

Interviewer: What do you think the impacts have been for students? 
Participant 1: The impacts for students? Well, they get a happier instructor because I get $\$ 500$ now [laughs].

Participant 6, who was previously an adjunct before accepting a full-time instructor position, also noted that the monetary incentive was an important factor in her decision to pursue QM:

So originally, I decided to pursue it because I was still an adjunct and I was trying really hard to get a full-time spot here, and they were pushing Quality Matters certification. They were also, for a while, offering additional money and even adjuncts make very little. So, the extra 500 for every course that you get QM certified, it was really nice...I mean, it's like more than 20 percent of what you get paid as an adjunct. (Participant 6)

Participant 7, a tenure-track assistant professor, also noted the stipend but did not ascribe the same level of significance to it than Participants 1 and 6:

The other part of this was we actually had the incentive to do it. If I remember correctly, at some point there was like a $\$ 500$ award if you get a course QM certified. So that too helps, I think. (Participant 7)

These sentiments can be contrasted to those of Participant 3, an associate professor who could barely remember if he received a stipend or not:

Interviewer: Aside from being told [to pursue QM], were you incentivized at all? Some programs offer a stipend.

Participant 3: Maybe I was, I don't...I don't recall. 250 bucks, something like that. Interviewer: So not enough, if anything, to remember?

Participant 3: Right.

This participant's uncertain memory of a stipend suggests that, in his privileged position as a tenured professor, financial motivation was not a compelling factor in his pursuit of Quality Matters certification. 
However, not all schools and colleges offered a financial stipend for Quality Matters. The possibility of a financial incentive arose in my conversation with Participant 8 , who noted the lack of any such incentive in her college:

Interviewer: Some professors have mentioned that their departments offered a monetary incentive for going through QM.

Participant 8: Not [my college].

Interviewer: No?

Participant 8: So [the quality assurance manager] said, "You could see if they offer." No, they don't offer. If I want to do it, then that's up to me. It will have the sticker on the course. There's no money. So, I didn't do it for that reason. I didn't get any reward. None whatsoever.

For those colleges and departments that offer a financial incentive to faculty members who earn QM certification for a class, these results indicate that the incentive was a meaningful driver for some faculty members to pursue QM. The degree to which it incentivized these participants was clearly segmented by faculty rank and status, with adjuncts (and former adjuncts) ascribing more meaning to it than assistant and associate professors with whom the topic arose. This segmentation of responses in relation to the financial stipend along the full-time/adjunct line is troubling. Cross-referencing the published list of QM-certified courses (Quality Matters, 2018d) with the FIU phonebook, I found that more than half of the instructors who earned Quality Matters certification for one or more courses in 2017 were adjuncts or graduate students - those who would likely be impacted most by a financial incentive. It presents the distinct possibility that the institution is leveraging the precarious position of contingent labor to pursue an agenda of quality. This logic is consistent with the findings of Worthington and Hodgson (2005), 
who reported that more vulnerable faculty shoulder more of the burden of complying with quality assurance programs.

\section{Expectations and Mandates: Because They Told Me To}

Most of my research participants engaged in Quality Matters voluntarily, not because it was mandated by their department, college, or particular program. Only one participant, Participant 3, indicated that he pursued Quality Matters because it was expected of him as part of degree program in which he taught. Imbued in this disconfirming case was a compelling reflection on faculty autonomy in relation to quality, warranting, I feel, an extended excerpt of our conversation:

Interviewer: Why did you decide to pursue Quality Matters certification?

Participant 3: Because they told me to. They said we would like to have all of our master's level online courses QM certified.

Interviewer: Who's “they"?

Participant 3: "They" is my boss. Word comes down from on high. Most of the time - less than it used to be, but, still most of the time - nobody bothers me about anything I do, except to see at once a year that I'm doing it. And that's a very serious moment, and if I don't do it then I'm in big, big damn trouble. But most of the time nobody hassles me about what I do in my classes. I don't even think anybody has ever known what I've done in my classes.... That's a privilege that I don't think I abuse. In fact, if you listen to my boss, he will tell you that I've gone too far the other way. I spent too much time on the teaching, spend too much time belaboring the assignments. I spend too much time changing it up from one semester to the other, trying to tweak it and trying to make it better. So, I don't think I'm taking advantage of the degree of autonomy I'm given, but occasionally that autonomy is limited. And in this case, what happened is word went out at a faculty meeting. We have been told - and I don't remember any more than that, but it came from my boss to me - if you're doing an online course, we'd like to have it QM certified. Now, there were other pressures. It wasn't just him. Ours is an accredited program. They like to see that sort of thing. The guy who was running the master's program, at the time, and I'm sure anybody else who takes over that program will be morbidly concerned about quality — being able to say we're a high-quality program, being able to say, here are the little bells and whistles here. The things that show that we are a high-quality program. Because we're not the law school, we're not the med school, we're not the business school, 
we're not STEM, and we're not football, so, and as it turns out, [my department] doesn't generate a lot in the way of grants. So why are we here? Okay. So, the more bells and whistles we can put on it, the better. So that's sort of an internal pressure. And so, I was told, not directly, but you know, it would be good if you could get your courses [QM certified] — this was said at the faculty meeting.

In this selection, Participant 3 situated his initial experience with Quality Matters within the context of academic freedom and faculty autonomy. He admitted that, as a result of this "privilege," he can generally go about his teaching without close supervision or influence. Quality Matters represented a break from this convention and a managerial intrusion on his autonomy. To him, the pursuit of quality was justified by his superiorsexplicitly or implicitly_-because his was not a high-profile program or one that brought in considerable money. His use of "bells and whistles" to describe Quality Matters certification connotes superficiality and meaninglessness - he seemed to say that QM was superfluous, a decoration. The priority was not improvement of the student experience. Rather, the emphasis - the "internal pressure" as he put it—was one of perception. This finding is consistent with Shore and Wright (2000), who noted that the neoliberal rationality undergirding the logic of auditing "encourages the displacement of a system based on autonomy and trust by one based on visibility and coercive accountability" ( $\mathrm{p}$. 566). No longer could Participant 3 be trusted to autonomously regulate the quality of the learning experience he created for students; he was being coerced into measures of accountability that were rendered visibly though Quality Matters certification.

Relating a similar experience, Participant 5, whose courses were due for their five-year Quality Matters re-certification, expressed that she engaged with Quality Matters for re-certification not for the improvement of her courses as she had the first time but because it was "pushed" on her: 
At this point, re-certification I did not do because I thought would make my courses better. I did it because the department, the college-I don't know at what level it was coming from - but they were really pushing: get your courses QM certified. And since I had already been through it, I thought, oh, it won't be that hard to resubmit...I honestly did it this time just because, you know, it was encouraged, so why not? I don't think it improved my courses this time around. (Participant 5)

This passage is telling because it portrays a longer-term experience with QM; Participant 5 had originally engaged with QM because of a sense that it would improve her courses. Five years later, her reasoning for re-certification was related more to having it "pushed" on her than it was any sense of meaningful improvement.

Despite the fact that most participants engaged with QM for reasons other than that it was required or "pushed" on them, some participants reflected on how they would feel if it were mandated or expected of them, given the possibility of quality goals emanating from the Florida Board of Governors (Florida Board of Governors, 2017, p. 2). Participant 4, for example, would be happy to oblige: "Now if the Board of [Governors] want it, then yes, I will. Every single online course, I will, of course.” Again, this evokes Shore and Wright (1999), who characterized neoliberal auditees as "selfactivating, free agents who have internalized the new normative framework" (p. 566). However, Participant 7, who had an overall positive experience with Quality Matters, was not keen on the idea of a mandate:

Participant 7: Now I'm not a big fan of coercion. You know, if you asked me, do I think we have to force everybody who is teaching online to go through it, I would say probably not, because I just don't see the same, improvement-oriented spirit among everybody. You know, when you start forcing everybody doing it on a large scale...I think actually...[hesitates] So I don't know how to scale it up in a way that is really a useful undertaking in the same way that it was useful to me when I was going through it, right? I'm not sure that forcing everybody to do it is actually going to have the same positive results all around. I'm not sure, but I don't know what would be the best way to do it. 
Interviewer: So, let's unpack this a little. Why do you think that if it were something that were mandated or required that it wouldn't have the same impact?

Participant 7: Once you mandate it, you basically need to scale up this entire operation, and you need a lot more reviewers and you need, you know, and everybody has to go through it. So basically, you know, you start getting into the zone of, you know, a lot of people serve as reviewers because they have to, not because they want to. And a lot of people are doing these things because they have to, not because they want to. And I don't know how much value you're getting when that's kind of the sentiment that is around it. You see what I mean? But again, but I don't know how to make everybody want to do it. I don't know. Right? I wanted to do it because I thought it was cool. I wanted to improve. I had a great instructional designer. So, you know, I don't know. Maybe the answer is to have great instructional designers for everybody, you know? But how many great instructional designers do we have? I don't know. (Participant 7)

Participant 7 raised several issues. He questioned if Quality Matters, as implemented at this institution, was reasonably scalable. However, he also suggested that, implemented at scale resulting from a mandate, $\mathrm{QM}$ would not have the same impact because faculty members would not be engaging with an "improvement-oriented spirit." To me, this insinuates the possibility that it is possible to merely perform quality-a theme that will be addressed in a later section of this chapter. Curiously, Participant 7 seemed to think that reviewers are required to be involved in the process; however, external QM reviewers opt into the process and are paid a stipend for their services. Furthermore, the role of instructional designers in the Quality Matters process described by Participant 7 will also be discussed in detail in a later section of this chapter.

Participant 6, who may have expressed the most skepticism about QM among all my research participants, explained how she would respond in the context of a Quality Matters mandate, given her administrative position in her department:

I would go through with it, and I would encourage others in the department to go through with it because, you know, [administrative title in her department]. I kind of have to lead by example. And I would put my classes through QM. I'd make 
the changes they recommend...If they mandate going through with it, I'll go through with it. I may not necessarily keep the changes because I don't [hesitates] believe in the philosophy behind their rubric. You know, I don't think that it's just checking a whole bunch of boxes in a course and "Okay, you meet the standards, you're good to go." I don't think that QM really gives you an idea of what the quality of the course is like. (Participant 6)

Here, Participant 6 noted that, despite serious misgivings about Quality Matters, she would "lead by example" and actively encourage others to pursue it as a result of her administrative leadership role in her department. Again, the performative aspect to which Participant 6 alluded—not keeping the course changes recommended by the Quality Matters reviewers-will also be discussed later section in this chapter.

Quality Matters occupies an anomalous position in the landscape of quality assurance in higher education in its optionality. Accordingly, motivations for pursuing an optional quality assurance program are not well established in the existing literature as discussed in Chapter II, which presumes that quality assurance mechanisms are required, typically as part of an accreditation process or legislative mandate. The findings of this study in relation to the second research question-what motivated participating faculty members to pursue Quality Matters certification?—revealed that some faculty members engaged with Quality Matters because of a perception that it represented an indicator of prestige, recognition, and distinction. Others pursued Quality Matters certification because their academic department offered a financial incentive. These first two major findings were deeply segmented on the basis of faculty rank; the adjunct professors who participated in this study ascribed far more emphasis on both QM as an indicator of recognition and on the financial incentive than did the full-time and tenured or tenuretrack faculty. This finding presents a troubling possibility that contingent faculty are 
being leveraged for their precarious positions in order to pursue an agenda of quality. In less frequent instances among the participants in this study, Quality Matters was presented to them as a mandate or expectation. In those cases, QM was positioned as an incursion on professional autonomy and something that had become a part of the professional conditions of working in the academy, findings which are consistent with the literature on other forms of quality assurance in higher education (Barrow, 1999; Filippakou, 2011; Morley, 2003; Worthington and Hodgson, 2005). Quality Matters reflects, in these instances, what Shore and Wright (2000) coined "coercive accountability" (p. 566).

\section{Negotiating, Maneuvering, and Resisting QM}

The third research question of this study asked how have participating faculty members negotiated, maneuvered, and/or resisted the QM program and process? This part of the study was informed by the literature on how quality audit practices in higher education serve as articulations of power (Brennan \& Shah, 2000; Cheng, 2010; Filippakou, 2011; Morley, 2003; Shore \& Wright, 1999, 2000; Worthington \& Hodgson, 2005), how faculty members maneuver and resist these mechanisms (Anderson, 2006; Barrow, 1999; Newton, 1999, 2000, 2002; Worthington \& Hodgson, 2005), and how organizations and actors deal with techniques of audit (Power, 1997). The major theme I identified in relation to this research question was that participants in this study relied heavily on decoupling. Furthermore, participants in this study related how they engaged in various types of performance in order to either meet or circumvent the requirements of a Quality Matters review. 


\section{Decoupling: The Good Thing About the Way FIU Went Through It}

According to Power (1997), audits can only be conducted when an auditable performance is defined through performance standards: "audits work because organizations have literally been made auditable; audit demands the environment, in the form of systems, and performance measures, which makes a certain style of verification possible" (p. 91). In understanding Quality Matters as an audit practice, the auditee is the faculty member and the online course, stripped of all student data and artifacts, embodies the audited performance. The organizational structure in which the audit takes place may be tailored in such a way that supports audit practices. Power (1997) described decoupling as a process by which organizations create distinct and purposeful sub-units for dealing with and managing external audits. In this way, the audit process becomes remote from the operational practices for which it is intended to account, possibly leading to a managed ritualistic or dramaturgical performance. Decoupling buffers the audit process from the auditee; it occurs because "individuals are infinitely more complex and adaptable than normalizing attempts to measure and control them" (p. 120).

One major theme of my study in relation to the question on how participants navigated and maneuvered Quality Matters, described in this section, was that they relied heavily on a decoupled organizational structure in order to successfully complete the Quality Matters review. All eight research participants described the involvement and support of an instructional designer in the Quality Matters review process, and three participants noted the involvement of a quality assurance manager at the institution.

In higher education, the job title "instructional designer" can refer to many different, distinct roles, ranging from an instructional consultant and faculty developer to 
a role involving production or technical support of online courses (Acevedo \& Roque, 2019). Participants in this study described instructional designers in the context of the latter's roles in relation to supporting, enabling, and preparing for the Quality Matters review in such a way that their involvement was not only crucial but necessary for the successful completion of the review. Essentially, much of the responsibility for the audit was not carried out by the auditee, the faculty member. Through a decoupled structure involving instructional designers in a production role and a quality assurance manager, the burden of the Quality Matters audit was partially buffered from the course instructors.

Participant 3 noted, succinctly, "The good thing about the way FIU went through it is that [instructional designer's name] did almost all the work." Later in the interview, he elaborated:

[It] was done mostly by [instructional designer's name], who said, "Does it meet the checklist?" And she sends back this long, long thing with everything highlighted and then I got to go through and fix this and that and this and that and this and that, and give her the material in the proper format. You know, where are the modules? You need to restate this, you need to have this in this subsection. Right. And so, she has a checklist. Right. And I'm trying to meet her checklist and trying not to fight with her, right? Because I know she's, you know, she's doing her best and so it's "Okay, [instructional designer's name], what do you need?" (Participant 3)

Participant 3's experiences closely reflected decoupling: the instructional designer, who was not the auditee, handled most of the work required for the audit. His indication that part of the process included "trying not to fight with her" further highlights his hesitance in the process and underscores the coercive nature of the quality audit process (Shore and Wright 1999, 2000). Participant 1 also noted the back-and-forth interaction with an instructional designer involving a checklist: 
The instructional designer mentioned QM to me when we went through it for the first time and then they advise you, you should wait one semester until the course was taught once, right? So that everything's ready and you know, it's good quality, I guess. Right. Oftentimes there's already QM in mind when the course is designed now, after the first time. Then the process is that the instructor and instructional designer will talk and the instructional designer then says, okay, let me look through the course to see if it's good - if it's up to QM rubrics, I guess. Then after she did that, she oftentimes comes up with a list. Okay, these are some things that identified that we need to work on in order to get it QM-ready. (Participant 1)

Participant 1 noted that the instructional designer inspected the course and generated the checklist of things that "we need to work on." While Participant 1 was the instructor of record for the course, the responsibility for the audit was shared with the instructional designer, who represented part of the decoupled organization. Participant 8 described the interaction with an instructional designer as less collaborative and more unilateral:

Interviewer: You mentioned working with an instructional designer. Can you tell me more about their role in the process?

Participant 8: They're very helpful because they knew exactly what you needed to meet QM. So, they would tell me what I needed and I would do it.

[laughs]....They told me and I did it. I was very obedient. So, they told me what I needed to do, and I did it.

In this case, the instructional designer was "helpful," but the participant's own role was to be "obedient" and to do what was required of her, further highlighting the power dynamic inherent in the audit process.

Further illuminating the operation of the decoupled structure, some participants noted that instructional designers handled much of the technicalities required by the Quality Matters rubric and process. Participant 4 described the instructional designer's guidance on the Course Worksheet that was completed to begin the review process: "The designer sent me a form and with the form she also sent me suggested answers that were pretty much like, yes, this is what FIU does." Participant 7 also indicated that an 
instructional designer assisted with some of the paperwork and technicalities, both within the online course environment and without:

I think also having FIU Online support me this by kind of explaining things to me, taking care of a lot of the stuff inside the course, you know, like making sure that the learning objectives for each week are explicitly noted on Blackboard and things of that nature. And also taking care of the actual submissions to QM. My instructional designer actually went and submitted the course in the system, which I could've done myself as well. It's not a hard thing to do, but it's kind of nice to feel like you have that support system. I mean, it was my course. I know it inside out. I went to the review process. I responded to the reviews. I made the changes and all that stuff, but it was nice to have somebody to sometimes take care of a little bit of the paperwork. (Participant 7)

Later, he elaborated:

The instructional designer was more on the Blackboard functionality kind of a thing. So, for instance, one thing that I remember, QM wanted us to do is do kind of have an Excel spreadsheet that details the learning objectives of each module and how each assignment or quiz or exam corresponds to these learning outcomes. And so, I kind of see this pairing of what corresponds to what, but my instructional designer put it in a nice document and put it in a linked place on Blackboard that users can immediately see. So that was kind of nice. (Participant 7)

Participant 6 also noted that an instructional designer assisted with some of the technical

aspects the course that Quality Matters reviewers might look for:

My ID catches it whenever I upload a video and it has bad subtitles or it's missing subtitles. She catches it and she'll let me know. But it's made me more aware of, like, with my hybrid classes, where I don't necessarily have an ID assigned, it's made me more aware of.... I have to double check all the links and I have to make sure everything's working. (Participant 6)

These responses suggest that the instructional designers' responsibilities are wide ranging, from handling paperwork and forms to resolving technical matters in the learning management system. These reflect the bureaucratic requirements of the Quality Matters audit, and the responsibility for these requirements has been relegated through decoupling. 
As noted earlier, Quality Matters is an optional process for faculty members in most contexts at this institution. Some participants noted that they could not - and would not-have pursued Quality Matters certification if it were not for the contributions of an instructional designer. For example, in a follow-up question, I asked Participant 2 if he could have gone through QM without an instructional designer. He replied:

Honestly, no, because, at the time that they had mentioned QM, I had not heard about it. And the first instructional designer I had, she was really helpful working with me.... We got along really well and she was really just giving me a clear-cut explanation of what QM is and what each of those criteria had meant and what would I have to do to [meet] it. And so, I think if I didn't have an instructional designer, I wouldn't have had a QM-certified course when there were so many questions that I had off the top of my head and some of the criteria they had asked was not really that clear....So, if you were going to ask me, like, if I'm designing a QM course right now and if I would need an instructional designer, I would still say yes, because the instructional designer is more likely going to be kept up to date with any changes that have been made for QM. (Participant 2)

A similar, but briefer, exchange occurred with Participant 4:

Interviewer: So, do you think you could have gone through this process without the instructional designers that you've worked with?

Participant 4: No, and I probably would not have. It wasn't in my thought process to get it.

These accounts further highlight the decoupled organizational structure that supports Quality Matters audit. Not only were instructional designers integral to faculty members' successful engagement with it, these participants reported that they would not have pursued QM or even known about it; instructional designers were responsible for introducing it into their "thought process." This theme was echoed by other participants. For example, Participant 6 noted:

I forgot the name of my original instructional designer. I've had like seven instructional designers. The first one I had really pushed for Quality Matters. I think that's why I went through with it because she basically set everything up for me and she went through and filled out most of the rubrics for me and she told 
me, hey, I think your course meets QM standards, you know? You just need to tweak these things and go through it and make sure, you know, everything is ADA-compliant and all the links work and, you know, if you can add an objective here and there, it would, it would increase it. So, her doing that is what pushed me to seek QM for it. (Participant 6)

Participant 7 had a similar experience:

At FIU, we work with instructional designers for our online courses, as I'm sure you know, and my instructional designer suggested that we looked into this and try to get it to the QM level because it helps improve the course. And I looked into it. It kind of made sense. My instructional designer was very good about taking care of most of the kind-of-behind-the-scenes technical adjustments that need to be made to the course shell. So, I was okay with it because again because, you know, I had the support of my instructional designer and you know those kinds of those things. (Participant 7).

In this decoupled structure by which instructional designers supported faculty members though an optional audit process, the coercive nature of audits is realized through the way instructional designers evoked the programmatic element of Quality Matters - improving the quality of the course - while simultaneously reassuring faculty members that most of the process will be handled on their behalf.

In the previous section of this chapter, I explored participants' motivations for pursuing Quality Matters, intentionally leaving out one theme that was more relevant in this section on decoupling: engaging in Quality Matters for the benefit of an instructional designer. This aspect of faculty members' interactions with the instructional designers was particularly unexpected and surprising for me. As one of his motivations for engaging in QM, Participant 1 noted:

And I mean there's other, I guess, more altruistic aspects like, it's good for the instructional designer you work with. It looks good for them, right? I'm not sure that they get $\$ 500$ out of it, but they get badges, I know, and bragging rights. And it looks good for, you know, when they do their annual evaluation, which I'm sure they do. So, they might have certain goals like getting so many percent of their courses QM'd. (Participant 1) 
Similarly, the instructional designer's benefit was the first motivation mentioned by Participant 4:

Interviewer: Why did you decide to pursue Quality Matters for your course?

Participant 4: The designer, both of them — and I've had different ones each time-I know they strive to do very good work. And I do know that this is also part of - at least I felt it was part of - their evaluation for their work.

Later, she added, "I felt it was important to the designer, and that was pretty much the impetus that got me to do it." To summarize this logic: A voluntary audit process-in this case, Quality Matters - exists to verify and certify the quality of an online course. To facilitate the process, the organization has undergone a process of decoupling, in which part of the organization is responsible for managing the audit process. These auditees then report engaging in the audit (at least partly) for the benefit of the individuals involved in managing the audit process. I have a hard time making sense of this. On one hand, I find the altruistic, human element of this logic genuinely touching. From an organizational perspective, I am intrigued and befuddled by this as a motivation for engaging in a voluntary audit process, particularly one that may result in material changes to one's teaching. The audit apparatus has twisted itself inward. Is this some sort of recursive decoupling? Or is it Stockholm Syndrome? There is no literature that firmly supports this logic, aside from perhaps the findings of Filippakou (2011), who noted that quality-related practices had become a normal and accepted part of university life for faculty; perhaps Participant 1 and Participant 4 had internalized the normalization of audit and engaging in $\mathrm{QM}$ was seen to them as inconsequential.

In addition to working with an instructional designer, four participants noted the involvement of a quality assurance manager at FIU, although some only knew her by 
name rather than by title. Her role, to some, was opaque or elusive. Participant 5

mentioned the quality assurance manager in passing, and I asked, as a probing question,

if she knew specifically about the quality assurance manager's role in the process. She

admitted she did not:

I don't, really. You know, I don't really quite know what she does. I feel like she's, you know, sort of the FIU QM God person that, you know...she goes through [the course] with a fine-tooth comb and makes sure it looks good before she puts it out there. You know, to keep FIU courses sharp, which is a great thing. I mean the committees, both review committees that I interacted with the summer were like, "Oh, you're from FIU. FIU Online is amazing. Of course, your course is great, you know, because they are great and, you know, you have such awesome support and also instructional designers," you know? So, I think because of [the quality assurance manager's] role, FIU has this awesome reputation. So, I guess I view her job is keeping FIU's reputation positive by, by being the...you know, giving it the once over before it goes through. And I don't know what else she does. (Participant 5)

Participant 6 noted the quality assurance manager's role in promoting Quality Matters around the institution:

The last time I went through [Quality Matters], it was more of a conversation I had at the FIU Online Conference with [the quality assurance manager], where she asked me if all my courses were QM'd, and I was like, well, about half of them are. You know, I haven't done it for these five classes yet. And she had emailed me a few times, "Hey, are you going to QM your class?" Back then I had [name redacted] as my ID and he's amazing. But he wasn't the one pushing me. It was more [the quality assurance manager] saying, can you...you should go after QM. (Participant 6)

Participant 8 similarly described the details of her own meeting with the quality assurance manager:

I had to meet with the QM person here and have her go through the whole process. She told me what to expect from this time on...So in that meeting, she came out with a checklist of other things I needed to do and what... how my course needed to be structured. She also informed me that there will be a shell, like a dummy course, that will be available to the subject matter experts who would go through it from the point of view of a student. (Participant 8) 
As these responses illustrate, part of the decoupled organization that supports the Quality Matters audit at this institution involves a dedicated manager who inspects the course separately from and in addition to the instructional designers' involvement. Her role also involves promoting Quality Matters to faculty within the institution and promoting the institution's reputation in the broader community. Furthermore, Participant 5's idea of the quality assurance manager as "QM God," connoting omnipotence and omniscience, is the ultimate indication of the power relations inherent in Quality Matters.

Participant 1 had a clearer understanding of the quality assurance manager's role in the organization and the process. His explanation also gives a better sense of the quality management apparatus put in place as a result of decoupling: to begin the QM process, he completed an online form on the institution's website, which triggered the quality assurance manager to conduct an initial review. The quality assurance manager's changes were then sent back to instructional designer and faculty member to rectify. All of this took place before the course was sent to the official QM review board:

I go there to the webpage, fill it out. It's a very easy form. Not [much] information is required, and that goes out to the quality assurance manager, which is - you asked about me instructional designers - so that's separate, right? And then I think from there, the instructional designer is not really involved anymore. They're kept in the know by being copied by the quality assurance manager. She will review the course then and see on her part if there's anything that she feels that is not QM-ready yet. And then it might go back to the instructional designer, which I did last time. And then the instructional designer and I met, which wasn't the case for all QM courses. Sometimes we didn't meet during the second or third QM course. But now recently the QM changed their rubric slightly. They added some more things. So, I guess that was a reason why we met, as well, and why the quality assurance manager noticed some things that are not up to QM standards, because also the standard sort of changed-ish. (Participant 1)

Once these changes were complete, the quality assurance manager was responsible for working through the Quality Matters pool of reviewers to find a review board: 
The quality assurance manager puts together a team. So, I've heard for some people that takes a long time. Like for me, I think the longest it might've taken once was maybe two months. And for others I've heard it could take maybe half a year. I would probably be frustrated if it took that long. But, for me, my experience was they always found someone. Recently during the fourth course that's now under QM review, the quality assurance manager found them like within maybe a week even. Right. So, I was pleased with that. (Participant 1)

Results from my participant interviews illuminated the decoupled context of FIU in which they pursued Quality Matters. Without the apparatus that had been created to support the QM audit mechanism, involving instructional designers and a quality assurance manager, these faculty members likely would not have earned or attempted Quality Matters certification. Consistent with Power's (1997) description of decoupling, this audit management apparatus distances the audit practice from the auditee; much of the audited work is handled by others, namely one of many instructional designers who work at this institution and a quality assurance manager whose job is to manage the process. This decoupling represents a crucial aspect of how faculty members at this institution navigated and maneuvered the Quality Matters process.

\section{Performing Quality: It Was All About Repackaging}

Critical to an understanding of how faculty members maneuver and negotiate Quality Matters is insight as to how they perform quality. Power (1997) noted that audit practices operate through the examination of auditable performances. For Quality Matters, the audit examines the performance embodied in the online course containing the course syllabus, instructional materials, assignments and tests, discussion prompts, and meta-instructional items (e.g. instructions, lists of learning objectives, rubrics, and policies). However, the performance required by audit can be considered distinct, but related, to a distinct type of performance that is characterized by ritual, inauthenticity, 
perfunctoriness, or simply going through the motions. Barrow (1999) referred to this as a dramaturgical performance, in which "the sum of this compliance is not the achievement of the outcomes defined by the institutions as being quality in higher education, nor ongoing quality improvement" (pp. 32-33), further suggesting that "a culture of dramaturgical compliance is perhaps an almost inevitable consequence" of quality assurance (p. 33).

Some research participants suggested to me that aspects of navigating the Quality Matters program involved simply meeting the QM rubric or process requirements for their own sake, not for improvement in the quality of their courses. In several instances, this intersected with what participants described as the "technicalities" of Quality Matters. Participant 1 noted, at the outset, going through the motions with the required conference call with the review panel:

I think the most it might've taken was 20 minutes, and I don't know if that was actually ever necessary. Perhaps they prepared the course so well at FIU....Perhaps if I had a course that wasn't as well prepared, that would be a longer call with more questions, but the last time - that was, like, just last weekthey run any questions by [you], you know, and I knew two out of the three reviewers from before already. There was a third one that was sort of education focused - a sidekick. And she didn't have any questions either. Right. So, the only question was whether I had a question for them, and then I didn't, right? So, it was sort of superfluous. It wasn't really necessary, but it's part of the review process. So, we did it to satisfy their process. (Participant 1)

Later, when I asked him about the extent to which he applied the QM logic of objectives and alignment (discussed further in the next section) in his other teaching contexts, he responded, simply, "I mean, the thing with aligning objectives to assessments, I'm only doing because of QM basically, right?” These responses suggest that he attributed little 
value to either the QM process or the overall logic of the QM rubric, which heavily emphasizes "the thing with aligning objectives to assessments."

Participant 4 also mentioned the performative aspect of the initial conference call with the review panel. She described being nervous about the call for her first QM review for fear of giving the panel incorrect answers, although she also intimated that she was coached by FIU staff in preparation for the call:

Interviewer: So, you had some concerns going into the first [conference call]?

Participant 4: That I might not have the right answers or I might say answers that were...not that I was prompted by anybody, but they [FIU staff] would say this is what they're going to do, this is what they're going to say. And it was like, okay, and I just don't want... when people give me those kind of preparation things, it's like, well, that's what they wanted me to say, but this is what I wanted to say. So, which is it that I should [say], you know? This is what I thought I should say versus what they had wanted me to say. So, it's just sometimes I just say what I want to say, but if it's contrary or negative, then I usually listen to what I'm told to say.

Interviewer: So, who was telling you what to say?

Participant 4: Oh, not what to say, but this is what they will be asking. Because I do ask, I do say what's it going to be like and, and what kind of answers should I give?

These statements are positioned at the intersection of decoupling, discussed in the previous section, and performance; FIU staff-either the instructional designer or the quality assurance manager-prepared Participant 4 for her initial conference call with the review panel. Although she seemed to equivocate in her responses, it appeared as though she was given stock answers for the call.

Participant 7 explained that he made some adjustments to the course solely to satisfy the review requirements, despite feeling as though they did not reflect meaningful improvements in his course: 
Not everything about QM is good. There's a lot of stuff that feels more like it's just, you know, a bureaucratic checklist, in that sense....For QM, there's, like, this list of - a long list — of things that you need to show in order to get a passing grade or a grade by the reviewers. And a lot of those things felt like they were reasonable, and they made sense. But, you know, part of it was, it felt like, you know, whether we did this or didn't do this is it, I don't know that it makes an improvement in the course and so, but that's okay. You know, you take those things because the other stuff as a package. (Participant 7)

He circled back to this later in our conversation in the context of the feedback provided by the reviewers:

I think there were a few instances where I wasn't sure how much value there will be in a given suggestion or comment. There weren't too many of those. But it's just like when you try to publish a paper and you get peer review, right? Peer review means that people are going to review your work and give you comments based on what they think will make it better. And many times, you agree with the reviewers. Many times, you think this is not necessarily going to improve the manuscript, but it also doesn't hurt. So, I don't think there was anything that the reviewers said or asked that we do that, I thought would make the course worse. Usually I was fine with what they were asking. Sometimes I felt like, you know, it's a wash whether you do it, whether you don't do it. So, in the end, I was fine with basically everything they wanted. Because it was either a positive or neutral from my perspective. (Participant 7)

Participant 7's admission of making changes to his courses only to satisfy the requirements of the Quality Matters review is reflective of the ritualistic aspects of performance. He related this practice to peer review for a scholarly publication; as a tenure-track assistant professor, he has been socialized in a system that rewards making concessions of dubious value and deferring to others for the sake of acceptance.

While Participant 7 changed aspects of his course he thought were immaterial, Participant 3 changed an element of his course he explicitly disagreed with; he noted that, despite his objections, he added a reference bibliography to his course to satisfy the QM review. Other than that, he made no substantive changes to his course aside from "repackaging" what he already had to fit the QM-compliant course structure: 
My perception is that...QM is really about quality through structure. Here are the things you have to have. Here's the format they have to be in. I don't think I changed any of the content, except for maybe they wanted a more extensive bibliography. I have, generally speaking, especially in the class that was QM certified, I have tried to avoid giving bibliographies because it's not - these aren't research courses, right? I understand that if, if you have a research-based course, there's only so much of the literature you can cover. You presume the students are pursuing their own research agendas, giving them additional bibliographical sources is the appropriate thing to do. The course I taught online is part of our [degree] program that is not a research program. It is a professional program. So, the idea is not to send the students out to do more and to gather more and to assess the literature. It is instead to give them practical techniques that they can use in their jobs.... That can be conveyed via the Internet, I think, and still be useful, but it doesn't require an extensive bibliography. In fact, my goal is to, as I say, just please read the things I've assigned you. Just read that, just those things.... I didn't want to put a bibliography in there at all, but as part of QM, I need to. So that's what I added. But that was the only change in substance to what I did. (Participant 3)

He continued:

The rest of it seemed to be focused on two areas. One was how it was broken up and grouped and organized - the creation of the modules, which I thought I had done anyway by saying we're organized in three phases organized around or based on the books that we're reading, but they wanted me to, you know, make it even clearer that it was this module this module and this module.... And then there had to be some coordination between objectives for the course and objectives for each module. Well, at the time, what that felt like, mainly, was just a pain in the neck. But I sorta knew these things anyway. But articulating them and then putting them in this - and I know it's the right thing to do, but it's still a pain in the neck-Bloom's taxonomy. It's always got to be organized according to that guy's ideas. Oh, okay. All right. So, then I got to bend over backwards to try to frame what I already have. In no case did it compel me to redo the substance or to redo the assignments. It was all about repackaging. (Participant 3)

He later reflected on the performative aspect of engaging with Quality Matters:

Overall, in my experience it was more, it was - it almost felt like filling out the paperwork. I just had to fill out the paperwork and show [them] that I filled out the paperwork and I had to go to Staples and get lots of colored tabs and put them in there and have it color-coded and cross referenced and everything. (Participant 3)

Participant 3's colorful portrayal of his performance for Quality Matters was consistent with findings by Barrow (1999), who noted the dramaturgical performance associated 
with abiding by quality assurance mechanisms, and also those of Newton (2002), who described faculty members' "sterile and ritual" theater-like performativity and gameplaying (p. 40). Participant 3's deliberate use of the word "repackaging" to describe his approach to meeting the Quality Matters audit highlights the emptiness of the whole exercise; for the most part, he changed nothing of substance. However, the fact that he capitulated over the bibliography — something he has "tried to avoid" because it felt it at odds with the context of the course and the students—-demonstrates that, ultimately, he was unable to fully resist the coercive encroachment on his professional autonomy.

The severest form of performativity in response to Quality Matters described by my research participants was expressed by Participant 6 , who related a particular form of resistance she employed against the feedback with which she disagreed: She made changes to the copy of the course used for the QM review but reverted those changes for her live course for students:

I made some tweaks to the course based on their feedback. They wanted me to do more low-stakes assignments. So, I did things like I removed the group contract because they didn't like that. I put it right back in after it was QM certified because $I$ understand why it was there. But I did do some tweaks to the course in order to get them to pass it. They wanted the objectives made more concrete. Which is fine. But in a 4000-level class I don't like, you know, define, select. I like, you know, I want them to compare and contrast and do deeper-level thinking. You know, apply this to your life kind of things. And yeah, they made them lower-level objectives and they, you know, [said] "Oh you don't, you don't have them exactly doing these things." Well I kinda do, in the project. They're doing it in the discussion. They're doing it, but it's not, you know... I guess it wasn't clearly defined enough for them. So, I had a challenging time with the last two courses because they were really...the people doing the reviews weren't subject matter experts. They didn't get how I designed the courses, those two courses. (Participant 6) 
Because this exceptional means of resistance to Quality Matters - manufacturing a false performance for the audit's sake - was unprecedented after the interviews I conducted prior to this one, I made sure to clarify and further explore with her:

Interviewer: I just want to make sure I'm understanding this correctly: you made some tweaks for the review, but when the review was over, you went right back to what you were doing before?

Participant 6: Yes.

Interviewer: Okay.

Participant 6: Yeah. Because they don't follow up and make sure that you keep all of the things that they want you to do. And some of the things they said —okay, so for [one] course I'm teaching, they told me that I should add a whole bunch of quizzes in there. It's a [seminar] course where they're working on a group project and they're discussing. If I taught on campus, I'd have them sit in a circle and talk. I wouldn't hand out Scantrons. So, it just didn't feel like a really good match to what I wanted to do. I didn't use quizzes, I used StudyMate [an interactive flashcard tool] because they wanted low-stakes assignments because they didn't like how my discussions were worth 50 percent of the grade. It's a seminar class! They're supposed to discuss! That's what you do when you're sitting in a seminar. You get points based on whether you show up and discuss. So, I think I switched it up so the StudyMates, where [students] created questions based on the materials, was worth, like, 20 percent of the grade, and they said they were going to put it through with that.

Interviewer: Is that something you would've kept in the actual course?

Participant 6: No. Quizzes are not helpful.

Interviewer: Even the StudyMate?

Participant 6: Even the StudyMate. I don't find that it increases the student learning.

Participant 6's blatant resistance to the mechanisms of Quality Matters, realized through a staged performance, was reminiscent of what Newton (2002) called game-playing.

Participant 6 produced what she had to in order to satisfy QM but ultimately did 
something different in her live course - something she thought was better for her students.

These results demonstrate that nearly all of the faculty members I interviewed related some performative aspect of their engagement with Quality Matters, consistent with the findings of Barrow (1999) and Newton (2000). Some participants reported complying with the reviewers' feedback and suggestions despite mixed feelings about their usefulness or meaningfulness. In Participant 6's case, she intentionally manufactured a false performance for the sake of the Quality Matters review as a way to resist and subvert the process.

The findings of this study in relation to the third research question-how have participating faculty members negotiated, maneuvered, and/or resisted the QM program and process? - illustrate that faculty members relied heavily on a decoupled organizational structure involving instructional designers and a quality assurance manager who relieved faculty members of much of the responsibility and burden of the audit. Some participants noted that they would not or could not have engaged with Quality Matters without this decoupled structure in place. Furthermore, participants in this study related how they engaged in various types of performance in order to either meet or circumvent the requirements of a Quality Matters review.

\section{Impacts and Significance of QM}

The fourth and final research question of this study asked what impacts and significance do these faculty members ascribe to Quality Matters? As discussed in Chapter II, within the existing literature on the faculty members' perceptions of the impact of teaching quality assurance mechanisms, perspectives are decidedly mixed 
(D'Andrea, 2007; De Vincenzi, Garau, \& Guaglianone, 2018; Jones, 2003; Pham, 2018;

Tavares, Sin, Videira, \& Amaral, 2017). In the course of my conversations with my research participants, I asked them what they thought were the most notable aspects of going through the Quality Matters process. As with some of the other questions, answers varied widely. Participant 1, for example, joked, "The impacts for students? Well, they get a happier instructor because I get $\$ 500$ now [laughs]." Participant 6 felt that, as a result of changes made to satisfy a QM review, she fielded fewer questions from students requesting clarification:

It was extremely helpful when I taught the class again, I got a lot less questions from students asking, you know, what are we supposed to do? Because the QM review helped me to clarify the directions in the course and make the assignments a lot more transparent.... So, the first time I went through [QM], there was a decrease in the number of questions students were emailing me that could've been answered by looking at the syllabus or by navigating through the course more. So that was a definite positive. (Participant 6)

Participant 8 simply appreciated the fact that her course was QM certified, which, for her, served as a sort of shorthand for telling others about the features of her course:

Interviewer: For you, what have been the most notable impacts of going through QM? Good or bad?

Participant 8: I like the fact that I could say it's QM-certified.... If you have a product that's certified to do a certain thing - then instead of explaining what you offer your online students, it's easier to say it's QM-certified. Then they can see what it offers to the students. So, it reduces the conversation from an hour to a couple of seconds. Like, what do you offer in your online course? Oh, it's QMcertified. Then they can look it up. I don't have to go through, "I do this with the students then we would say this way. I offer quizzes. They have discussions and this is what they have to do."

Interviewer: And that would be conversations with the students?

Participant 8: No, with other professors. Or with my chairperson. If he's wondering, well, what are you offering in your online class? How is your online class structured? It's QM-certified, and then he knows what it offers. 
While answers to this question were diverse, I identified two major, recurrent themes I identified relating to this research question: colonization and reflection. The remainder of this section will explore these themes.

\section{Colonization: I Can't Imagine a World Without QM}

Colonization is result of audit practices in which "the values and practices which make auditing possible penetrate deep into the core of organizational operations" (Power, 1997, p. 97), leading to "new mentalities, new incentives and perceptions of significance" (p. 97). Under colonization, "new forms of organizational language become institutionalized [and] percolate into domains even where active decoupling is pursued" (p. 120). Colonization occurs when the logic that defines the auditable performance becomes imbedded in the everyday practices of the auditee. The results of my interviews with research participants demonstrated that colonization resulting from Quality Matters represented a major impact for them; the logic of Quality Matters permeated their professional practice across contexts.

No other aspect of Quality Matters demonstrates the colonizing logic of QM more than learning objectives. The Quality Matters rubric presumes a particular logic that prioritizes, above anything else, alignment between course- and unit-level learning objectives and other aspects of an online course, so much so that a special "Alignment" icon is used in the QM Rubric Workbook for pertinent standards. According to the introduction to the QM Rubric Workbook (Quality Matters, 2018a):

Critical course components - learning objectives $(2.1,2.2)$, assessment (3.1), instructional materials (4.1), learning activities (5.1), and course technology (6.1) - reinforce one another to ensure that learners achieve the desired learning outcomes. When aligned, assessments, instructional materials, learning activities, and course technologies are directly tied to and support the learning objectives. 
Look for the Alignment symbol that indicates the Specific Review Standards included in the principle of Alignment. (p. 5)

The emphasis that Quality Matters places on (and that the logic of QM relies on) measurable learning objectives cannot be overstated. Quality Matters Standard 2: Learning Objectives is the only General Standard for which all Specific Review Standards (in this case, five) are valued at three points, making compliance with them mandatory for successful completion of a QM review. In the Rubric Workbook, the annotations for Standard 2.1 ("The course learning objectives, or course/program competencies, describe outcomes that are measurable") issue nearly a page and a half of guidance pertaining to what learning objective language is suitable to satisfy Quality Matters. For instance, including a learning objective that reads "Upon completion of the course (module/unit), learners will be able to: ... demonstrate understanding of the role of digital marketing" (p. 15) is sufficient cause for a Quality Matters review to fail because "these types of learning outcomes are very difficult, if not impossible, to measure" ( $p$ 15). Measurable learning objectives, to QM, utilize verbs that are demonstrable and measurable and associated with the different levels of Bloom's Taxonomy.

The use of learning objectives as an element of a course design process is well documented (Dick, Carey, \& Carey, 2009; Mager, 1962). Learning objectives can guide and inform the development of courses, materials, activities, and assessments. However, this logic is twisted and reversed by Quality Matters. Quality Matters does not examine if learning objectives were used to inform course design; QM assesses whether learning objectives are written as though they were used to inform course design — specifically a 
kind of transferable-skill-focused course design that is privileged by QM. The priority is simply the language used.

The colonization of this logic into my research participants' practices and priorities was evident. Nearly all of them brought up learning objectives and alignment in relation to their experience with Quality Matters, unprompted by me. Some participants described learning objectives as integral to their teaching practice, while others were more skeptical of QM's emphasis on learning objectives.

Participant 2, using a business plan as example, explained that the emphasis on learning objectives was something he admired:

What I did admire was how many objectives had to be measurable and you had to have activities and assessments that were matching those objectives, which makes sense. Because if you're going to be telling a student that one of the objectives is that you will be able to come up with a business plan, but you have nothing in the course that actually gives them the chance to compose a business plan, how is this really an objective? How would you even know if they have been able to come up with a business plan? (Participant 2).

However, later in our conversation, he expressed some frustration with the technicalities

surrounding inclusion of QM-approved learning objectives:

So, you had course objectives and then there were modular objectives. And what I was trying to decipher then was, so I can have an objective within a module that is different from what is to get into the course objective, but if they also need to meet these course objectives. I mean, what happens if there seems to be this inconsistency? Or can the modular objectives at least lead up to the course objectives? And maybe, if anything, it can lead to learning outcomes. So, if I only didn't put the learning outcomes or the course goals, like what students would be doing after completion of the course, their expectations, maybe it leads towards that. And I just thought at that point...I'll be honest and [say] that it was...it seemed tedious in that if we already have the course objectives and here are the learning outcomes, modular objectives, okay, maybe I can see here where they're going to be fulfilling this goal. (Participant 2) 
Despite the frustration, he reported QM-approved learning objectives to be an important part of QM's impact on his teaching practice, particularly his ability to find noncompliant objectives, which related to part of his role as a staff member in his academic unit. He positioned this in relation to how he understood the pedagogical influence of QM:

Interviewer: Something you mentioned in passing was pedagogy. I'm interested if you can tell me a little more about how Quality Matters has influenced your teaching practice and your pedagogy.

Participant 2: One was the measurable outcomes, the objectives. And I didn't realize at the time was where... "Understand." Whenever I see this on the syllabus now - before I didn't mind it - whenever I see on the syllabus now, I say, "That's not a measurable objective, and the reason for this is because it's too broad, where it can be misleading for students." Like if, let's say, okay, an objective here is to understand how to make a souffle. What does that mean? Are you saying that the students are going to be learning about recipes and how to make a souffle? Are they going to be reviewing material and then taking a test on it to assess their understanding of how to make a souffle? Are they actually going to make a souffle, and that's how they'll understand it? And what would be the measuring, the measurement, or the score that actually [shows] that they understand the material?

Measurable learning objectives were also important to Participant 5 and a notable part of her experience with Quality Matters. When I asked her if she thought Quality Matters improved her courses, she replied:

Probably, just because I was much newer to online teaching and so some of the things that I hadn't really thought of, like, for example, measurable learning objectives. I don't think I had learning objectives in my courses prior to going through QM...The first time [I went through QM, years ago], it wasn't emphasized as much then, if I remember correctly, as it is now. Like, well make sure you're using these certain action verbs and things like that. It wasn't as emphasized, but still I was like, oh yeah, well that's a good idea to have objectives in my course, and you know, why didn't I think of that kind of thing? (Participant 5)

However, later she questioned if students read or care about learning objectives: 
Now do the students really care about those objectives? Do they...especially how we had them initially, just like lists, you know, do they, do they care? Do they look at them? I don't know. How I have them now, I'd like to think they're more beneficial for students. Because they're specifically there in a table and they're specifically linked, you know, how to master this objective, these assignments, and then evidence of mastery, such and such percent on that assignment or whatever. So, I'd like to think that now they help students understand why assignments are important. (Participant 5)

Despite this uncertainty, she still considered learning objectives to be an important part of going through Quality Matters.

Interviewer: What have been the most notable impacts [of going through QM]?

Participant 5: Okay, so initially, like I said, the incorporation of objectives and, this time, I guess, getting more to those action verbs that they're looking for. And, also, the big change that I made this time around is my objective tables. I'm linking them to assignments and showing, so students can look and say, "Okay, well in order to master this objective I need to do this assignment and I need to get this score on it." That's the main thing.

Participant 6 also expressed a similar skepticism regarding if her students read the

learning objectives and, more generally, apprehension with the degree to which Quality

Matters emphasizes learning objectives:

It's important [to QM] to have really clearly stated objectives, because that's one of the things they look at is how clear your objectives are, which I'm not really sure students ever look at or read...I don't think they're reading my objectives. I don't think they're sitting down and saying, "Okay, this is the outline, what the professor wants me to know. Let me read off these objectives. This is how the professor is assessing these objectives," which is very, very QM, right? You have to lay out your table with your objectives and how you're meeting those objectives. And I don't think...I mean, I know it's important to be transparent with students, but I don't think they need that level of: this is the objective your meeting by doing this assignment. I think that's a little too much... They drive you crazy with QM and the objectives. (Participant 6)

The skepticism that Participant 5 and Participant 6 noted regarding whether students read the learning objectives further underscores the problematic logic of the rubric. The QM 
audit strongly weighs these learning objectives and their form, but if they are not being read by anybody, their value is dubious.

Participant 3 noted that the requirement to provide learning objectives was helpful, but he described the performative aspects of complying with this requirement (discussed further in a previous section):

Insofar as there was anything really helpful about the QM process, it would have been this other requirement which was spell out the objectives of this modulenot mainly the course, but there had to be some coordination between objectives for the course and objectives for each module. Well, at the time, what that felt like, mainly, was just a pain in the neck. But I sorta knew these things anyway. But articulating them and then putting them in this - and I know it's the right thing to do, but it's still a pain in the neck-Bloom's Taxonomy. It's always got to be organized according to that guy's ideas. Oh, okay. All right. So, then I got to bend over backwards to try to frame what I already have. In no case did it compel me to redo the substance or to redo the assignments. It was all about repackaging. (Participant 3)

Despite his apparent frustrations with QM and, specifically, QM-compliant learning objectives, he further described how he has submitted to this logic, not only in his online course but also in other contexts:

Interviewer: Has Quality Matters impacted your teaching?

Participant 3: [groans and sighs] Oh, well, I use Bloom's Taxonomy a lot more than I used to [laughs]. I've just submitted a 2000-level course and you know, I'm generating the learning outcomes. I have an idea what they think they are, but I know...All right. And this wasn't QM, and it wasn't online, but, I thought, all right, somebody's gonna ask me about it. So, let me go look up the....and use the right words to phrase it. Put it in the right order. All right. Okay, got it. That's the way. Right. There are the...[hesitates] there's...there's protocol. You at least have to adhere to protocol.

His indication that "somebody's gonna ask [him] about it" and that he has to adhere to protocol is associated with Quality Matters highlights the powerful colonizing ability of the logic of the program. Quality Matters, in a sense, trained him to apply this logic to other contexts. Similarly, Participant 4 explained that the logic of aligning learning 
objectives to other aspects of her teaching has "flowed over" from her online courses to her face-to-face courses as a result of QM:

Interviewer: In preparation for your face-to-face classes that you've taught, do you go through the same sort of process with the objectives and the activities and the alignment?

Participant 4: Yes. It doesn't matter. That's why I said, the QM taught me how to do that, and that's how I've done it for each of them. So, I think it benefits me because then I have them [objectives] on a lineup and then it benefits them.

Interviewer: So, some of those QM practices have-

Participant 4: Yes, it flowed over.

Participant 7 noted the same carryover of QM logic to his face-to-face courses:

I think going through Quality Matters definitely put this transfer, gave it a boost...I think with Quality Matters there were [things that transferred]. For instance, the way I word my learning objectives. That is something that was an improvement that I went through with Quality Matters. And what I did is that I then reworded my learning objectives for my other [course], for my face-toface...I think basically once you go through the QM process, you kind of realize some of the frictions and areas of improvement that you can do through your course, and also as an instructor, that you can immediately transfer to you face-toface courses. (Participant 7)

These responses illustrate the ways in which learning objectives and alignment reflect a salient example of how the logic of Quality Matters has led to new forms of organizational language and perceptions of significance. In addition to this specific, notable aspect of the colonizing logic of QM, some participants noted that QM-type thinking, more broadly, had influenced them. When I asked Participant 1 if Quality Matters had impacted his teaching practice, he noted an interesting intersection between the colonizing logic of QM and the decoupled organizational context of the institution:

I think it did, but I was steered into the direction without me noticing that it did. So, I don't know if that's a good answer, but... [hesitates] I know the instructional designers are well versed in the QM rubrics and yes, I provide the content, but the truth is the instructional designer does a lot, right?...But they have a lot of ideas, 
and I know that they are trained to make the course already basically QM-ready, and they just need to tip the instructor into the direction of "You should, you know, QM a course or whatever. You know, it'll look good on your CV. You'll get \$500." But, so yeah, now that you asked me this question and as you can see, I just now started to think about it. I think, yes, it did influence me, but subconsciously, right? They steered me into the direction of caring about it, uh, because they already designed the course sort of QM-ready. (Participant 1)

Later, when I asked if he would be doing anything different if it were not for QM, he elaborated:

Well, as I said before, I think I'm doing some things QM-like because also other people at FIU Online care about that, right? So, the instructional designer cares about it. The quality assurance manager cares about it. Importantly, probably the supervisor of the instructional designer cares about it, right? Because they want to see that everything's QM-ready or QM'd. And the [Florida Board of Governors] likely will care about it as well...So, I think, you know, the answer to your question is: what's the alternative? I mean, it's alternative-less. QM is important, and it is the prime standard in the nation for quality in online courses. At least I don't know any other standard. So, I can't...I can't imagine a world without QM. (Participant 1)

Participant 1's note that there is no alternative to Quality Matters- “it's alternativeless" - and that he "can't imagine a world without QM" is striking. To him, the programmatic demands that warrant the audit practice can only be met by Quality Matters, implying that quality is objective and universally defined and that Quality Matters is the ultimate arbiter of that quality.

Two participants even suggested that the auditing practice of Quality Matters should be applied more broadly, such as in face-to-face courses:

There has to be something [that] we can take from QM that can be transferrable to other courses... There has to be some way we can just try to take from QM and apply it to hybrid and face-to-face. Maybe not have it come off as a new standard rubric, but maybe something that when, letting those who review syllabuses are just letting faculty know, like, here are some suggestions that we maybe think could work for your course but not have it come off as if, like, the course was terrible. But just to think about that and just to see if they would like to decide upon making that change. (Participant 2) 
[Online and face-to-face] are different, but they both should have that evaluation. And speaking of which, as far as me being evaluated for my teaching ability, having a QM is the online aspect, but did the students learn what they needed to learn? So, I still need to have that student evaluation tell them that they...however they perceived my teaching ability. Whereas the face-to-face, I just have their written [evaluations]. Something has to be improved there. So maybe having a person come in and watch your teaching more frequently would be able to be documented for the teaching ability for evaluation rather than the [student evaluations]...But we do need a different type of documentation for our teaching efforts. Student evals don't always cut it in that. But I think we need some other kind of documentation. So as far as QM to me, it's smack dab. (Participant 4)

These responses suggest that these participants' experiences with Quality Matters legitimized, to them, a peer review-based audit. While Lomas and Nicholls (2005) suggested that peer review of teaching held the potential to be a positive influence on teaching, they noted possible detriments, including challenges to academic freedom and professional autonomy, concerns about objectivity, and the possibility that peer review could be used as part of an accountability system. Peer review is discussed further in the next section.

As demonstrated in this section, the logic of Quality Matters, particularly the overwhelming emphasis on measurable learning objectives, has created new perceptions of significance and new mentalities for the participants in this study, reflecting Powers's (1997) description of colonization in the context of audit practices. For instance, with most participants, providing measurable learning objectives was not an important part of their teaching practice prior to engaging with Quality Matters, but engaging in QM led to the creation of new practices and new priorities for them. In some cases, the logic extended beyond the context of online courses and, as Participant 4 put it, "flowed over" into face-to-face courses. 


\section{Reflection: That Modicum of Mindfulness}

In addition to the colonizing logic of Quality Matters, one theme recurred frequently among several participants in relation to its overall impact—one that I think might be one of the more crucial takeaways about their experiences with QM: they mentioned that going through the Quality Matters process afforded them a meaningful opportunity for reflection on their teaching. Relatedly, some participants also noted that they found the peer review process a meaningful part of this reflection. Participant 5 suggested that QM was the impetus for her to be a reflective teacher:

I think about my teaching more, you know, having gone through initially a review process. It made me think that, oh yes, I should be critiquing my teaching constantly, and I should reach out to colleagues to help, you know, them, critique my teaching by asking questions.... So I think QM is sort of what got me going on the idea that yes, you should constantly be thinking about your teaching and constantly striving to improve it for the sake of students. (Participant 5)

Even Participant 3, among the more skeptical of my research participants, appreciated the "mindfulness" that QM prompted, although he was unsure if it was worth the time and effort in going through QM:

Anything that makes me more mindful of what I'm doing is probably a good thing. Take a minute, step back. Say, what am I really trying to do here? Is there a clear format? Is there a way that's expected? So, to ask myself a few questions, which is what I'm supposed to be doing all along for anything anyway. And so perhaps it has made me somewhat more mindful. Again, this is one of those things where you have to ask: for that modicum of mindfulness, was all that worth it? [laughs] I'm not sure the answer is yes, but insofar as there was a good thing that came out of it, it was a little bit more mindfulness. (Participant 3)

Participant 7 also expressed that the reflective aspects of Quality Matters were valuable for him:

I think QM helps instructors think about aspects of their course that they didn't think about before. And the other thing is that QM helps you create a very structured course that is kind of well thought through.... It quote-unquote "forces" 
you to go through a certain process of, I guess, kind of reflection and structuration of your course. The outcome is, I think, almost always a net positive. Again, some of the things you might do are neutral in the sense that, you know, they neither improved nor hurt the course. But you will almost certainly find ways in that where you can introduce some improvements, however incremental. And that's a good thing, right? So why not?...And again, it's not that QM has something magical about it. It's just that going through a process of peer review under certain general guidelines of what makes a course good that compelled [me] to take it to the next level. (Participant 7)

At the conclusion of our conversation, he circled back to the helpfulness of the peer review aspect of the $\mathrm{QM}$ process:

I don't want to sound like a champion of QM, right? Because again, my point is not that QM, itself, is some kind of a golden standard or the answer to everything. My point is that going through a process of peer review-independent peer review, right? - is helpful because it, you know, particularly peer review by people who are trained and engaged and really care and really go through the stuff and take the time to give you feedback on your course is helpful. It helps you get better and helps you see things that might not be working so well. And that's, that's the value. (Participant 7)

Participant 6 echoed these sentiments about the value in peer review of her course but felt that it was more meaningful to have colleagues review her course than QM reviewers:

I do find the peer feedback component helpful. It's just not necessarily having a stranger at QM. So, I'll ask other people to look at my course. So other instructors to go through my course or I'll have my TA, you know, go through and make sure all the links work, make sure that it's clear what I want them to do. Can you read over these announcements and make sure that it's clear exactly what assignment I want them to complete? You know, is it too wordy? The peer feedback is really valuable but not necessarily from Quality Matters. (Participant 6)

That several participants noted finding value and meaning in reflection and peer review of courses, although not necessarily tied to Quality Matters, is telling. Quality Matters is filling a void by providing a platform for collegial dialogue, feedback, and input into online teaching practice. This echoes Lomas and Nicholls's (2005) suggestion that "formative peer review can be a positive means of enhancing teaching and learning within the academic community" (p. 139). 
The findings of this study in relation to the fourth research question-what impacts and significance do these faculty members ascribe to Quality Matters?- suggest that, while participants had varied responses, two major themes recurred frequently: the colonizing logic of Quality Matters and the meaningful opportunity for reflection and peer review. The colonizing logic of Quality Matters can most readily be detected in how participants ascribed new significance to the importance of learning objectives and alignment to instructional materials and assessments, both major components of the Quality Matters rubric. Participants also highly valued the opportunity that QM provided to be self-reflective about their course and their teaching, something that some participants noted they would not have experienced or thought about otherwise.

\section{Summary}

This chapter presented the results of this qualitative interview study. I interviewed eight faculty members about their experiences with and perceptions of Quality Matters in pursuit of answers to the following research questions:

- What are the relations between the understandings of course quality among faculty members who have gone through the Quality Matters process and the criteria used by Quality Matters?

- What motivated them to pursue Quality Matters certification?

- How have they negotiated, maneuvered, and/or resisted the QM program and process?

- What impacts and significance do these faculty members ascribe to Quality Matters? 
The participants of this study were forthcoming and genuine. Analyzing the transcripts of our conversations, as well as several textual artifacts such Quality Matters websites, FIU websites, and the QM Rubric Workbook, I identified broad themes informed by the conceptual framework of the audit (Power, 1997; Shore and Wright, 1999, 2000).

Regarding participants' understandings of online course quality, I found that there was some overlap between the QM rubric items and faculty members' conceptualizations of quality, particularly in terms of course navigation and clarity of instructions. However, participants in this study also emphasized other factors of quality — those relating to course content, engagement and interaction, and student learning - which are not addressed by the Quality Matters rubric. Since there is a disparity between these ideas of quality, the programmatic goals of Quality Matters for assuring quality, and the technological elements of QM, I identified that an expectations gap exists in relation to participants' understandings of quality and the capabilities of the QM audit (Power, 1997).

Regarding what motivated participants to pursue Quality Matters certification I found that some faculty members engaged with QM because of a perception that it represented an indicator of prestige, recognition, and distinction. Others pursued Quality Matters certification because their academic department offered a financial incentive. In less frequent instances among the participants in this study, Quality Matters was presented to them as a mandate or expectation. In those cases, QM was positioned as an incursion on professional autonomy, reflecting what Shore and Wright (2000) coined “coercive accountability" (p. 566). 
In exploring how faculty members have negotiated, maneuvered, and resisted Quality Matters, I found that they relied heavily on a decoupled organizational structure involving instructional designers and a quality assurance manager who relieved them of much of the responsibility and burden of the audit. Some participants noted that they would not or could not have engaged with Quality Matters without this decoupled structure in place. Furthermore, participants in this study related how they engaged in various types of performance in order to either meet or circumvent the requirements of a Quality Matters review. Some of these performative aspects could be characterized as dramaturgical or simply going through the motions (Newton, 1999). In one notable case, the participant manufactured a fictional performance for the audit; she added things to the review version of the course solely to pass the QM review and then removed them for the version that students experienced.

The participants noted various factors relating to the impacts and significance of Quality Matters, but two major themes recurred: the colonizing logic of Quality Matters and the meaningful opportunity for reflection. Under colonization (Power, 1997), the logic that defines the auditable performance become imbedded in the everyday practices of the auditee. Participants noted applying the logic of Quality Matters to other contexts, and they demonstrated new perceptions of significance, particularly in terms of leaning objectives and alignment. Several participants also noted that QM afforded them a new opportunity to engage in reflection about their courses and their teaching, something they felt they did not otherwise have.

In the final chapter, I present the ultimate conclusion of the study and present possible future directions for research and practice. 


\section{CHAPTER V}

\section{SUMMARY AND DISCUSSION}

\section{Summary}

Partially influenced by my own background in working with instructional designers, faculty members, and Quality Matters, I began this study to explore and better understand the experiences and perspectives of faculty members who have engaged in the Quality Matters process. The purpose of this qualitative study was to explore how faculty members negotiate, maneuver, and resist the Quality Matters process, as well as the motivational factors, impacts, and significance that lead up to and followed their engagement with Quality Matters. Additionally, this study explored the relations between the standards of the Quality Matters rubric and faculty members' own conceptualizations of quality. The overarching research questions that drove and guided this study were:

- What are the relations between the understandings of course quality among faculty members who have gone through the Quality Matters process and the criteria used by Quality Matters?

- What motivated them to pursue Quality Matters certification?

- How have they negotiated, maneuvered, and/or resisted the QM program and process?

- What impacts and significance do these faculty members ascribe to Quality Matters?

To answer these research questions, I conducted open-ended, semi-structured interviews with eight faculty members who teach online at Florida International University and have had one or more of their courses pass a formal Quality Matters 
review. I analyzed the interview data I collected, as well as relevant textual data, such as the QM Rubric Workbook and QM websites, to identify relevant and salient themes pertaining to participants' experiences with the Quality Matters program. My study was informed and guided by Power's (1997) and Shore and Wright's (1999, 2000) scholarship on audits as an interpretive lens.

The results of this study, which were discussed in the previous chapter, are manifold. In regard to participants' understandings of quality in the context of online courses, I found that there is some overlap between the QM rubric items and faculty members' conceptualizations of quality, particularly in terms of course navigation and clarity of instructions. However, participants in this study also emphasized other factors of quality - those relating to course content, engagement and interaction, and student learning, which are not addressed by the Quality Matters rubric. Furthermore, the programmatic elements of Quality Matters - the ideas that characterize the mission of the audit practice and relate to broader policy objectives at the institutional level—suggest that the program serves as a holistic indicator of course quality, while the technological elements are capable only of evaluating certain aspects of course design. As a result, the Quality Matters program is associated with an expectations gap. Admittedly, Quality Matters is deliberate in specifying that the rubric and process only examine "forethought and planning of the course, as well as in the creation, assembly, and layout of instructions and course components" (Quality Matters, 2018a, p. 5). However, this narrow scope becomes highly problematic when these narrow targets serve as a proxy for quality writ large. Such is the case in Florida, where several state colleges and universities have defined online course quality as meeting Quality Matters standards and the Florida Board 
of Governors is moving forward with a statewide quality initiative that uses Quality Matters as the benchmark of course quality (Florida Board of Governors, n.d., 2015, 2017).

This study's participants reported many different reasons for engaging in the Quality Matters review process, but the salient themes I identified were: they pursued QM certification for reasons relating to prestige, recognition, and distinction, whether real or perceived; for a monetary incentive offered by their academic department; and/or because it was mandated or expected of them. In addition, participants who taught as adjunct faculty members ascribed more importance to prestige, recognition, and distinction and the possibility of a monetary incentive than did the full time faculty, suggesting the possibility that more vulnerable faculty members could be differentially impacted by institutions' agendas of quality; this logic is consistent with findings by Worthington and Hodgson (2005).

The participants in this study were able to navigate and maneuver QM in large part through the support of a decoupled organizational structure; instructional designers and a quality assurance manager handle a great deal of technical work and logistics required as part of a QM review, relieving faculty members from much of the burden of the audit. For other aspects of the Quality Matters review, participants described a dramaturgical, performative aspect of their involvement—abiding by certain requirements or making adjustments for the sake of certification, not for the bona fide improvement of their courses. In one notable case, this performance was entirely fictional and used as a form of resistance: The adjustments made for the sake of the QM review 
were abandoned in the actual course that students experienced, a maneuver this participant felt was in the best interests of her students and their learning.

The participants in this study related a variety of impacts that resulted from their engagement with Quality Matters. Among the most salient themes I identified was that Quality Matters was associated with a colonizing logic, particularly in regard to measurable learning objectives and alignment with instructional materials and assessment instruments. This alignment logic represents the most significant emphasis of the QM rubric, so much so that the inclusion of a single unmeasurable learning objective (e.g. “Students will understand...”) would lead to an unsuccessful QM review. In many cases, participants described applying this logic to other contexts, such as their face-to-face courses. Consistent with Power's (1997) characterization of colonization, the logic of the Quality Matters review created new perceptions of significance, new mentalities, and new forms of language. Whereas learning objectives and alignment had never been a part of several participants' teaching practice, the logic of Quality Matters instilled in them a new way of thinking about and approaching their teaching, including beyond the online context. Finally, a major impact attributed to Quality Matters by this study's participants was that QM served as a platform for self-reflection of teaching practice, in part enabled by peer review. Several participants noted that they found significance in the platform provided by their engagement with Quality Matters to mindfully reflect on their own teaching, which was something that they may not have had otherwise.

\section{Discussion}

This study explored faculty members' experiences with the Quality Matters program and process, understanding the QM review as an audit process. The results 
suggest that, consistent with Power's (1997) and Shore and Wright's $(1999,2000)$

discussion of audit practices, the QM audit led to new mentalities, languages, and perceptions of significance while inscribing new norms and values. To Power (1997),

The point is not just that audit may be decoupled ritualistically or that it permeates the auditee organization totally. It is rather that the imposition of audit and related measures of auditable performance leads to the opposite of what was intended, i.e. creates forms of dysfunction for the audited service itself. (pp. 97-98)

Thus, the issue is not with the audit itself; the problem is whether the QM audit leads to educational dysfunction rather than meaningful improvement of the quality of courses.

The Quality Matters rubric prescribes a narrow understanding of what a higher education course could or should be. The most important standards of Quality Matters involve the explicit inclusion and expression of course- and unit-level learning objectives that articulate what demonstrable skills students will achieve, exemplifying what Giroux (2011) described as a "pedagogy under the sway of technical mastery, instrumental logic, and various other fundamentalisms" (p. 5) —a pedagogy that is "largely reduced to a transmission model of teaching [and is] limited to the propagation of a culture of conformity and the passive absorption of knowledge" (p. 5). A successful Quality Matters review excludes the possibility that a teacher may list non-behavioral learning objectives; it excludes the possibility of a teacher creating an environment in which students have meaningful agency and choice in what they learn. Furthermore, the interactions between participants of the course are preconfigured and controlled through explicit expectations and "etiquette," which may limit the breadth and depth of class discussions. The QM rubric's indication that a course is something that is "used" suggests a particular understanding of the student's role—one that is passive and consumptive. Quality 
Matters, essentially an attempt to quantify teaching and normalize its narrow skills-based pedagogy, is emblematic of the neoliberalization of the university which privileges efficiency and standardization.

Contrast these conditions to the sentiments of Charles Wedemeyer, widely considered to be an early pioneer and visionary in the field of distance education (Diehl, 2011), who wrote:

We now know that intelligence and needs are distributed randomly throughout the world, our global village. Yet schools are distributed discretely. As a result, opportunity to learn has been uneven and unequal. Educational opportunity has historically been related to power-social, economic, political, military. (Wedemeyer, 1981, p. 99)

Long before the ubiquity of the personal computer, Wedemeyer suggested a solution to this problem of access, stating, "Wherever learners may live, however remote from instructional resources, whatever their socioeconomic condition, the ancient restrictions to access derived from a space-time-elite perception of learning can be overcome by various communications media" (p. 61). In other words, distance education, today manifested primarily by online education, holds a certain liberatory potential—an ability to provide educational opportunity to learners who would not otherwise have access.

However, if Quality Matters, characterized by ritualistic performances, decoupled organizational structure, colonizing logic, and an expectations gap, in any way limits pedagogical possibilities or constrains academic freedom, then this liberatory potential is threatened. Put differently, if one considers education as the practice of freedom (hooks, 1994), then the logic of Quality Matters is, indeed, dysfunctional.

This was a study that, from the outset, intended to be a critical and questioning study about Quality Matters. The results of this study illuminated, in some ways, 
troubling aspects of Quality Matters. Still, it would be irresponsible to overlook the fact that several participants found meaningful impact in how Quality Matters provided a platform for self-reflection, collegial dialogue, feedback, and input related to online teaching practice. In the next section, I will discuss the possibility of meeting this need without the audit and all the things it entails.

\section{Directions for Practice}

In a now oft-quoted interview, Foucault (1997) once noted:

My point is not that everything is bad, but that everything is dangerous, which is not exactly the same as bad. If everything is dangerous, then we always have something to do. So my position leads not to apathy but to a hyper- and pessimistic activism. I think that the ethico-political choice we have to make every day is to determine which is the main danger. (p. 256)

If the Quality Matters program and process are in dangerous tension with the liberatory aims of distance education, what is the ethico-politically correct course of action? The answer is simple, yet radical: abandon Quality Matters. As demonstrated by this study and supported by the literature, quality is nebulous, socially constructed, and multidimensional. By subscribing to a rigid and proprietary conceptualization of quality that is externally defined and realized through an audit practice, institutions and institutional actors risk neglecting local context and sponsoring the encroachment of faculty autonomy, agency, and creativity. The decoupled organizational structure and the dramaturgical performances associated with abiding by Quality Matters are surely resource intensive and costly. The research on any positive effects of Quality Matters are simply not compelling enough to justify its continued use. By abandoning Quality Matters and forsaking quality audits, institutions are freed to implement programs that 
improve teaching and learning that honor local contexts and respect the professional autonomy of teaching faculty.

The questioning of the ideas of quality and quality assurance in online higher education should not be conflated with or mistaken for a misguided idea that the goodness of teaching, including in online spaces, does not matter, or that we should not genuinely strive to engage students in the best possible learning and meaning-making experiences. Indeed, the opposite: the desire to improve student learning experiences is virtuous and appropriate, but the ideas of "improving the quality of courses" or "striving for teaching excellence" are rendered hollow in the context of meaningless watchwords. How then, can educators endeavor to improve (and help each other improve) the acts of design and teaching without resorting to checklists and rubrics such as Quality Matters, which assume universal applicability to all contexts, and inscribing an audit technology that encroaches on faculty autonomy and creativity?

In suggesting a direction for future practice, I want to speculate, optimistically, about the possibility of a self-supporting, non-hierarchical community of educators who support each other in the improvement of teaching. In Rolfe's (2013) The University in Dissent, his spiritual successor to Readings's (1996) seminal The University in Ruins, he envisions a community of thinkers that follows a rhizomatic structure—one which resembles a botanical network of underground stems that expand horizontally, "an underground, acentred, non-hierarchical, transdisciplinary network" of "thinkers [who] come together temporarily in order to pursue specific short-term collaborative teaching and research projects" (Rolfe, 2013, p. 44). These short-term projects of supporting each other's teaching could draw from the ideas of educational connoisseurship and 
educational criticism, as put forth by Eisner (2017). Connoisseurship, according to Eisner, is "the ability to make fine grained discriminations among complex and subtle qualities ... It can be displayed in any realm in which the character, import, or value of objects, situations, and performances is distributed and variable, including educational practice" (p. 63). The educational connoisseur, like the wine connoisseur, is able to "differentiate between the subtle and complex qualities" based on antecedent knowledge, an "understanding of the conditions that give rise to these qualities" (pp. 64-65). Here, it is necessary to differentiate between "quality" and "qualities," where the latter refers to "those features of our environment that can be experienced through any of our senses" ( $p$. 17); according to Eisner, the meaning we assign to qualities constitutes the content of experiences.

Contrary to the genericism of the rubric used by Quality Matters, educational connoisseurship assumes a holistic approach that respects the educational context, the background of and relationships between the teacher and students, and the particularities of the subject matter. Connoisseurship is a type of "epistemic seeing"; it is "the means through which we come to know the complexities, nuances, and subtleties of aspects of the world in which we have a special interest" (Eisner, 2017, p. 68). Related to educational connoisseurship is the idea of educational criticism. Criticism (not necessarily negative in this sense) is the published account of the connoisseur's observations of a given educational phenomenon, generated for the purpose of assisting others. The educational critic's task is to perform what Eisner calls a "mysterious feat": to transform the particular qualities of a given learning experience, such as an online course, into a form that illuminates, interprets, and appraises them (p. 56). According to Eisner: 
Since there is no literal linguistic equivalent for qualities per se, the task cannot be simple translation. With no rules of equivalence, there is no one-to-one correspondence of referent to symbol. Thus every act of criticism is a reconstruction. The reconstruction takes the form of an argued narrative, supported by evidence that is never incontestable; there will always be different interpretations of the "same" [course]. (p. 86)

In other words, educational experiences, as complex human activities, are open to multiple interpretations or perspectives, depending on the sensibilities and perceptions of the connoisseur - a stark contrast to the one-size-fits-all approach of the Quality Matters rubric. Eisner suggests a structure for educational criticism: the dimensions of description, interpretation, evaluation, and thematics, which each intersect with the dimensions of connoisseurship at the point of criticism. However, Eisner is clear to point out that these dimensions "do not prescribe a sequence among the parts of an educational criticism," nor do they "imply that each is wholly independent of the others" (p. 88).

Essentially, educational criticism involves the holistic interpretation and feedback of a more practiced (or differently practiced) educator with the aim of improvement of the educational environment. However, rather than emulate an archetype rendered by a narrow rubric, education criticism fosters and supports pedagogical distinctiveness, the different capacities of teachers and students, the particular educational contexts of those learning experiences, and academic freedom. While audits take place in the absence of trust and may elicit ritual performances of compliance, educational criticism enables the possibility of a dialog between the teacher and the connoisseur predicated on trust and authenticity. This model may have the potential to fulfill the need, demonstrated in this study, for a platform for collegial dialogue, feedback, and input into online teaching practice without the logic of the audit and all the things it entails - the decoupled 
organizational structure, the colonizing logic, the ritual performances, and the expectations gap. Eisner's frameworks have already been successfully employed in online course environments in limited capacities (Thompson, 2005). The challenge, then, is to develop structures and communities around these ideas: self-supporting, selfregulating communities of educational connoisseurs—Readings's "community of thinkers" put into practice (1996). This work could be realized through formal institutional structures, such as a university teaching center, or informally and organically through networks of teachers and others. However, in the formation of such a community, we must be careful not to reinscribe the bureaucratic, hierarchical formations of power and distrust which largely shape the neoliberal university.

To re-emphasize, this is a single, highly speculative possibility for educators involved in online education to have a platform for collegial dialogue, feedback, and input into their teaching practice. Abandoning Quality Matters and replacing it was a nonhierarchical, rhizomatic support structure is a bold suggestion for future practice and perhaps too bold for this humble study. Any claims regarding practices relating to quality and quality assurance must be firmly rooted in the research, lest we return to the issue of Bertrand's teapot. In the next section, I will outline possible directions and suggestions for future research studies.

\section{Directions for Future Research}

This study explored the experiences and perceptions of eight faculty members who have had one or more of their courses complete the Quality Matters program, including their conceptualizations of quality in relation to QM, the motivations and impact they ascribe to $\mathrm{QM}$, and how they navigated and maneuvered the $\mathrm{QM}$ review 
process. From the outset, I intended to differentiate this study from the existing research on QM by taking a critical and questioning approach, informed, philosophically, by postmodernism. While much literature adopts this sort of approach with quality and quality assurance in higher education more broadly, there continues to be a dearth of critical scholarship on Quality Matters, a paucity notable given the continued growth in adoption of Quality Matters. As the visibility of issues relating to social justice and critical pedagogy continues to grow within the higher education teaching and learning community, my hope is that there will much more to come.

By basing this study around faculty members who have experience with Quality Matters, I limited myself to a pool of participants who, for one reason or another, decided QM was worth pursuing. Future researchers may choose to explore perceptions of Quality Matters among faculty members who have not engaged with QM, particularly within the context of possible mandates and expectations. Certainly, critical approaches to the study of Quality Matters and its impact should also take place in other institutional contexts, including other universities and community colleges. This could help illuminate the nature of other organizations that support (or mandate) faculty engagement with Quality Matters and the extent to which they represent decoupled organizational structures.

One salient issue worthy of further consideration is segmenting of motivational factors along faculty ranks. The participants in this study placed different levels of emphasis on Quality Matters in relation to prestige, recognition, and distinction as well as the possibility of a monetary incentive; the two adjunct faculty members ascribed more meaning to these factors than the full-time faculty members, and one participant who 
transitioned from an adjunct role to a full-time role described the shift in her thinking. This presented the possibility that the institution was leveraging the precarious position of contingent labor of further its agenda of quality. Future research could further explore this segmenting and the possibility of disproportional effects of quality assurance on adjunct faculty.

Importantly, as illuminated by this study, faculty members are supported through the audit process by a decoupled organizational structure in which instructional designers assume much of the responsibility of the audit. While the present study focused on the experiences and perceptions of faculty members in relation to Quality Matters, future research that explores the perspectives of instructional designers would be timely and relevant. Instructional designers are at risk of deprofessionalization as they are increasingly employed in technical support roles rather than as pedagogical experts (Acevedo \& Roque, 2019), and their involvement in handling the technical and bureaucratic aspects Quality Matters may exemplify this trend.

Lastly, one possible quantitative avenue for possible research occurred to me in the course of analyzing my interview transcript with Participant 2, who (erroneously) celebrated seeing his name on the QM website alongside Harvard faculty. Since all Quality Matters courses and their institutions are listed on the Quality Matters website, perhaps one direction for future research could be to explore the relationships these institutions, their numbers of QM-certified courses, and other institutional variables (size, student population, research classification, etc.). This could be useful for exploring what types of institutions more highly prioritizes quality assurance. For example, there may be 
a compelling relationship between the extent to which institutions pursue agendas of quality and the degree to which they engaging striving behaviors (O’Meara, 2007).

Regardless of specific research goals or methodologies, I hope that future research on Quality Matters adopt positions that does not take Quality Matters for granted and explores the impact on faculty members and others who are subjected to it or otherwise engaged with it.

\section{Limitations}

The goal of this qualitative interview study was to explore the experiences and perceptions of a group faculty members with the Quality Matters program and process. While lack of generalizability should not be considered a limitation in qualitative research, this study should not be misconstrued as one whose goals were broader generalizability to or representation of a population. It is possible — or even probablethat the experiences of the faculty participants in this study would vary from those at other institutions or in different contexts. For example, the highly decoupled organizational structure in which the study's faculty members engaged in Quality Matters, as was the case at the site of this study — might be an anomaly in the broader context of higher education. However, it has been my intention to capture and illuminate certain perspectives, experiences, and issues that may be applicable or relevant to faculty members who teach online in general.

Despite generalizability not being a goal with this study, the possibility remains that a larger sample could have led to a richer array of data. This is the case particularly where I noted themes that were segmented along faculty ranks, particularly in relation to motivational factors. With only two participants of each represented faculty rank in my 
sample, these conclusions are somewhat tentative, highlighting the need for future research in this area.

Selection bias may also have been a factor in the data I collected; most faculty members I contacted with requests of participation either declined or did not respond. As a result, my data is collected from interviews with participants who were willing and motivated to share their experiences. It is problematic to speculate what impacts, if any, this may have had on my data.

\section{Conclusion}

This study revealed that engagement with the Quality Matters process was, for this study's participants, associated with a decoupled organizational structure, colonizing logic, dramaturgical performances, and varying motivations. Furthermore, the participants' conceptualizations of online course quality had only limited overlap and intersection with the criteria of the Quality Matters rubric, reflecting an expectations gap. While dysfunctional elements of QM may be partially mitigated by the program's role in providing a platform for reflection and feedback on online teaching practice, the encroachment of Quality Matters into participants' professional autonomy is consistent with the literature on the effect of quality assurance in other higher education contexts.

From a practical and economic perspective, I find troubling the extent to which the institution that was the site of this study allocates resources to enable a decoupled organizational structure that facilitates instructors' engagement with Quality Matters. I reflected upon this, and my own past involvement with it, as part of my subjectivity statement in Chapter I. From a philosophical and pedagogical perspective, I find the skillbased transmissive pedagogy inherent in Quality Matters to be disconcerting, particularly 
in relation to distance education's liberatory potential and especially because of its colonizing logic that may transfer to other contents or "flow over" as one participant in this study framed it. Given state and institutional contexts where QM's influence shows no signs of abating, I hope this study serves as a starting point or a beacon for others who are questioning the role or impact of Quality Matters, quality assurance in higher education more generally, or other mechanisms that hold the potential to affect the teaching practice of faculty members. 


\section{REFERENCES}

Acevedo, M. (2013). Beyond understanding: Working with faculty to compose exemplary objectives. Concurrent session presented at the 5th Annual QM Conference on Quality Assurance in Online Learning, Nashville, TN. October 1-4.

Acevedo, M. (2014a). Debunking the learning styles myth, or: How I learned to stop worrying and love QM. Concurrent session presented at the 6th Annual QM Conference on Quality Assurance in Online Learning, Baltimore, MD. September 29-October 1.

Acevedo, M. (2014b). Collaborating with faculty to compose exemplary learning objectives. Invited pre-conference workshop held at the 6th Annual QM Conference on Quality Assurance in Online Learning, Baltimore, MD. September 29-October 1.

Acevedo, M. (2014c). Collaborating with faculty to compose exemplary learning objectives. Internet Learning, 3(1), 5-16.

Acevedo, M. \& Roque, G. (2019). Resisting the deprofessionalization of instructional design. In Y. Vovides \& L.R. Lemus (Ed.), Optimizing instructional design methods in higher education. Hershey, PA: IGI Global.

Aleckson, J. D., \& Ralston-Berg, P. (2011). MindMeld: Micro-collaboration between eLearning designers and instructor experts. Madison, WI: Atwood Publishing.

Aman, R. R. (2009). Improving student satisfaction and retention with online instruction through systematic faculty peer review of courses (Unpublished doctoral dissertation). Oregon State University.

Anderson, G. (2006). Assuring quality/resisting quality assurance: Academics' responses to 'quality' in some Australian universities. Quality in Higher Education, 12(2), 161-173.

Barczyk, C. C., Hixon, E., Buckenmeyer, J., \& Ralston-Berg, P. (2017). The effect of age and employment on students' perceptions of online course quality. American Journal of Distance Education, 31(3), 173-184.

Barnett, R. (1997). Higher education: A critical business. McGraw-Hill Education (UK).

Barrow, M. (1999). Quality-management systems and dramaturgical compliance. Quality in Higher Education, 5(1), 27-36.

Bensimon, E. M. (1995). Total quality management in the academy: A rebellious reading. Harvard Educational Review, 65(4), 593-612. 
Birnbaum, R. (2000). The life cycle of academic management fads. The Journal of Higher Education, 71(1), 1-16.

Blackmore, J. (2009). Academic pedagogies, quality logics and performative universities: Evaluating teaching and what students want. Studies in Higher Education, 34(8), 857-872.

Blanco Ramírez, G. (2013). Studying quality beyond technical rationality: Political and symbolic perspectives. Quality in Higher Education, 19(2), 126-141.

Bloland, H. G. (1995). Postmodernism and higher education. The Journal of Higher Education, 66(5), 521-559.

Brennan, J., \& Shah, T. (2000). Quality assessment and institutional change: Experiences from 14 countries. Higher Education, 40(3), 331-349.

Canning, J. (2017). The UK Teaching Excellence Framework (TEF) as an illustration of Baudrillard's hyperreality. Discourse: Studies in the Cultural Politics of Education, 1-12.

Cheng, M. (2010). Audit cultures and quality assurance mechanisms in England: A study of their perceived impact on the work of academics. Teaching in Higher Education, 15(3), 259-271.

Cheng, M. (2011). 'Transforming the learner' versus 'passing the exam': Understanding the gap between academic and student definitions of quality. Quality in Higher Education, 17(1), 3-17.

Clarke, J. (2008). Living with/in and without neo-liberalism. Focaal, 2008(51), 135-147.

Creswell, J. W., \& Poth, C. N. (2018). Qualitative inquiry \& research design: Choosing among five approaches (4th ed.). Thousand Oaks, CA: SAGE Publications.

D'Andrea, V. M. (2007). Improving Teaching and Learning in Higher Education: Can Learning Theory Add Value to Quality Review? In D. F. Westerheijden, B. Stensaker, \& M. J. Rosa (Eds.), Quality assurance in higher education: Trends in regulation, translation, and transformation (pp. 209-223). Dordrecht: Springer.

De Vincenzi, A., Garau, A., \& Guaglianone, A. (2018). Has the quality of teaching and learning processes improved as a result of the implementation of quality assurance coordinated by the state?. Quality in Higher Education, 24(1), 55-65.

Deem, R., \& Brehony, K. J. (2005). Management as ideology: The case of 'new managerialism' in higher education. Oxford Review of Education, 31(2), 217-235.

Dick, W., Carey, L., \& Carey, J. (2009). The systematic design of instruction. (7th ed.). Upper Saddle River, NJ: Merrill. 
Diehl, W. (2011). Learning at the back door: Charles Wedemeyer and the evolution of open and distance education (Unpublished doctoral dissertation). Pennsylvania State University.

Dill, D. D. (2010). Quality assurance in higher education: Practices and issues. In International Encyclopedia of Education (3rd ed.). Elsevier.

Douglas, J., \& Douglas, A. (2006). Evaluating teaching quality. Quality in Higher Education, 12(1), 3-13.

Drennan, L. T., \& Beck, M. (2001). Teaching quality performance indicators-key influences on the UK universities' scores. Quality Assurance in Education, 9(2), $92-102$.

Dropbox. (2018). Security architecture. Retrieved March 10, 2018, from https://www.dropbox.com/business/trust/security/architecture

Eaton, J. (2015). An overview of U.S. accreditation. Washington, DC: Council for Higher Education Accreditation.

Eisner, E. W. (2017). The enlightened eye: Qualitative inquiry and the enhancement of educational practice. New York: Teachers College Press.

Espeland, W. N., \& Stevens, M. L. (1998). Commensuration as a social process. Annual Review of Sociology, 24(1), 313-343.

Ewell, P. (2007). The 'Quality Game': External review and institutional reaction over three decades in the United States. In D. F. Westerheijden, B. Stensaker, \& M. J. Rosa (Eds.), Quality assurance in higher education: Trends in regulation, translation, and transformation (pp. 119-153). Dordrecht: Springer.

Filippakou, O. (2011). The idea of quality in higher education: A conceptual approach. Discourse: Studies in the Cultural Politics of Education, 32(1), 15-28.

Filippakou, O., \& Tapper, T. (2008). Quality assurance and quality enhancement in higher education: Contested territories?. Higher Education Quarterly, 62(1-2), $84-100$.

FIU Online. (2016). The Benefits of Quality Matters Certification: What the Analytics Reveal. Retrieved January 23, 2019, from http://insider.fiu.edu/qmreport/

FIU Online. (2018). Quality Commitment - FIU Online. Retrieved March 10, 2018, from http://online.fiu.edu/faculty/quality-commitment/index.php

Florida Board of Governors. (n.d.). Taskforce for Online Strategic Planning Quality Subcommittee survey results. Retrieved November 3, 2018, from 
https://www.flbog.edu/about/taskforce/_doc_del/strategic_planning_online_ed/20 15_05_13_Survey Results.pdf

Florida Board of Governors. (2015). Online education 2025 strategic plan. Retrieved from http://www.flbog.edu/board/office/online/_doc/strategic_planning_online_ed/201 5_11_05 FINAL_StrategicPlan.pdf

Florida Board of Governors. (2017, March 29). State University System of Florida Board of Governors Innovation and Online Committee. Retrieved from https://www.flbog.edu/documents_meetings/0265_1080_8180_4.2.2\%20IOC\%20 02a_Minutes\%20March\%2029\%202017\%20MeetingFinal.pdf

Florida International University. (2018). Rankings \& Facts | Florida International University. Retrieved March 10, 2018, from https://www.fiu.edu/about/rankingsfacts/index.html

Foucault, M. (1997). Ethics: Subjectivity and truth (P. Rabinow, Ed.; R. Hurley, Trans.). New York, NY: The New Press.

Garrison, D. R., Anderson, T., \& Archer, W. (1999). Critical inquiry in a text-based environment: Computer conferencing in higher education. The Internet and Higher Education, 2(2-3), 87-105.

Gillard, J. W. (2018). An initial analysis and reflection of the metrics used in the Teaching Excellence Framework in the UK. Perspectives: Policy and Practice in Higher Education, 22(2), 49-57.

Giroux, H. A. (2011). On critical pedagogy. New York, NY: Continuum.

Harkness, S. S. J. (2015). How a Historically Black College University (HBCU) established a sustainable online learning program in partnership with Quality Matters. American Journal of Distance Education, 29(3), 198-209.

Harvey, L. (2005). A history and critique of quality evaluation in the UK. Quality Assurance in Education, 13(4), 263-276.

Harvey, L. (2018). Analytic Quality Glossary. Retrieved January 7, 2019, from http://www.qualityresearchinternational.com/glossary/

Harvey, L., \& Green, D. (1993). Defining quality. Assessment \& Evaluation in Higher Education, 18(1), 9-34.

Harvey, L. \& Newton (2007). Transforming quality evaluation: Moving on. In D. F. Westerheijden, B. Stensaker, \& M. J. Rosa (Eds.), Quality assurance in higher education: Trends in regulation, translation, and transformation (pp. 225-245). Dordrecht: Springer. 
Harvey, L., \& Stensaker, B. (2008). Quality culture: Understandings, boundaries and linkages. European Journal of Education, 43(4), 427-442.

Harvey, L., \& Williams, J. (2010). Fifteen Years of Quality in Higher Education (Part Two). Quality in Higher Education, 16(2), 81-113.

Hill, Y., Lomas, L., \& MacGregor, J. (2003). Students' perceptions of quality in higher education. Quality Assurance in Education, 11(1), 15-20.

Hollowell, G. P., Brooks, R. M., \& Anderson, Y. B. (2017). Course design, Quality Matters training, and student outcomes. American Journal of Distance Education, 31(3), 207-216.

hooks, b. (1994). Teaching to transgress: Education as the practice of freedom. Routledge.

Hou, Y. W., Lee, C. W., \& Gunzenhauser, M. G. (2017). Student Evaluation of Teaching as a disciplinary mechanism: A Foucauldian analysis. The Review of Higher Education, 40(3), 325-352.

Houston, D. (2007). TQM and higher education: A critical systems perspective on fitness for purpose. Quality in Higher Education, 13(1), 3-17.

Jarvis, D. S. L. (2014). Regulating higher education: Quality assurance and neo-liberal managerialism in higher education-A critical introduction. Policy and Society, 33(3), 155-166.

Jones, S. (2003). Measuring the quality of higher education: Linking teaching quality measures at the delivery level to administrative measures at the university level. Quality in Higher Education, 9(3), 223-229.

Kristensen, B. (2010). Has external quality assurance actually improved quality in higher education over the course of 20 years of the 'Quality Revolution'?. Quality in Higher Education, 16(2), 153-157.

Laughton, D. (2003). Why was the QAA approach to teaching quality assessment rejected by academics in UK HE?. Assessment \& Evaluation in Higher Education, 28(3), 309-321.

Layne, M. (2014). Quality Matters [Special issue]. Internet Learning, 3(1).

Legon, R. (2015). Measuring the impact of the Quality Matters Rubric: A discussion of possibilities. American Journal of Distance Education, 29(3), 166-173.

Lomas, L., \& Nicholls, G. (2005). Enhancing teaching quality through peer review of teaching. Quality in Higher Education, 11(2), 137-149. 
Mager, R. F. (1962). Preparing instructional objectives. Palo Alto, Calif.: Fearon Publishers.

Maxwell, J. A. (2013). Qualitative research design: An interactive approach. Thousand Oaks, CA: SAGE Publications.

Miner, A. (2014). The effect of Quality Matters on student satisfaction, grades, and retention at Florida International University (Unpublished doctoral dissertation). Morgan State University.

Moore, G. M. (2017). Quality Matters [Special issue]. American Journal of Distance Education, 31(3).

Morley, L. (2003). Quality and power in higher education. Society for Research into Higher Education and Open University Press.

Morris, S. M., \& Stommel, J. (2018). Critical Digital Pedagogy: A Definition. In An Urgency of Teachers. (pp. 2-11). Hybrid Pedagogy, Inc.

Newton, J. (1999). An evaluation of the impact of external quality monitoring on a higher education college (1993-98). Assessment \& Evaluation in Higher Education, 24(2), 215-235.

Newton, J. (2000). Feeding the beast or improving quality?: Academics' perceptions of quality assurance and quality monitoring. Quality in Higher Education, 6(2), 153163.

Newton, J. (2002). Views from below: Academics coping with quality. Quality in Higher Education, 8(1), 39-61.

O’Meara, K. (2007). Striving for what? Exploring the pursuit of prestige. In J. C. Smart (Ed.), Higher education: Handbook of theory and research (pp. 121-179). Dordrecht: Springer.

Olssen, M., \& Peters, M. A. (2005). Neoliberalism, higher education and the knowledge economy: From the free market to knowledge capitalism. Journal of Education Policy, 20(3), 313-345.

Paechter, M., Maier, B., \& Macher, D. (2010). Students' expectations of, and experiences in e-learning: Their relation to learning achievements and course satisfaction. Computers \& education, 54(1), 222-229.

Pham, H. T. (2018). Impacts of higher education quality accreditation: A case study in Vietnam. Quality in Higher Education, 24(2), 168-185.

Power, M. (1994). The audit explosion. Demos. 
Power, M. (1997). The audit society: Rituals of verification. Oxford: Oxford University Press.

Quality Matters. (2018a). Quality Matters higher education rubric workbook: Standards for course design (6th ed.).

Quality Matters. (2018b). Preparing for a QM course review. Retrieved January 1, 2018, from https://www.qualitymatters.org/qm-membership/faqs/course-reviewpreparation

Quality Matters. (2018c). Why QM?. Retrieved November 1, 2018 from https://www.qualitymatters.org/why-quality-matters

Quality Matters. (2018d). 2018 QM-certified courses. Retrieved March 2, 2018, from https://www.qmprogram.org/qmresources/courses/grouped_by_inst.cfm?program $=0$

Quality Matters. (2018e). Curated resources. Retrieved April 13, 2018, from https://www.qualitymatters.org/research/curated-research-resources

Quality Matters. (2018f). Course review fees. Retrieved April 13, 2018, from https://www.qualitymatters.org/qm-membership/faqs/course-review-fees

Quality Matters. (2018g). About Quality Matters. Retrieved November 14, 2018, from https://www.qualitymatters.org/about

Ralston-Berg, P., \& Nath, L. (2008). What makes a quality online course? The student perspective. Proceedings of the 24th Annual Conference on Distance Teaching and Learning.

Ralston-Berg, P. (2014). Surveying student perspectives of quality: Value of QM rubric items. Internet Learning, 3(1), 117-126.

Readings, B. (1996). The university in ruins. Cambridge, MA: Harvard University Press.

Reeves, C. A., \& Bednar, D. A. (1994). Defining quality: alternatives and implications. The Academy of Management Review, 19(3), 419-445.

Rolfe, G. (2013). The university in dissent: Scholarship in the corporate university. New York: Routledge.

Rubin, H. J., \& Rubin, I. S. (2012). Qualitative interviewing: The art of hearing data (3 ${ }^{\text {rd }}$ ed.). Thousand Oaks, CA: SAGE Publications.

Russell, B. (1952). Is There a God? [1952]. In J. Slater (Ed.). The collected papers of Bertrand Russell, Volume 11: Last philosophical testament, 1943-68. Routledge. 
Saldaña, J. (2016). The coding manual for qualitative researchers (3 ${ }^{\mathrm{rd}} \mathrm{ed}$.). Sage.

Schade, A. (2003). Recent quality assurance activities in Germany. European Journal of Education, 38(3), 285-290.

Seaman, J. E., Allen, I. E., \& Seaman, J. (2018). Grade increase: Tracking distance education in the United States. Retrieved from https://onlinelearningsurvey.com/reports/gradeincrease.pdf

Seidman, I. (2013). Interviewing as qualitative research: A guide for researchers in education \& the social sciences (4th ed.). New York, NY: Teachers College Press.

Shore, C., \& Wright, S. (1999). Audit culture and anthropology: Neo-liberalism in British higher education. Journal of the Royal Anthropological Institute, 5(4), 557-575.

Shore, C., \& Wright, S. (2000). Coercive accountability: The rise of audit culture in higher education. In M. Strathern (Ed.), Audit cultures: Studies in accountability, ethics and the academy (pp. 57-89). Routledge.

Simunich, B., Robins, D. B., \& Kelly, V. (2015). The impact of findability on student motivation, self-efficacy, and perceptions of online course quality. American Journal of Distance Education, 29(3), 174-185.

Saunders, D. B. (2015). They do not buy it: exploring the extent to which entering firstyear students view themselves as customers. Journal of Marketing for Higher Education, 25(1), 5-28.

Standards and Guidelines for Quality Assurance in the European Higher Education Area (ESG). (2015). Brussels, Belgium.

Stensaker, B. (2007). Quality as fashion: Exploring the translation of a management idea into higher education. In D. F. Westerheijden, B. Stensaker, \& M. J. Rosa (Eds.), Quality assurance in higher education: Trends in regulation, translation, and transformation (pp. 99-118). Springer, Dordrecht.

Stumbrys E. (2004), Internal and External Quality Assurance in Higher Education. The Quality of Higher Education, 58-165.

Swan, K., Matthews, D., Bogle, L., Boles, E., \& Day, S. (2012). Linking online course design and implementation to learning outcomes: A design experiment. The Internet and Higher Education, 15(2), 81-88.

Tavares, O., Sin, C., Videira, P., \& Amaral, A. (2017). Academics' perceptions of the impact of internal quality assurance on teaching and learning. Assessment \& Evaluation in Higher Education, 42(8), 1293-1305. 
Thompson, K. (2005). Constructing educational criticism of online courses: A model for implementation by practitioners (Unpublished doctoral dissertation). University of Central Florida.

Tomlinson, M., Enders, J., \& Naidoo, R. (2018). The Teaching Excellence Framework: symbolic violence and the measured market in higher education. Critical Studies in Education, 1-16.

Venkatraman, S. (2007). A framework for implementing TQM in higher education programs. Quality Assurance in Education, 15(1), 92-112.

Vinni, R. (2007). Total quality management and paradigms of public administration. International Public Management Review, 8(1), 103-131.

Wedemeyer, C. A. (1981). Learning at the back door: Reflections on non-traditional learning in the lifespan. Madison, WI: The University of Wisconsin Press.

Williams, J. (2016). Quality assurance and quality enhancement: Is there a relationship? Quality in Higher Education, 22(2), 97-102.

Worthington, F., \& Hodgson, J. (2005). Academic labour and the politics of quality in higher education: a critical evaluation of the conditions of possibility of resistance. Critical Quarterly, 47(1-2), 96-110.

You, J., Hochberg, S. A., Ballard, P., Xiao, M., \& Walters, A. (2014). Measuring online course design: A comparative analysis. Internet Learning, 3(1), 6.

Youger, R. E., \& Ahern, T. C. (2015). Is a quality course a worthy course? Designing for value and worth in online courses. Online Journal of Distance Learning Administration, 18(1), 1-9. 


\section{APPENDIX A: SAMPLE PARTICIPATION REQUEST}

\section{Dear [potential participant name],}

I hope this message finds you well. My name is Matt Acevedo and I am a doctoral candidate in the Higher Education PhD program in the College of Arts, Sciences \& Education at FIU.

My dissertation research is about faculty members' experiences with and perceptions of the Quality Matters online course review program; I am currently seeking research participants who have firsthand experience with QM. I understand that you have received QM certification for your online [course title] course (it is listed on the Quality Matters website).

I am writing to ask if you would be willing to participate in my study, involving one interview with a duration of approximately 60 minutes to take place in your office or another location at FIU that is convenient for you. I'll be asking questions about your experience going through the QM process and how you feel QM has affected your teaching practice. The interview will be audio recorded and transcribed, and you will have the opportunity to review the transcripts.

Your identity as a participant in the study will be considered entirely confidential, and the utmost care will be taken in ensuring that any quotes or information you provide will be anonymized in the final report. There is no obligation to participate in the study and there are no anticipated risks or benefits associated with participation. The study has been approved by the FIU Institutional Review Board.

Your participation would be a valuable addition to my dissertation research and findings could lead to greater public understanding of how Quality Matters and other quality assurance programs affect faculty members and their teaching practices.

If you are willing to participate in this research study, or if you have any questions about my study, please respond to this message so that we may discuss further details and hopefully schedule a time to meet. You may also reach out to my Major Professor, Dr. Daniel Saunders, via email at dsaunder@fiu.edu with any questions or concerns.

Thank you! I'm looking forward to hopefully working with you.

Kind regards,

Matthew M. Acevedo

Doctoral Candidate, Higher Education 


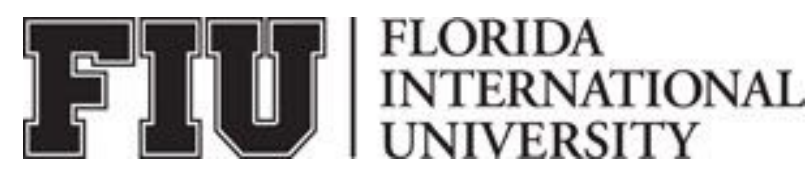

\section{ADULT CONSENT TO PARTICIPATE IN A RESEARCH STUDY \\ Faculty Perceptions of Quality Matters}

\section{PURPOSE OF THE STUDY}

You are being asked to be in a research study. The purpose of this study is to explore faculty members' perceptions about their experiences with Quality Matters, a quality assurance process for online courses.

\section{NUMBER OF STUDY PARTICIPANTS}

If you decide to be in this study, you will be one of up to 15 people in this research study.

\section{DURATION OF THE STUDY}

Your participation will require approximately 90 minutes over the course of a single interview session. At a later date, a follow-up interview may be requested by the interviewer or by you.

\section{PROCEDURES}

If you agree to be in the study, you will be asked to respond to a series of open-ended questions and to engage in conversation with the interviewer. The interview will be audio recorded, and a transcript or recording of the interview will be provided to you upon request.

\section{RISKS AND/OR DISCOMFORTS}

There are no known or anticipated risks associated with your participation in this study.

\section{BENEFITS}

There are no known or anticipated benefits associated with your participation in this study.

\section{ALTERNATIVES}

There are no known alternatives available to you other than not taking part in this study. However, any significant new findings developed during the course of the research which may relate to your willingness to continue participation will be provided to you.

\section{CONFIDENTIALITY}

The records of this study will be kept private and will be protected to the fullest extent 
provided by law. In any sort of report we might publish, we will not include any information that will make it possible to identify a subject. Your responses to interview questions will be coded with a pseudonym or false name. Research records will be stored securely in a password protected environment and only the researcher will have access to the records. However, your records may be reviewed for audit purposes by authorized University or other agents who will be bound by the same provisions of confidentiality.

\section{COMPENSATION \& COSTS}

You will not be compensated for your participation in this study. You will not be responsible for any costs to participate in this study.

\section{RIGHT TO DECLINE OR WITHDRAW}

Your participation in this study is voluntary. You are free to participate in the study or withdraw your consent at any time during the study. Your withdrawal or lack of participation will not affect any benefits to which you are otherwise entitled. The researchers reserve the right to remove you without your consent at such time that they feel it is in the best interest.

\section{RESEARCHER CONTACT INFORMATION}

If you have any questions about the purpose, procedures, or any other issues relating to this research study you may contact Matthew Acevedo at (786) 449-0880 or by e-mail at macev028@fiu.edu.

\section{IRB CONTACT INFORMATION}

If you would like to talk with someone about your rights of being a subject in this research study or about ethical issues with this research study, you may contact the FIU Office of Research Integrity by phone at (305) 348-2494 or by e-mail at ori@fiu.edu.

\section{PARTICIPANT AGREEMENT}

I have read the information in this consent form and agree to participate in this study. I have had a chance to ask any questions I have about this study, and they have been answered for me. I understand that I will be given a copy of this form for my records.

Signature of Participant

Printed Name of Participant

Signature of Person Obtaining Consent
Date

Date 


\section{APPENDIX C: INTERVIEW GUIDE}

This interview guide includes guiding questions that were used during the research interviews after discussing and completing the informed consent document. Since each participant's experience with Quality Matters was different, each interview was tailored to the participants' own context and approached as a conversation. Depending on the direction of each interview, not every question was asked, and additional follow-up and probing questions were utilized when appropriate.

1. What, in your view, is quality in the context of online courses?

2. Why did you decide to pursue Quality Matters certification for your course(s)?

3. Do the criteria used by QM reflect your understanding of course quality?

4. Can you walk me through your experience going through the Quality Matters process?

5. Was there any feedback from the reviewers that you disagreed with? What recourse did you feel you had?

6. What have been the most notable impacts of going through QM, good or bad?

7. How has Quality Matters impacted your teaching?

8. How do you think things have changed for students as a result of your going through QM?

9. Is there anything you would have done or would be doing differently in your course(s) if it weren't for QM?

10. Who supported you during the Quality Matters process? How?

11. Do you think the emphasis on quality is different for online courses and face-toface courses? Why?

12. Has your face-to-face teaching changed since going through the QM process? How?

13. Is there anything that I haven't asked about your experience with Quality Matters that you feel I should know about? 


\section{APPENDIX D: PARTICIPANT PROFILES}

Participant 1 is an adjunct faculty member in a social sciences field as well as a full time administrator at Florida International University. He has earned Quality Matters certification for several fully online courses that he teaches. He teaches primarily online courses, which enables him to accommodate the responsibilities of his primary job at the university, but he occasionally teaches face-to-face courses.

Participant 2 is an adjunct faculty member who teaches courses that are multidisciplinary in nature. He has earned Quality Matters for multiple online courses. He also works full time as an administrator at Florida International University, where his role includes working with other faculty members in his academic unit. He teaches online and face-to-face courses.

Participant 3 is an associate professor in a social sciences field. He teaches primarily face-to-face courses, but also teaches one graduate-level course online, which successfully completed a Quality Matters review.

Participant 4 is an assistant professor in an applied science field. She has earned Quality Matters certification for two online courses. She teaches primarily online courses.

Participant 5 is an associate professor in a social science field. She has earned Quality Matters certification for several online courses and has won several teaching awards. She teaches primarily online courses.

Participant 6 is an instructor in a social science field as well as a faculty administrator in her department. She has earned Quality Matters certification for multiple online courses. She withdrew from the Quality Matters process for two other courses because of disagreements with the reviewers and their feedback. She teaches online and 
face-to-face courses and has won several teaching awards.

Participant 7 is an assistant professor in an applied professional field. He has earned Quality Matters certification for multiple courses. He teaches online and face-toface courses.

Participant 8 is an instructor in an applied professional field. She has earned Quality Matters certification for one course. She teaches online and face-to-face courses. 
VITA

MATTHEW M. ACEVEDO

Born, Burlingame, California

2007

B.F.A, Film

University of Central Florida

Orlando, Florida

2012

M.A., Instructional Design and Technology: Instructional Systems University of Central Florida

Orlando, Florida

2012 - $2014 \quad$ Instructional Designer

Florida International University

Miami, Florida

$2014-2016$

Senior Instructional Designer

Florida International University

Miami, Florida

$2016-2017$

Instructional Design Manager

Florida International University

Miami, Florida

2017 - $2019 \quad$ Director, Learning Innovation and Faculty Engagement

University of Miami

Coral Gables, Florida

2015 - $2019 \quad$ Doctoral Candidate, Higher Education

Florida International University

Miami, Florida 